\title{
Toward an Improved Representation of Middle Atmospheric Dynamics Thanks to the ARISE Project
}

\author{
E. Blanc ${ }^{1}$ - L. Ceranna ${ }^{2}$ - A. Hauchecorne ${ }^{3}$ - A. Charlton-Perez ${ }^{4}$. \\ E. Marchetti ${ }^{5}$ L. G. Evers ${ }^{6,7}$ - T. Kvaerna ${ }^{8}$ - J. Lastovicka ${ }^{9}$. \\ L. Eliasson ${ }^{10}$ - N. B. Crosby ${ }^{11}$ - P. Blanc-Benon ${ }^{12}$ - A. Le Pichon ${ }^{1}$. \\ N. Brachet ${ }^{1}$ - C. Pilger ${ }^{2}$ P. Keckhut ${ }^{3}$ J. D. Assink ${ }^{6}$ - P. S. M. Smets ${ }^{6,7}$ • \\ C. F. Lee L J. Kero $^{10} \cdot$ T. Sindelarova ${ }^{9} \cdot$ N. Kämpfer ${ }^{13}$ • \\ R. Rüfenacht ${ }^{13}$ - T. Farges ${ }^{1}$ - C. Millet $^{1}$ - S. P. Näsholm ${ }^{8}$. \\ S. J. Gibbons ${ }^{8}$ - P. J. Espy ${ }^{14}$ • R. E. Hibbins ${ }^{14}$ - P. Heinrich ${ }^{1}$.

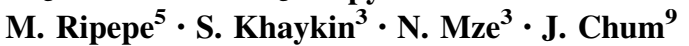

Received: 22 August 2016/ Accepted: 20 October 2017/Published online: 28 November 2017

(C) The Author(s) 2017. This article is an open access publication

\begin{abstract}
This paper reviews recent progress toward understanding the dynamics of the middle atmosphere in the framework of the Atmospheric Dynamics Research InfraStructure in Europe (ARISE) initiative. The middle atmosphere, integrating the stratosphere and mesosphere, is a crucial region which influences tropospheric weather and climate.
\end{abstract}

\section{E. Blanc}

elisabeth.blanc@cea.fr

1 CEA DAM DIF, 91297 Arpajon, France

2 Federal Institute for Geosciences and Natural Resources, Stilleweg 2, 30655 Hannover, Germany

3 LATMOS, IPSL, UVSQ Université Paris-Saclay, UPMC Univ. Paris 06, CNRS, 78280 Guyancourt, France

4 Department of Meteorology, University of Reading, Reading, Berkshire RG6 6BX, UK

5 Department of Earth Sciences, University of Firenze, Via G. La Pira, 4, 50121 Firenze, Italy

6 Department of Seismology and Acoustics, Royal Netherlands Meteorological Institute, P.O. Box 201, 3730 AE De Bilt, the Netherlands

7 Department of Geoscience and Engineering, Delft University of Technology, Delft, the Netherlands

8 NORSAR, PO Box 53, N2027 Kjeller, Norway

9 Institute of Atmospheric Physics, CAS, Bocni II, 14131 Prague 4, Czech Republic

10 Swedish Institute of Space Physics, Box 812, 98128 Kiruna, Sweden

11 Royal Belgian Institute for Space Aeronomy, Ringlaan-3-Avenue Circulaire, 1180 Brussels, Belgium

12 LMFA, UMR CNRS 5509, École Centrale de Lyon, Lyon, France

13 Institute of Applied Physics, University of Bern, 3012 Bern, Switzerland

14 Department of Physics, Norwegian University of Science and Technology, 7491 Trondheim, Norway 
Enhancing the understanding of middle atmosphere dynamics requires improved measurement of the propagation and breaking of planetary and gravity waves originating in the lowest levels of the atmosphere. Inter-comparison studies have shown large discrepancies between observations and models, especially during unresolved disturbances such as sudden stratospheric warmings for which model accuracy is poorer due to a lack of observational constraints. Correctly predicting the variability of the middle atmosphere can lead to improvements in tropospheric weather forecasts on timescales of weeks to season. The ARISE project integrates different station networks providing observations from ground to the lower thermosphere, including the infrasound system developed for the Comprehensive Nuclear-Test-Ban Treaty verification, the Lidar Network for the Detection of Atmospheric Composition Change, complementary meteor radars, wind radiometers, ionospheric sounders and satellites. This paper presents several examples which show how multi-instrument observations can provide a better description of the vertical dynamics structure of the middle atmosphere, especially during large disturbances such as gravity waves activity and stratospheric warming events. The paper then demonstrates the interest of ARISE data in data assimilation for weather forecasting and re-analyzes the determination of dynamics evolution with climate change and the monitoring of atmospheric extreme events which have an atmospheric signature, such as thunderstorms or volcanic eruptions.

Keywords Atmospheric dynamics - Middle atmosphere - Infrasound - Gravity waves · Volcanoes · Atmospheric disturbances · Extreme events

$\begin{array}{ll}\text { Abbreviations } & \\ \text { ALOMAR } & \text { Andøya Space Centre, Norway } \\ \text { AMSU } & \text { Advanced Microwave Sounding Unit } \\ \text { ARISE } & \text { Atmospheric dynamics Research InfraStructure in Europe } \\ \text { CMIP } & \text { Coupled Model Inter-comparison Project } \\ \text { CTBT } & \text { Comprehensive nuclear-Test-Ban Treaty } \\ \text { ECMWF } & \text { European Centre for Medium-range Weather Forecasts } \\ \text { GCM } & \text { General Circulation Model } \\ \text { GPS RO } & \text { GPS Radio Occultation } \\ \text { GW } & \text { Gravity Wave } \\ \text { HIRDLS } & \text { High Resolution Dynamics Limb Sounder } \\ \text { HWM } & \text { Horizontal Wind Model } \\ \text { IAVWOPSG } & \text { International Airways Volcano Watch Operation Group } \\ \text { IMS } & \text { Infrasound Monitoring System } \\ \text { LIDAR } & \text { Light Detection and Ranging } \\ \text { MA } & \text { Middle Atmosphere } \\ \text { MERRA } & \text { Modern Era Retrospective analysis for Research and Applications } \\ \text { MLT } & \text { Mesosphere Lower Thermosphere } \\ \text { MPI-ESM-LR } & \text { Max Planck Institute-Earth System Model-Low Resolution } \\ \text { MSIS } & \text { Mass Spectrometer and Incoherent Scatter } \\ \text { MST } & \text { Mesosphere, Stratosphere, Thermosphere } \\ \text { NDACC } & \text { Network for the Detection of Atmospheric Composition Change } \\ \text { NWP } & \text { Numerical Weather Prediction } \\ \text { OHP } & \text { Observatory of Haute-Provence, France } \\ \text { OPAR } & \text { Observatory of Atmospheric Physics of Reunion Island } \\ \text { PW } & \text { Planetary Wave } \\ & \end{array}$




$\begin{array}{ll}\text { SSW } & \text { Sudden Stratospheric Warming } \\ \text { SVERT } & \text { Sakhalin Volcanic Eruption Response Team } \\ \text { TRMM } & \text { Tropical Rainfall Measurement Mission } \\ \text { VAAC } & \text { Volcanic Ash Advisory Centre } \\ \text { WIRA } & \text { Wind Radiometer } \\ \text { WRF } & \text { Weather Research and Forecasting }\end{array}$

\section{Introduction}

The atmosphere is a dynamic medium with variability on time and space with scales ranging from thousands of kilometers to tens of meters and extending in the different atmospheric layers from the troposphere up to the lower thermosphere. It includes the middle atmosphere (MA) which extends from the tropopause $(10-15 \mathrm{~km})$ to the turbopause $(100-105 \mathrm{~km})$ comprising the stratosphere and mesosphere. Atmospheric dynamics is driven by atmospheric waves such as gravity waves $(\mathrm{GW})$ at periods larger than the Brunt-Väisälä frequency, produced in the troposphere by flow over topography, convection related to thunderstorms, cold fronts and jet imbalance. At planetary scales, it includes Rossby waves (or planetary waves $\mathrm{PW}$ ) which owe their existence to the equator to pole gradient of potential vorticity and are produced by flow over orography and by contrasts in temperature between the land and ocean. The upward propagation and breaking of GWs and PWs control to a large extent the circulation system in the MA and play an essential role in local weather and climate.

Since the pioneering studies of Baldwin and Dunkerton (2001); Baldwin et al. 2003 there has been renewed focus on the ways in which variability in the MA on all timescales can lead to shifts and changes to the tropospheric jet stream and hence to changes in surface weather and climate (Shaw and Shepherd 2008a). A key example of the variability of the MA, critical to the link between the troposphere and stratosphere, is the sudden stratospheric warming events (SSW) during which normally winter westerly winds in the stratosphere are temporarily reversed due to momentum transfer from PW breaking. During these events, PW breaking leads to a rapid deceleration of the normally westerly stratospheric jet. In recent years, there has been a renewed focus on studying and understanding the dynamics of SSW events and their evolution both dynamically and climatologically (e.g., Charlton and Polvani 2007). The review of Tripathi et al. (2014) showed that correctly predicting the evolution of extreme events in the stratosphere such as stratospheric sudden warnings can lead to improvements in tropospheric weather forecasts on weekly timescales. Similarly, Sigmond et al. (2013) showed that seasonal forecast skill (2-3 months ahead) is significantly enhanced following SSW events in a dynamical seasonal forecast system including a good representation of the stratosphere. On longer timescales, future changes in stratospheric climate could play a significant role in determining changes in surface climate over the coming century (Manzini et al. 2014).

GWs transfer energy and momentum from one part of the atmosphere to another. The deposition of momentum is associated with wave dissipation or breaking which exerts a drag force on the mean flow and significantly alters the dynamical structure of the atmosphere (Dunkerton 1978; Lindzen 1981; Holton 1983; Holton et al. 1995; Butchart 2014). GW sources and their contribution to atmospheric circulation and variability in the MA were reviewed by Fritts and Alexander (2003). Although the scales of the individual waves are small, GWs have collectively important global-scale effects as they drive 


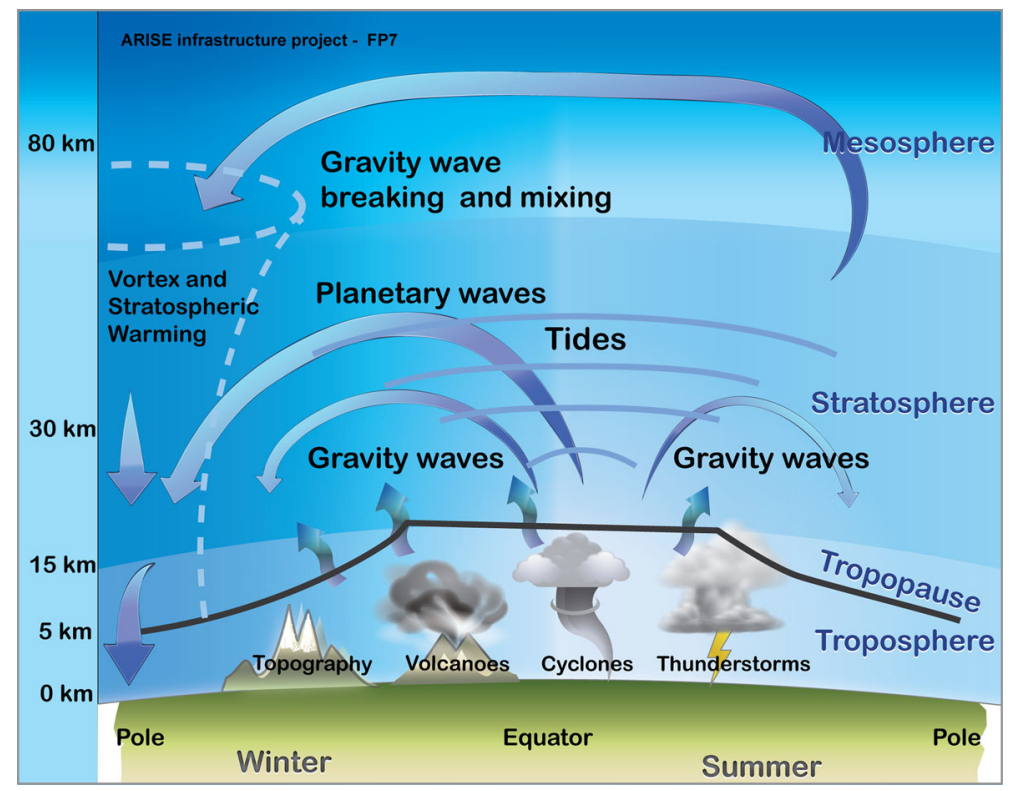

Fig. 1 Schematic diagram of the atmospheric dynamic processes in the Earth's atmosphere. Gravity and planetary waves contribute to the middle atmospheric transport as illustrated by arrows

the global summer-to-winter pole circulation, in addition to the PW action, as shown in Fig. 1 .

GW geographical distribution reflects their different origin. Mountain GW activity is observed by satellite mainly in Southern Andes, over Rockies in Northern America, in Antarctica and in Northern Europe (Wu et al. 2006; Hoffmann et al. 2014). Tropical and equatorial convection forms large GW sources over continents where thunderstorms are quasi-continuously observed by Tropical Rainfall Measurement Mission (TRMM) satellites (Christian et al. 2003). GWs propagate upward with growing amplitude because of the decrease in the atmospheric density where the altitude increases in order to satisfy the wave energy conservation. GWs break when the phase velocity is in the opposite direction to the winds. A significant part of their energy is transmitted to the ionosphere where they contribute to the traveling disturbances frequently observed in the ionosphere (Vincent 2009; Lastovicka 2006). The cumulative effects of GW activity may disturb the general atmospheric circulation (Holton et al. 1995; Shaw and Shepherd 2008b). A strong air descent observed by satellite in Northern Polar Regions by Hauchecorne et al. (2007) was explained by a pure atmospheric dynamical phenomenon induced by the GW effects. At larger scales, it was recently shown that PW could favor particular regional weather extremes (Screen and Simmonds 2014).

At shorter scales, the impact of infrasound waves on the atmosphere is expected to be local or regional. However, quasi-continuous infrasound sources like ocean swells affect a large surface over oceans. They are currently observed in seismic and atmospheric recordings (Ardhuin and Herbers 2013; Landes et al. 2014). Rind (1977) estimated that the dissipation of infrasound produced by ocean swells in the Atlantic Ocean could produce significant heating rates in the 110-140 km altitude range. Similar results were found by Hickey et al. (2001). Additional significant infrasound sources are tropical thunderstorms and winds over 
topography (e.g., Le Pichon et al. 2010). Thanks to ongoing development of the international monitoring system (IMS) dedicated to the verification of the Comprehensive Nuclear-TestBan Treaty (CTBT) enormous progress was made in the knowledge of infrasound sources (e.g., Campus and Christie 2010). Infrasound waves propagate in the atmospheric wave guide between ground and the temperature increase in the stratosphere and lower thermosphere (Francis 1975; Blanc 1985). They are strongly affected by the stratospheric winds variability and fluctuations from GWs in the wind profiles (Le Pichon et al. 2008; Kulichkov et al. 2010). It was suggested in the pioneering work of Donn and Rind (1971), Rind et al. (1973) and Rind and Donn (1975) that infrasound from well-identified repetitive sources could be used for remote determination of the upper-atmosphere wind speeds. IMS stations, quasi-continuously detecting infrasound from volcanoes, are well-adapted to these studies. Systematic differences between simulations and observations of the infrasound produced by the Lopevi volcano, detected in the New Caledonia IS22 station, were used to correct winds in the upper stratosphere and mesosphere (Le Pichon et al. 2005a, b), and new methods were further developed for infrasound inversions (Millet et al. 2007; Drob et al. 2010; Lalande et al. 2012; Assink et al. 2014a). Ocean swell at the origin of microbaroms detected at most infrasound stations could also be used as a natural and continuous source for passive acoustic tomography of the stratosphere and lower mesosphere in a global way (Le Pichon et al. 2006). This methodology will be reinforced thanks to recent improvements in ocean swell source characterization (Ardhuin et al. 2015). Recent studies focus on the use of infrasonic ambient noise to probe the atmosphere during SSW events (e.g., Evers and Siegmund 2009; Assink et al. 2014b; Smets and Evers 2014). In the study of Smets et al. (2016), a novel method for the evaluation of middle atmospheric weather forecasts using infrasound from volcanoes is introduced.

There is now an increasing interest to extend the altitude range considered in the atmospheric dynamics up to the mesosphere and lower thermosphere (MLT). This region of low temperature is characterized by a summer-to-winter temperature gradient, resulting from adiabatic cooling and warming associated with the GW-driven atmospheric circulation. The MLT dynamics is described by Smith (2012) and Vincent (2015). Recent studies show that the coupling between stratosphere, MLT and thermosphere is more important than expected and that it should be considered in models (Drob et al. 2008). Lidar observations at middle latitude showed that a warm signal in the upper mesosphere could indicate precursor effects in SSW events (Angot et al. 2012). At higher altitudes, strong ionospheric disturbances following SSW were observed by the Jicamarca radar at the geomagnetic equator and GPS stations (Goncharenko et al. 2013). Such processes need to be characterized and integrated in the future ionospheric models used for space weather studies.

The representation of these complex wave systems and associated large-scale disturbances in weather and climate models is still in its infancy. As shown by Charlton-Perez et al. (2013), only around half of the climate models used for the most recent fifth Coupled Model Inter-comparison Project (CMIP5) fully represented the stratosphere with consequent biases in the representation of stratospheric climate and variability for those that did not. One reason for the lack of representation of the MA in numerical models is the relatively limited current observational possibilities in this region.

Because of the coarse temporal and spatial resolution of most weather and climate models, a portion of the GWs cannot be resolved directly and is parameterized (Alexander et al. 2010; Lott and Guez 2013). This parameterization suffers from a lack of observational constraints due to the limited availability of GW observations. For instance, the link between the generation of GWs by tropical convection and regular oscillations of stratospheric and mesospheric winds such as the quasi-biannual oscillation well established in 
theory and represented in some models has only limited observational constraints. Many parameters of the GW parameterizations and particularly GW source parameters are uncertain due to a lack of long-term high-resolution observations. Most small-scale GWs are not resolved by typical climate models and only partially resolved by weather forecasting models.

At climatological timescales, assessing trends in the MA is difficult due to the lack of long-duration calibrated observations as shown, for example, by the discussions surrounding estimates of temperature trends from satellite instruments by Thompson et al. (2012). Trends in temperature evolution in the different atmospheric layers are valuable indicators for climate change studies. The long-term evolution of the atmospheric disturbances (cyclones, severe weather, gravity and planetary waves, stratospheric warming events) also needs to be determined to better understand and predict their evolution with climate change, to improve climate models and weather forecasts.

For all these timescales, improved and expanded routine measurements would provide significant opportunities for enhanced understanding of the climate and variability of the MA and MLT. Given the importance of their impact on weather and climate at the surface, this represents critical needs for many sectors of industry and society.

The ARISE project concept consists in integrating complementary international atmospheric observation networks including infrasound network, lidar network, different radars systems, observatories and satellites to provide a more comprehensive and coherent MA picture. The objective is to recover the vertical structure of the unresolved atmospheric motions and disturbances with unprecedented spatial-temporal resolution and study their impact on weather and climate (Blanc et al. 2015). The considered timescales for an accurate description of these phenomena range from seconds for atmospheric extreme events to minutes or hours for GWs, days for PWs, seasons and up to tens of years for longterm mean trend studies. The observations cover areas extending over Europe and outlying regions, including polar and equatorial regions which have very different climate. The altitude range covers the troposphere, stratosphere, mesosphere, lower thermosphere and ionosphere. Data will be collected over the long term to monitor atmospheric extreme events and atmospheric parameters related to climate change. One of the main applications is the use of these data to improve the weather forecasting models up to timescales of weeks. ARISE also represents a relevant network for the remote observation of atmospheric extreme events including meteorological events and large-scale disturbances such as sudden stratospheric warmings. Volcano monitoring by infrasound technology presents a strong interest for aviation safety in case of eruption of distant non-instrumented volcanoes.

The objective of this paper is to show how the ARISE project could provide new data sets, linked to modeling, to improve the representation of the middle atmospheric dynamics. After a short description of the ARISE objectives and network, the paper presents multi-technology observations performed to quantify the uncertainties in the weather predictions models. It then describes the potential of infrasound remote observations for the characterization and monitoring of extreme events such as meteors, thunderstorms or volcanoes. The paper then highlights the interest of the multi-technology observations to represent gravity waves and stratospheric warming events in the MA. The last part is dedicated to show the interest of ARISE data for future assimilation in weather forecasting and climate models. Perspectives for next project steps are presented in the last section.

This paper mainly reviews the ARISE results obtained in the first step of the project (EU FP7 program). Following these results, ARISE work is continuing in the framework of the EU H2020 program. 


\section{ARISE Concept}

\subsection{ARISE Objectives}

The objectives of the ARISE project are to provide 3D atmospheric observations in the different atmospheric layers to improve the modeling of the general global atmospheric circulation and develop related products and services.

The ARISE objectives focus on the main following topics:

- improving the representation of GWs and PWs in stratosphere resolving climate models to estimate the impact of stratospheric climate forcing on the troposphere and developing methods to parameterize GWs in the perspective of future assimilation in weather forecasting models,

- determining the evolution of the atmospheric disturbances in relation to climate change by providing observations of climate-related phenomena over large time periods, in order to better understand the processes involved and to characterize their evolution in relation to climate change,

- developing tools for future applications based on the quasi-real-time description of an atmospheric extreme event for civil applications. An example is remote volcano monitoring for civil aviation safety.

\subsection{ARISE Network}

The ARISE project integrates different atmospheric observation networks and satellite observations to recover the vertical structure of the unresolved atmospheric motions and disturbances with unprecedented spatial-temporal resolution and coverage.

The ARISE station network (Fig. 2) includes complementary infrastructures listed in this article.

The IMS infrasound network developed for the verification of the CTBT (http://www. ctbto.org) providing continuous infrasound measurements is unique by its global and homogeneous coverage as well as its data quality. It is larger and much more sensitive than
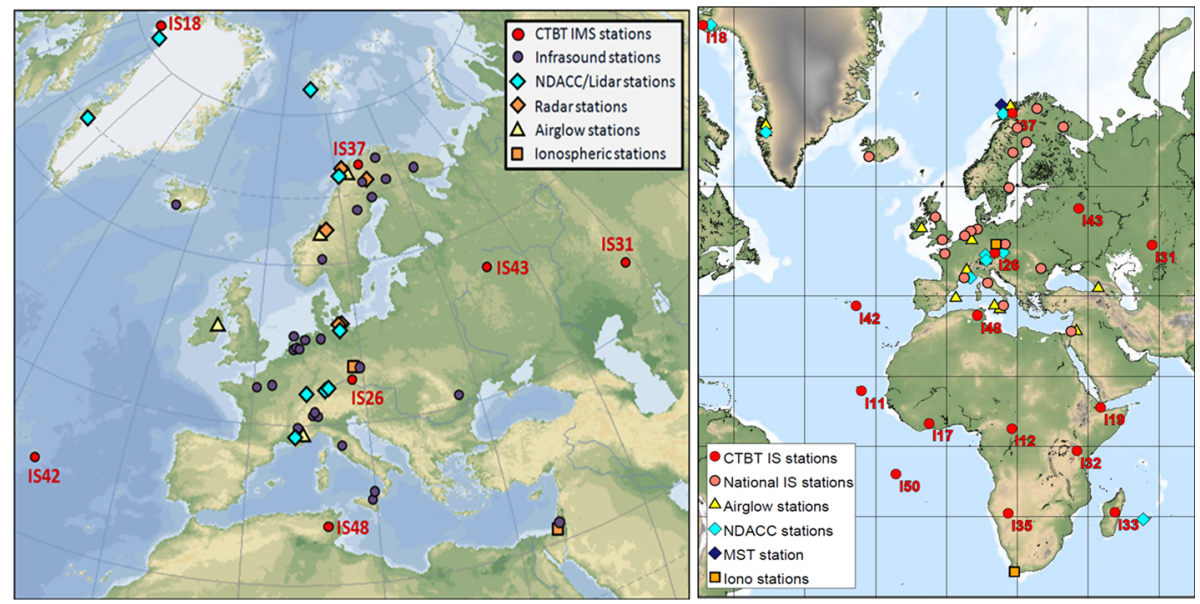

Fig. 2 The ARISE observation network 
any previously operated infrasound network. Once complete, the network will include 60 stations uniformly distributed across the globe. Today, more than $80 \%$ of this network is operational. The IMS infrasound sensors are microbarometers designed for the detection of atmospheric pressure fluctuations in the $0.02-4 \mathrm{~Hz}$ frequency range. They are grouped in mini-array stations including at least four sensors at distances of 1-3 km able to detect and characterize low coherent infrasound signals within the background noise. All technical aspects of infrasound monitoring related to sensors, stations and data processing have been redeveloped for CTBT verification (Christie and Campus 2010; Brachet et al. 2010). In the last decade, detection bulletins determined from near-real-time analysis have been produced and correlated with observations of natural or man-made atmospheric sources, such as exploding meteoroids, volcanic eruptions, severe weather, hurricanes, earthquakes and ocean swelling (Le Pichon et al. 2010). Infrasound technology also detects and characterizes waves at much lower frequencies such as GWs, tides and PWs (Blanc et al. 2010; Marty et al. 2013). This provides a unique broadband observation set of all atmospheric disturbances, leading to a new description of atmospheric dynamics and extreme events occurring in different parts of the world. The IMS network is completed by national infrasound stations which form a dense network in Europe.

The Network for the Detection of Atmospheric Composition Change (NDACC, http:// ndacc-lidar.org/) provides lidar measurements of the stratospheric temperature and wind. This international network was initially set up in 1991 for ozone monitoring after the ozone hole discovery and the launch of the UARS satellite. The measurement of stratospheric and mesospheric temperature using Rayleigh lidar technique was initiated 30 years ago at the Haute-Provence Observatory (OHP) by Hauchecorne and Chanin (1980). Monochromatic laser pulses are sent vertically into the atmosphere, and a temporal analysis of the backscattered light provides information about the vertical structure and composition of the atmosphere. Rayleigh lidars are well adapted to the study of PWs, GWs and tides in the upper stratosphere and mesosphere as well as their interaction to induce mesospheric inversions. The Haute-Provence lidar database is the longest temperature series and allowed one of the first detections of the cooling of the upper stratosphere and mesosphere (Ramaswamy et al. 2001). Now it is a key instrument to ensure inter-satellite adjustment like AMSU series (Keckhut et al. 2011). A Rayleigh-Doppler wind lidar was developed by Chanin et al. (1989) to measure the horizontal wind in the stratosphere and in the upper troposphere. Such a lidar has been used at the Haute-Provence Observatory to study GW characteristics and climatology and their interaction with the mean circulation (Hertzog et al. 2001). A similar wind lidar is recently operating at Reunion Island at the Maïdo observatory (Baray et al. 2013).

Mesospheric observations by $\mathrm{OH}$ spectrometers providing relevant information of wave activity in the mesosphere (Pilger et al. 2013) are integrated in the project. They are completed by airglow imagers in development for the ARISE multi-technology sites.

Stratospheric wind observations are performed by a microwave Doppler spectroradiometer (WIRA, Rüfenacht et al. 2014). This instrument well complements the other observations. An instrument was installed at OHP during the 2012-2013 campaign. It then moved to Reunion Island for forthcoming ARISE observations.

Furthermore, other technologies associated with ARISE or identified to be of relevance to the project include new lidar systems (ALOMAR), MST radars (MAARSY) and meteor radars (SKiYMET) as new observation techniques highlighting a novel possibility to observe high-altitude dynamics. Ionospheric Doppler sounding observations are used for studying the coupling between the atmosphere and the ionosphere. EISCAT (European 
Incoherent Scatter Scientific Association) radar measurements complement ionospheric observations.

ARISE also includes multi-technology sites at Haute-Provence, France, Andøya Space Center, Norway, and La Reunion Island, France, which are relevant ARISE reference stations.

The first ARISE multi-technology site at the Observatoire de Haute-Provence (OHP, $43.93^{\circ} \mathrm{N}, 5.71^{\circ} \mathrm{E}$, France) where a NDACC lidar is in operation provided high-quality data during the first 1-year observation campaign. A four-element infrasound array of $\sim 3-\mathrm{km}$ aperture was installed during the campaign. It becomes a permanent infrasound station. A WIRA microwave radiometer completed the observations during the campaign.

The Arctic Lidar Observatory for Middle Atmosphere Research (ALOMAR) in Norway (Andøya Space Center, $69.3^{\circ} \mathrm{N}, 16.0^{\circ} \mathrm{E}$ ) is one of the key facilities for ARISE network optimization identified as a future multi-technology site. It integrates airglow detections, radar facilities and a IMS infrasound station, which is less than $100 \mathrm{~km}$ away from the observatory. The use of radar observations in ARISE is of high interest and potential, especially when considering Radar information on wind and temperature for sparsely covered altitude regions like the mesosphere and thermosphere above $70 \mathrm{~km}$ altitude. While some of the globally distributed radar instrumentation is mainly used for wind profiling the lower troposphere $(<10-15 \mathrm{~km}$, e.g., MST Radar), other instruments (e.g., Meteor radar) especially focus on estimating mesospheric wind and temperature. Powerful MST radars can be used to derive mesospheric wind information.

Another observatory is Esrange $\left(67.88^{\circ} \mathrm{N}, 21.10^{\circ} \mathrm{E}\right)$ including the ESRAD MST radar operated in Northern Sweden. A facility such as the Swedish infrasound network reinforces the interest for the study of the dynamics of the atmosphere.

The Reunion Island lidar was developed in the framework of NDSC/NDACC (Network for the Detection of Stratospheric Change/Network for the Detection of Atmospheric Composition Change). In 2012, a new observatory was commissioned in Maïdo (OPAR $21^{\circ} \mathrm{S}, 55^{\circ} \mathrm{E}$ ) at $2200 \mathrm{~m}$ above sea level. It hosts various instruments for wind and temperature measurements, including Rayleigh lidar, Doppler lidar and Modem radiosonde, and the WIRA wind radiometer was installed in 2013.

\section{Multi-technology Observations and Model Assessment}

\subsection{Comparison of Lidar and Infrasound Data with the ECMWF Model}

One of the main objectives of the OHP campaign (July 2012-July 2013) was to investigate the synergy between different collocated techniques for the characterization of specific dynamics events. The SSW occurring in January 2013 during the campaign offered a good opportunity to test this synergy.

Comparing the European Centre for Medium-Range Weather Forecasts (ECMWF, http://www.ecmwf.int/) wind and temperature models, lidar and wind radiometer observations with collocated infrasound measurements provided an estimate of the model uncertainties in the stratosphere and mesosphere. Infrasound microbaroms in the Atlantic Ocean are dominant and permanent sources of infrasound signals in the $0.1-0.3 \mathrm{~Hz}$ frequency band, resulting from the nonlinear interaction of ocean waves. They are quasicontinuously detected during normal winter conditions when the infrasound propagation is driven by the prevailing westerly stratospheric winds (Landes et al. 2014). Infrasound 


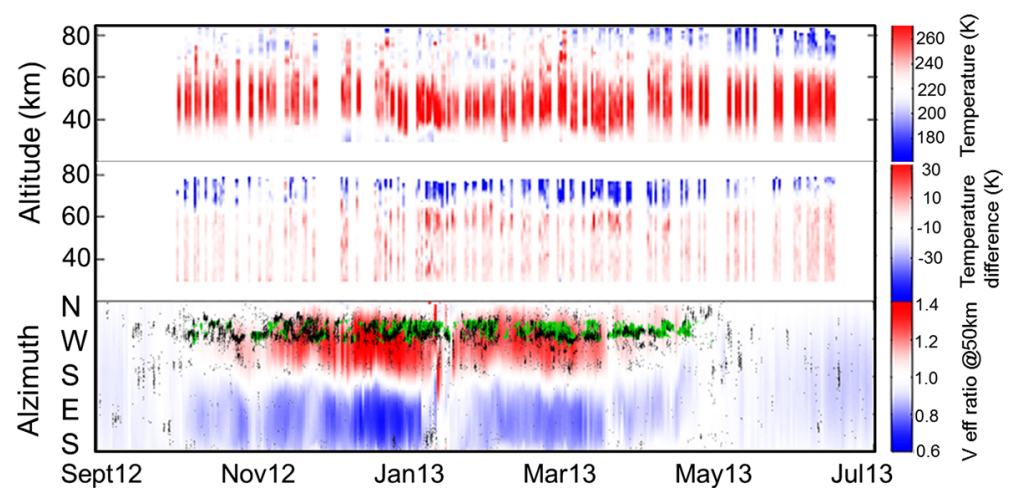

Fig. 3 Multi-technology synthetic view of the OHP measurement campaign showing from top to bottom: lidar temperature observations, temperature difference between L91 ECMWF and lidar observations, infrasound microbaroms from North Atlantic. Detected (black dots) and predicted signals (green regions) are superimposed on $V_{\text {eff-ratio }}$ computed from vertical profiles above OHP in the full range of azimuths

observations provide additional continuous, directional and integrated information about the structure of the stratospheric waveguide from the source to the station.

Figure 3 presents on the same time basis the temporal evolution of lidar and infrasound observations compared to the ECMWF operational deterministic high-resolution analysis consisting of 91 levels in the vertical (further referred to as L91). The systematic comparisons between lidar and model revealed differences as large as $20 \mathrm{~K}$. On average, the model temperature appears to be overestimated by $\sim 5 \mathrm{~K}$ in the stratosphere and underestimated by $\sim 10 \mathrm{~K}$ in the mesosphere. Microbarom detections (black) are superimposed to the onto the color-coded effective sound speed ratio $V_{\text {eff-ratio }}$ above the OHP site, defined as the ratio between the maximum of the along-path wind plus the adiabatic sound speed at $30-60 \mathrm{~km}$ altitude and the sound speed at the ground level, derived from the ECMWF model. This parameter can be used as a criterion to characterize the infrasound propagation (Kulichkov 2010). Red regions indicate favorable stratospheric propagation conditions, while blue to white colors indicate that stratospheric propagation is unlikely.

Microbarom sources are predicted using a source model and operational ECMWF ocean wave models. The back azimuths of predicted microbarom sources with respect to the OHP array are superimposed in green. As expected, improved detection capability occurs downwind during the period from October 2012 to May 2013 when stratospheric winds control the eastward microbarom propagation to the station. Good agreement between the observed and predicted azimuths is found in a range of $\sim 20^{\circ}$. Deviations from this trend are either related to short timescale variability of the atmosphere (e.g., large-scale PWs, stratospheric warming effects) or can be explained by unresolved changes in the nature of the microbarom sources. The effect of the major January 2013 SSW can be seen in the strong decrease in the number of microbarom detections from the north Atlantic representing the effect of stratospheric wind inversion during this event. 


\subsection{ECMWF Evaluation Using ARISE Multi-technology Observations}

\subsubsection{Evaluation Using Lidar and Wind Radiometer Observations}

Following these results, the OHP NDACC lidar station was considered for evaluating numerical weather prediction (NWP) such as ECMWF analyses at $40 \mathrm{~km}$ and above where very few observations are assimilated. Generally, ECMWF and lidar are in good agreement up to the stratopause but differences may reach an average of $-20 \mathrm{~K}$ in the mesosphere above $65 \mathrm{~km}$. This is expected since very little data are assimilated above $50 \mathrm{~km}$ altitude. The physics of the model characterizing the upper atmosphere, that is driven from below, still needs improvements to better represent the observations. The vertical resolution of the ECMWF model was increased in 2013 from 91 levels (L91) to 137 levels (L137), and comparison also included the NASA modern era retrospective analysis for research and applications (MERRA) model.

Figure 4 (top) presents examples of the statistical distributions of the differences between the ECMWF temperature models and lidar observations during the OHP measurement campaign in January and June 2013 (Le Pichon et al. 2015). Generally, ECMWF, NASA MERRA and lidar observations are in agreement up to the stratopause with a small, but systematic positive difference of $\sim 3 \mathrm{~K}$ at $\sim 35 \mathrm{~km}$ altitude. The median of the differences increases with altitude, predominantly above the stratopause region. The largest deviations noted in winter correspond to the time of the major SSW that occurred early in January 2013. After the vernal equinox, the median and 95\% intervals reduce by about a factor of two due to the lack of stratospheric and mesospheric variability in this season.

The horizontal wind of the MA is another fundamental atmospheric parameter to represent the atmospheric dynamics. However, there are no wind data assimilated in models above the top of radiosoundings (around $30 \mathrm{~km}$ ). The wind is indirectly derived from temperature and pressure fields solving the fundamental equations of the atmospheric dynamics.

Comparisons between ECMWF and WIRA observations (examples of January and April 2013 in Fig. 4, middle) show that measurements and model values are in good agreement between 30 and $60 \mathrm{~km}$. This is expected as the model winds are determined from thermal wind balances implicitly solved in the global circulation models (GCM). The median of the difference, especially above $60 \mathrm{~km}$, falls outside of the instrumental error in green and thus can be considered statistically significant. The mean flow of the zonal wind appears to be overestimated up to about $40 \mathrm{~m} / \mathrm{s}$ in the mesopause. As for the temperature, larger differences are noted during the winter months.

On longer timescales (October 2012-July 2013), the standard deviation of the mean difference in temperature exceeds $5 \mathrm{~K}$ between 40 and $60 \mathrm{~km}$ altitude. Significant differences in the zonal wind are also observed (Fig. 4, bottom). The largest deviations appear in winter when the variability from large-scale PWs dominates over the general circulation and SSW occurs (Le Pichon et al. 2015).

The current ARISE data set can be used as a benchmark to assess future upgrades in assimilation systems and as a comparator for model forecasts. As the ARISE network data coverage increases spatially and the number and diversity of remote sounding techniques increases, additional and more large-scale comparison will be possible. 

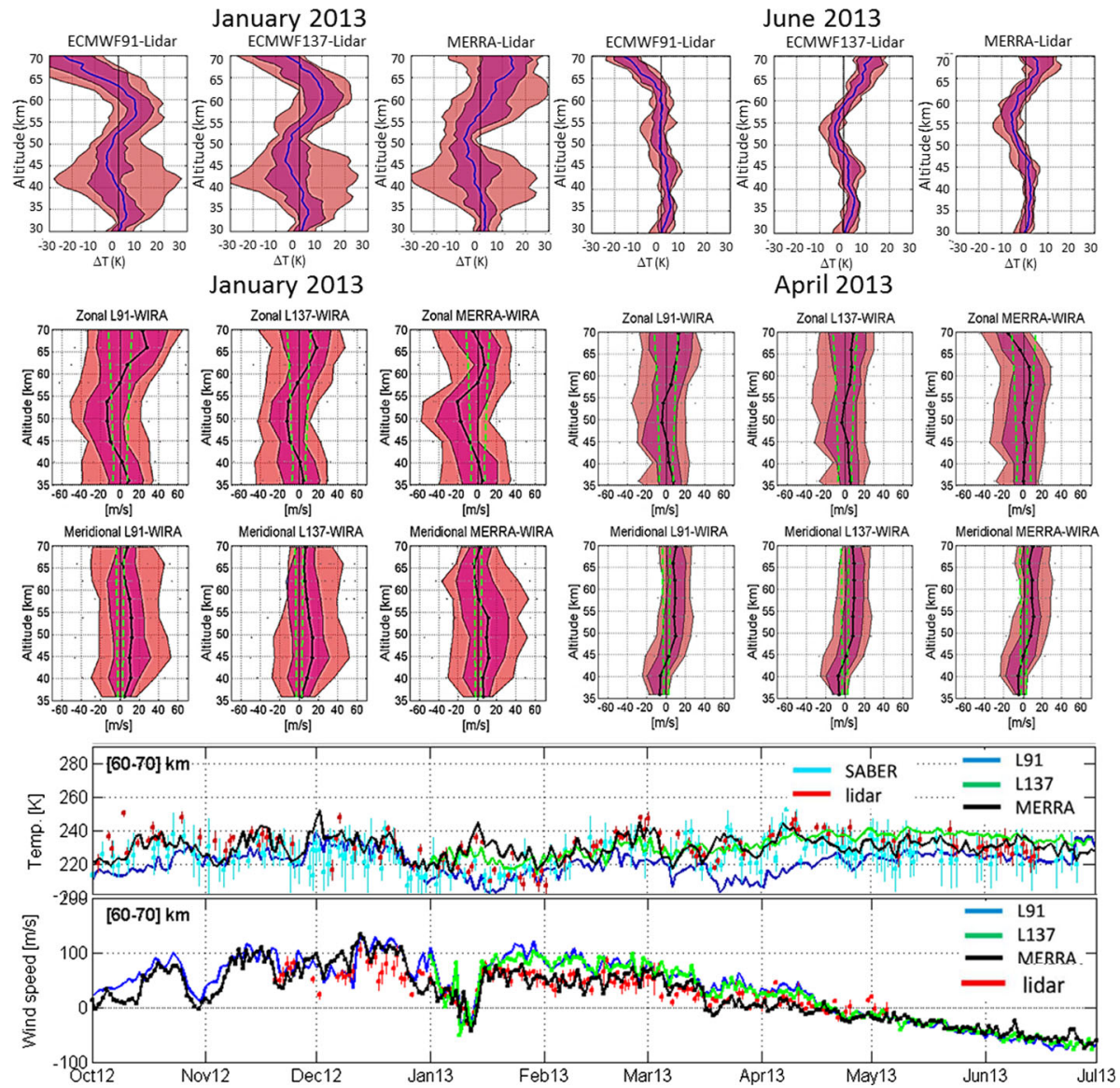

Fig. 4 Distribution of the monthly difference between ECMWF (L91 and L137) and MERRA temperature models at 0-h UTC and nightly averaged lidar measurements versus altitude at OHP in January and June 2013 (top) and between wind model at 12-h UTC and daily averaged WIRA measurements versus altitude in January and April 2013 (middle). Blue lines: standard error of the mean. Green dashed lines: instrumental error bars. The differences are significant when the blue lines fall outside of the green dashed lines. Purple and pink regions: 66 and 95\% confidence intervals of the difference profiles. (Bottom) Comparison between model and observation time series of wind and temperatures at the altitude range 60-70 km. (Adapted Le Pichon et al. 2015)

\subsubsection{Evaluation Using Infrasound Inversions}

Observations at the beginning of the 2000s showed that infrasound from quasi-continuous volcanic eruptions can be used as a passive remote sensing technique to probe the upper atmosphere (Le Pichon et al. 2005a, b). Different studies have then focused on the development of inverse methods to estimate upper atmospheric wind parameters and determine the uncertainties in the wind profiles provided by the models (Drob et al. 2010; Lalande et al. 2012; Chunchuzov et al. 2015).

The near-continuous activity of Mt. Etna, the favorable locations of the available infrasound arrays and the good detection capability at the far-field infrasound array make Mt. Etna a good candidate for passive acoustic remote sensing and general circulation 

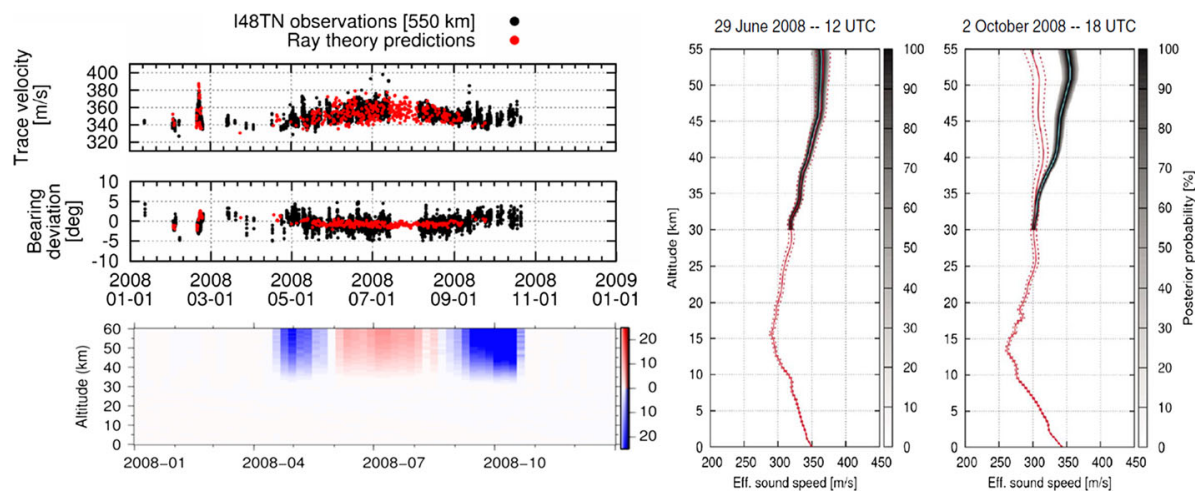

Fig. 5 Inversions using Etna volcano infrasound. (Left) Comparison between Etna trace velocity data (black) in Tunisia compared to ray theory predictions performed with ECMWF models (red). (Right) Examples of effective sound speed inversions for June 29, 2008, and October 2, 2008. The a priori model is represented by the red curve; the dashed lines indicate the intrinsic uncertainty in the model due to nonmodeled small-scale structure. The dark patched areas correspond to the a posteriori model distribution. While the a priori and a posteriori model distributions correspond well in the summer case, the fall equinox case shows that the effective sound speed is underestimated by about $30 \mathrm{~m} / \mathrm{s}$ at $50 \mathrm{~km}$. (Left bottom) differences between models and inversions from April to October 2008. (From Assink et al. 2014a)

model validation studies of the stratosphere. Other sources such as ocean swell are also considered (Garcés et al. 2004).

Using the trace velocity of Etna eruptions observed at the IMS IS48 station in Tunisia, a first-order update of the effective sound speed in the MA has been obtained by applying a Bayesian inversion formalism. Instead of a more rigorous inversion procedure that involves propagation paths, travel time and bearing deviations, we seek the ensemble of effective sound speed updates that would likely explain the observed spread in trace velocities. Figure 5 shows examples of inversions during the summer (June 29, 2008) and during the equinox period (October 2, 2008). While the a priori and a posteriori model distributions essentially overlap for the summer case, the results for October 2, 2008, show that the effective sound speed is underestimated by at least $25 \mathrm{~m} / \mathrm{s}$ at $50 \mathrm{~km}$ altitude. The dashed red lines indicate the estimated intrinsic uncertainty in the a priori model due to non-modeled small-scale structure estimated from the GW activity and represented by the solid red line. The cyan and red lines represent the maximum likelihood and a priori models, respectively. While a first-order agreement is generally found between wind model and the observations in summer, significant discrepancies during the equinox periods and some anomalous wintertime periods during the occurrence of major SSW events were reported (Assink et al. 2014a). The example of October 2, 2008 illustrates the effective sound speed underestimation by the model by at least $25 \mathrm{~m} / \mathrm{s}$ at $50 \mathrm{~km}$ altitude near the equinox period. These values are in agreement with the statistical approach using of ensembles of realistically perturbed analyses for infrasound propagation modeling. The spread in the ECMWF Ensemble of Data Assimilations shows that the yearly mean effective sound speed can reach variations up to $8 \mathrm{~m} / \mathrm{s}$ in the stratosphere, exceeding occasionally $25 \mathrm{~m} / \mathrm{s}$ (Smets et al. 2015).

This method was extended over several months. Results reported at the left (bottom) of Fig. 5 suggest that the effective sound speed is overpredicted in summer and underestimated during equinoxes by models (Assink et al. 2014a). 

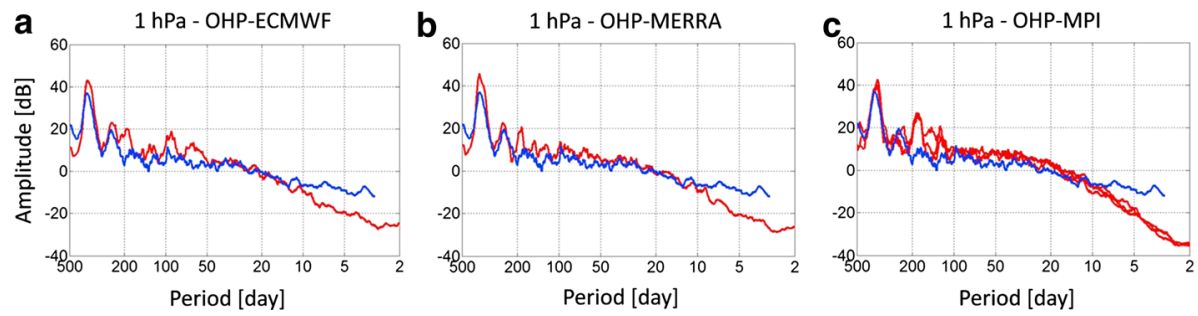

Fig. 6 Comparison between lidar (blue) and model (red) periodograms at $1 \mathrm{hPa}(\sim 47 \mathrm{~km})$ over OHP. a ECMWF (2003-2013). b MERRA (2003-2013). c MPI-ESM-LR (1991-2005). Each line corresponds to one ensemble member. (From Le Pichon et al. 2015)

\subsubsection{Planetary Wave Spectrum from Lidar Observations and Models}

Lidar observations provide PW information through the periodograms as shown in Fig. 6. Observations were compared with the spectral amplitude of ECMWF, NASA MERRA reanalyses and the climate Max Planck Institute-Earth System (MPI-ESM-LR) models.

A reasonable agreement in spectral amplitude is found down to 15-20 days for all models, showing that the annual and semiannual cycles are reasonably well resolved by the models. However, the variability at shorter timescales is lacking in both weather and climate models. We note that the measurement periodograms contain more narrow peaks compared to the model periodograms.

The MPI-ESM-LR periodogram appears to be smoother and the spectral tail has a steeper slope for periods smaller than 5 days, compared to the ECMWF/MERRA periodograms. The lower level of variability found in the free running MPI-ESM-LR model can partly be explained by its coarser resolution and the lack of data being assimilated. These results are in line with a recent study by Hoppel et al. (2013) who showed that assimilation of microwave imager/sounder data can provide reliable large-scale constraints throughout the mesosphere for operational high-altitude analysis.

\subsubsection{Planetary Waves and Tides from Infrasound Technology}

The infrasound sensors can detect low-pressure atmospheric waves in a very large bandwidth including infrasound, GWs, tides and PWs (Marty et al. 2010).

The spectrum of the atmospheric pressure of Fig. 7 (top) covers the period range from $1 \mathrm{~s}$ to 7 days. The slope change in the spectrum at the Brunt-Väisälä period indicates the difference between the infrasound (acoustic) and GW domains which are subject to different processes. The solar diurnal and semidiurnal tidal oscillations in surface pressure are well observed as shown in Fig. 7 spectrum. Barometric global tidal amplitudes are needed for the calibration of the ECMWF model (Ray and Ponte 2003). The IMS infrasound network could provide a new global data set to complete such observations.

The periodogram, obtained using 14 years of data recorded at the IS26 station, displays the PW activity at periods of several days. There is no apparent trend in the PW activity. The data series could be too small or trend effects too weak or masked by other processes for such observation. However, strong differences appear from one year to another in the PW structure.

Another way to characterize PWs is to analyze their effect on microbaroms measured in the infrasound stations. The ocean swell which forms a quasi-permanent infrasound noise 


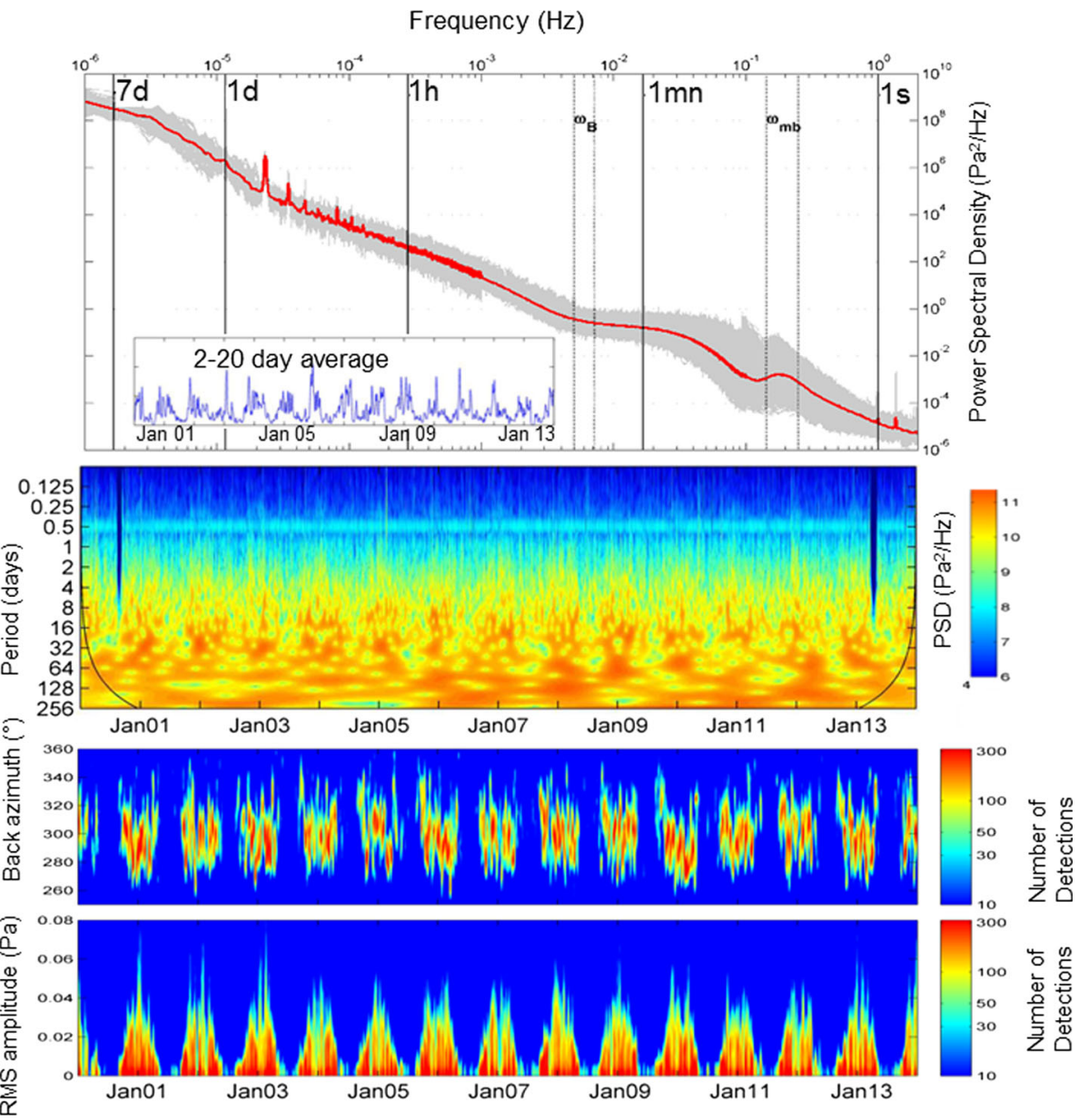

Fig. 7 (Top) Example of spectrum of the waves and wavelet analysis for 14-year data set recorded at the I26DE infrasound station in the Bavarian forest, Germany. The station detects infrasound, GWs, tides and planetary waves. (Middle) Wavelet periodogram and time series averaged on 2-20 days showing the planetary wave activity. (Bottom) Planetary wave effect on the microbarom amplitude and azimuth

observed everywhere in the world is the driving force materializing their activity; infrasound waves generated at the ocean interface are propagating over thousands of kilometers in the atmospheric wave guide between ground, stratosphere and thermosphere. Their amplitude is modulated by the PWs with a maximum of activity in winter (Blanc et al. 2010).

Figure 7 (bottom) shows several years of PWs observed in this way. Activity is larger in winter, and shows fluctuations in amplitude and azimuth in the range $70^{\circ}-120^{\circ}$ at timescales of weeks. The structure of these fluctuations is also variable from one year to another.

These infrasound data can be interesting for the long-term characterization of tides, for the study of satellite long time series. Tides induce bias in satellite observations such as advanced microwave sounding unit (AMSU) series (Keckhut et al. 2015). Ground-based 
instruments are needed to calibrate successive satellite instruments when overlap periods are missing (Keckhut et al. 2011).

\section{Extreme Event Monitoring}

The infrasound technology is well adapted to the characterization and monitoring of extreme events since the long-range infrasound propagation allows detections at very large distances from the infrasound sources. Several models using complementary approaches were developed to represent the infrasound propagation in the atmospheric wave channel between the ground and the temperature increases in the stratosphere and lower thermosphere (Drob et al. 2003; Gainville et al. 2010). Propagation models are needed to differentiate the source origin from the propagation effects in the detected infrasound signals. The stratospheric winds drive the infrasound propagation which mainly follows the zonal stratospheric wind. This effect is well represented at a first order. However, variations at shorter periods of time are more difficult to be represented as they are poorly integrated in the atmospheric models. Atmospheric disturbances at the origin of atmospheric model uncertainties (see Sect. 3) also contribute to the uncertainties in the infrasound propagation models. Other uncertainties are related to nonlinearity in the propagation.

This section presents examples of infrasound observations related to extreme events produced by meteorological activity, earthquakes and volcanoes which induce atmospheric effects detected by the ARISE network. It explains how propagation effects can be integrated to predict the detection capability of a specific infrasound network. It also proposes to use observations of quasi-permanent infrasound sources such as volcanoes as a monitor of disturbances such as GWs.

\subsection{Assessment of the Infrasound Technology Monitoring Capability}

\subsubsection{Simulations}

Because of its network coverage, time resolution and continuity in the observations, the infrasound technology is largely used to study all high-frequency sources which are at the origin of the extreme events. The large source number, routinely observed by the IMS network, demonstrates the high network efficiency (Le Pichon et al. 2010). However, the effect of the infrasound propagation needs to be determined to predict the detection efficiency of a specified infrasound network under any atmospheric conditions. Methods to determine the detection capability were developed for routine data analysis and interpretation (Le Pichon et al. 2008; Green and Bowers 2010). They are also used to assess the network performance in different configurations and promote its potential benefits for monitoring natural hazards.

Simulations were performed to determine the monitoring capability of any infrasound network under any atmospheric conditions. The methodology consists in computing the infrasound signal amplitude at any location and further evaluates whether the signal is detectable above the noise level at the receivers in specified atmospheric conditions (Le Pichon et al. 2008). Today, numerical modeling techniques provide a basis to better understand the role of different factors describing the source and the atmosphere that affect propagation predictions. In particular, more realistic model predictions have been further enhanced by the addition of perturbation terms, such as GWs, which are excluded from the 

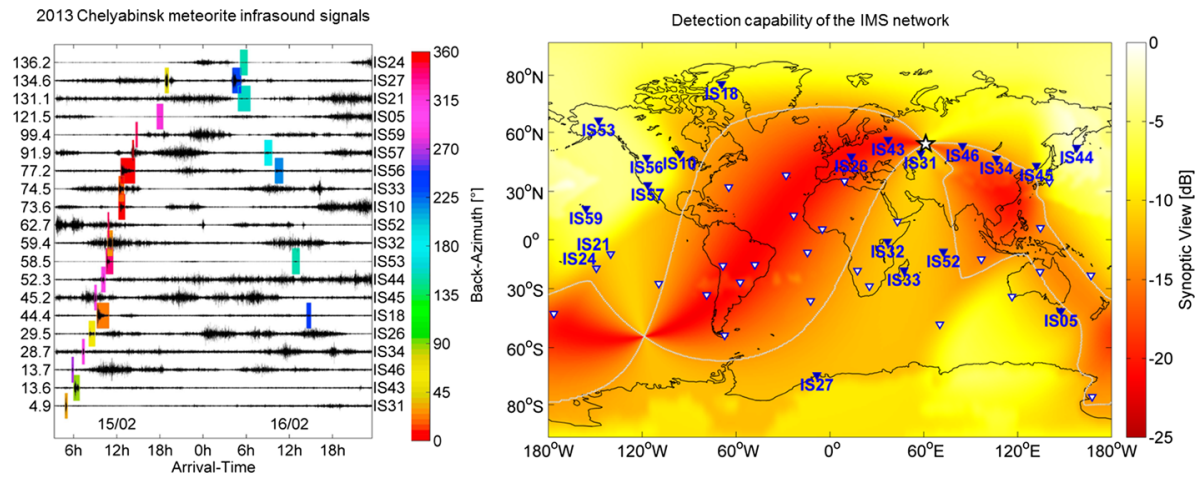

Fig. 8 (Left) Infrasound signals produced by the 2013 Chelyabinsk meteorite at 20 IMS stations using the mean back azimuth, UTC time and normalized amplitude. Stations are sorted by propagation range (in degrees) from the source. PMCC detections of the first and second arrivals are indicated by rectangles with color-coded back azimuths (from Le Pichon et al. 2013). The name and location of these stations are shown in the map (right) where the color represents the detection capability of the network (from Pilger et al. 2015)

current atmospheric specifications (e.g., Hedlin and Drob 2014). In order to quantify the infrasound network performance in higher spatiotemporal resolution, a frequency-dependent semiempirical attenuation relationship derived from massive range-independent parabolic equation simulations has been developed (e.g., Le Pichon et al. 2012). Coupled with realistic station noise and analysis products from ECMWF, simulations predict the minimum detectable amplitude at a reference distance of $1 \mathrm{~km}$ away from the source (Tailpied et al. 2013).

The detection capability methodology was calibrated using different events including the 2013 Chelyabinsk meteorite which generated a large airburst with an equivalent yield of $500 \mathrm{kT}$ of TNT equivalent, detected at global scale. Figure 8 displays the global detection capability map and the infrasound signals recorded at several stations. It is the most energetic event recorded by the infrasound component of the CTBT-IMS network, globally detected by 20 out of 42 operational stations (Le Pichon et al. 2013; Pilger et al. 2015).

Meteor entries will be included in the ARISE database as these observations provide new benchmark for future studies on exploding fireballs and help advance the development of monitoring procedures to identify potentially dangerous exploding near-Earth objects.

\subsubsection{Calibration Sources: Events in the Industrial Belt}

Another calibration infrasound source is human activity. The European infrasound network in the Arctic has become an exceptional observatory with its recent expansion, its synergy with collocated seismic stations and proximity of quarries (Gibbons et al. 2015). Explosive blasting is used almost globally as a means of extracting rock and minerals from quarries. Automatic or semiautomatic classification of infrasound from such explosions has long been deemed essential. Infrasound is an excellent discriminant for determining if a small seismic event originates from the surface or near surface rather than at a significant depth. The observation of infrasound signals that are clearly associated with a set of seismic signals can assist greatly in event classification and/or discrimination. The seismic recording of industrial blasts tells us exactly where an explosion took place and when it occurred (so-called ground truth information). Many quarries blast at least once per week, 
and sometimes as frequently as several times per day, and so provide us with vast numbers of events with which we can validate and calibrate our models of atmospheric specification for the prediction of infrasound arrivals. For ARISE industrial belt explosions, the primary parameters are the origin time, the latitude, longitude, depth and seismic magnitude. Such events are used as repetitive sources for calibrations or remote infrasound sounding (e.g., Smets et al. 2015). Other possible natural sources are repetitive volcanic eruptions.

\subsection{Meteorology Related Extreme Events}

\subsubsection{Polar Lows}

Cyclones and hurricanes are frequently observed by the infrasound stations (Stopa et al. 2012). Intense mesoscale maritime cyclones, called "polar lows" (Heinemann and Claud 1997; Claud et al. 2004), occasionally occur during cold season months mainly over Greenland and Norwegian seas at the start of the season and over the Barents sea further into the season (Rojo et al. 2015). These events are produced by the advection of very cold air over relatively warm water and are characterized by their small-scale extent (diameter less than $1000 \mathrm{~km}$ and thickness of about $1-5 \mathrm{~km}$ ) and short life span (a few hours to a few days). The sudden development of this phenomenon, together with the sparsity of conventional measurements in the genesis and development areas, results in a low forecasting skill (Noer et al. 2011). Therefore, polar lows represent a hazard for all maritime and coastal activities (fishing, oil drilling, etc.) and population.

Examples of infrasound measurements in Norway and Svalbard from turbulent convection produced by a polar low outbreak have already been reported in the Norwegian/ Barents Sea (Orbaek and Naustvik 1995). Systematic long-range infrasound measurements of polar low- in high-latitude regions are taken in the framework of ARISE. These analyses will use the recently installed IMS infrasound station IS37 and other infrasound arrays in Scandinavia which are ideally located to characterize the source mechanism involved in the generation of the signals. Compared with satellite observations (infrared imagery, microwave observations, etc.), the added value of infrasound data for polar low monitoring and short-term forecasting is investigated.

\subsubsection{Lightning and Sprites}

Thunderstorms are also an important focus of ARISE. They produce lightning in the troposphere and other high-energy transient events such as sprites, jets and elves, called transient luminous events (TLEs). They are the manifestation of an intense transient coupling between the troposphere and the lower thermosphere.

4.2.2.1 Infrasound Used for Lightning Source Description Thunder studies (measurements and theories) have been carried out since the 1960s. Recent observations show that infrasound from lightning can be measured within $50 \mathrm{~km}$ around the infrasound station. However, the increase in the number of lightning flashes inside the thundercloud indicates a hail-producing and strong convective thunderstorm. The monitoring of such intra-cloud activity has an important societal impact. If cloud-to-ground lightning flashes monitoring is possible with electric field measurements, at a global scale from ground [e.g., the worldwide lightning location network (WWLLN) or the Vaisala global lightning data set (GLD360)] or from space with lightning imagers on board geostationary satellites, the 


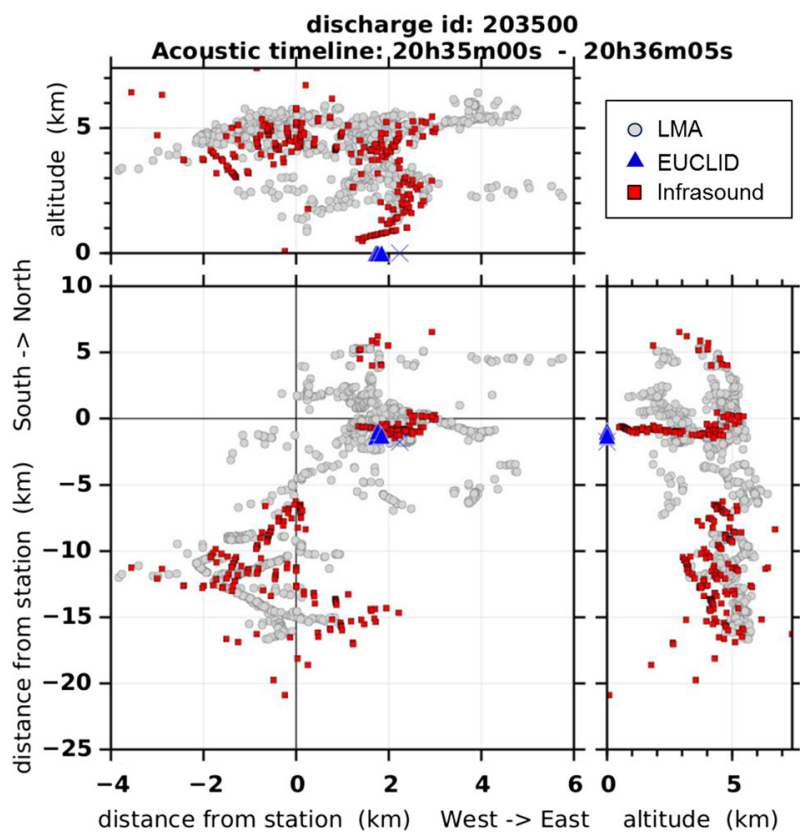

Fig. $93 \mathrm{D}$ structure of a single lightning from infrasound inversions compared with interferometry electromagnetic observations. The flash occurred on October 26, 2012, at 20:35:00 UTC. Gray dots: lightning mapping array detections, red squares: reconstructed acoustic detections and blue symbols: strokes from raw detections provided by the European Cooperation for Lightning Detection (EUCLID) operational lightning location network (Gallin et al. 2016). This method also allowed retrieving infrasound origin inside the sprite structures up in the stratosphere and mesosphere up to $100 \mathrm{~km}$ altitude. (Farges and Blanc 2010)

measurement of intra-cloud flashes on a continental scale is more difficult because it requires too many stations (i.e., lightning mapping array). Infrasound observations provide some lightning characteristics (Farges 2009). Recent studies have shown that the 3D geometry of intra-cloud discharges can be reconstructed using thunder measurements by a small-aperture (25-50 m) array of microphones (Arechiga et al. 2014; Gallin 2014). An example of infrasound inversion, providing the origin of the infrasound sources inside the lightning structure, is shown in Fig. 9 (Gallin et al. 2016). The good agreement between the infrasound observations and the observations of the lightning mapping array validated the infrasound inversions. Such infrasound mini-array station is able to monitor an area of at least $20 \mathrm{~km}$ radius. Infrasound measurements are an alternative to electromagnetic measurement or complementary methods. It provides additional information to improve knowledge about the source mechanism involved in the sound generation. Such 3D measurements in the tropics, e.g., in Ivory Coast, will be very useful when the future lightning imagers will be operational (2020 for the European Meteosat Third-Generation (MTG) satellites).

4.2.2.2 Transient Luminous Events Large thunderstorm systems are able to produce high-energy transient events such as transient luminous events (TLE) or terrestrial gammaray flashes (TGF) which were both discovered in the 1990s (Sentman and Wescott 1993; 

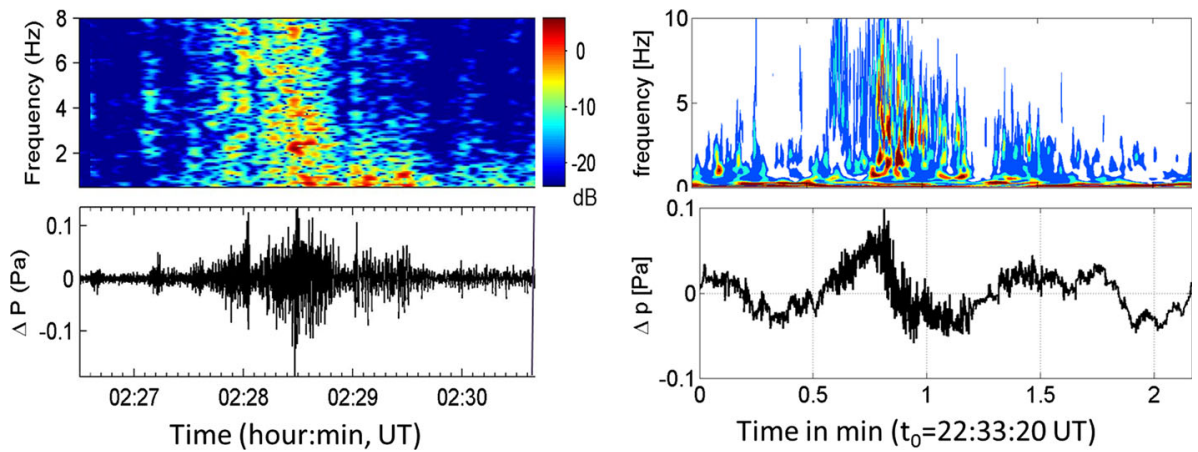

Fig. 10 Examples of sprite infrasound observed at close range from the sprites on September 9, 2005, in France by Farges and Blanc (2010) (left) and on July 09, 2011, by Sindelarova et al. (2015) (right)

Fishman et al. 1994). Among all kinds of TLEs, sprites are triggered by positive lightning discharges; they are usually composed of a cluster of vertical columns which form carrotor column-like features above thunderstorm clouds at 50-90 km altitudes. Sprite structures are typically characterized by diameters ranging from a few tens to a few hundreds of meters (Stenbaek-Nielsen et al. 2007; Neubert et al. 2008).

Satellites are well adapted to the detection of these events (Blanc 2010). However, observations are limited in time. Ground-based cameras are limited in coverage. Infrasound waves produced by sprites are detected at distances from 300 to $1000 \mathrm{~km}$. They can be identified thanks to their frequency chirp shape, low frequencies being observed before high frequencies due to propagation effects (Liszka 2004; Farges et al. 2005; Da Silva and Pasko 2014). More recently, Farges and Blanc (2010) showed that the direct measurements of the sprite azimuth and elevation angle together with the origin parent lightning time allow retrieving the location of the emission areas inside the sprite structures up to altitudes of $100 \mathrm{~km}$. The method was the same as the method used for lightning analysis (Fig. 9). These sprite events are characterized by an inverted-chirp infrasonic signature with high frequencies arriving before low frequencies. This is characteristic of direct observations at close range $(<150 \mathrm{~km})$ from the source (Fig. 10). The smaller structures at lower altitudes radiate higher infrasonic frequencies that arrive first at the observational point on the ground, while the low-frequency components are delayed because they originate at lower air densities at higher altitudes. The strong absorption of high-frequency infrasonic components at high altitudes may also contribute to formation of the inverted chirp signals at close range (de Larquier and Pasko 2010). Recent ARISE observations (Sindelarova et al. 2015) during an intense thunderstorm report signals with similar duration and frequency dispersion. The characteristics of these events differ from lightning, characterized by a shorter duration and the lack of frequency dispersion, and are similar to sprites signals observed by Farges and Blanc (2010) as shown in Fig. 10. These observations could confirm the possibility of sprite monitoring using this technology. 
Infrasound is an innovative technique for monitoring continuously the infrasound signals produced by lightning and TLEs in tropical regions where there are no groundbased current observations. They will be very useful for the validation of observation from space of future space mission as TARANIS (Blanc et al. 2007; Lefeuvre et al. 2008), ASIM (Neubert et al. 2009) and associated studies (Füllekrug et al. 2013). ARISE will provide a unique database and will contribute to their monitoring in the longer term.

\subsection{Earthquakes Effects in the Atmosphere}

\subsubsection{Earthquakes: An Extended Infrasound Source}

Earthquakes can radiate infrasound, both at the epicenter by direct shaking of the ground (primary infrasound) or from secondary sources that radiate infrasound as a consequence of being shaken by seismic waves (secondary infrasound). Infrasound produced by the strong earthquake (magnitude MI 8.1) which occurred in mountain areas of western China on November 14, 2001, was detected up to $1800 \mathrm{~km}$ from the epicenter for more than $1 \mathrm{~h}$. Using a precise determination of the arrival times and azimuths of the infrasonic waves and an appropriate velocity model in the atmosphere, the radiating zone in mountain areas was reconstructed (Le Pichon et al. 2003).

The high station density available within ARISE provides a good description of the infrasound origin for earthquakes with lower magnitudes. The recent seismic sequence occurring in Northern Italy in May 2012 was observed at distance of $300 \mathrm{~km}$. Infrasound from the $\mathrm{Ml}=5.9$ main shock of May 20, 2012, is considered as a reference event in ARISE. The infrasound radiation area has been evaluated from infrasound array observations (corrected for wind effect on propagation). Unlike most previous studies, the modeled area of maximum infrasound radiation appears to mimic an extended flat area (plain of Po River) with no significant contributions from nearby mountain ranges (Marchetti et al. 2016a). The shake map of the earthquake and the map of reported acoustic boom are in good agreement with the modeled area of infrasound radiation, suggesting how the transition of seismic waves into acoustic atmospheric waves is efficiently exciting infrasound recorded at far distances from the source (Fig. 11). This is particularly useful to improve earthquake monitoring and understanding especially in poorly instrumented areas.

Underwater earthquakes can also be detected by infrasound stations thanks to anomalous transparency of the sea surface for infrasound in the frequency range from 1 to $5 \mathrm{~Hz}$ (Evers et al. 2014). 

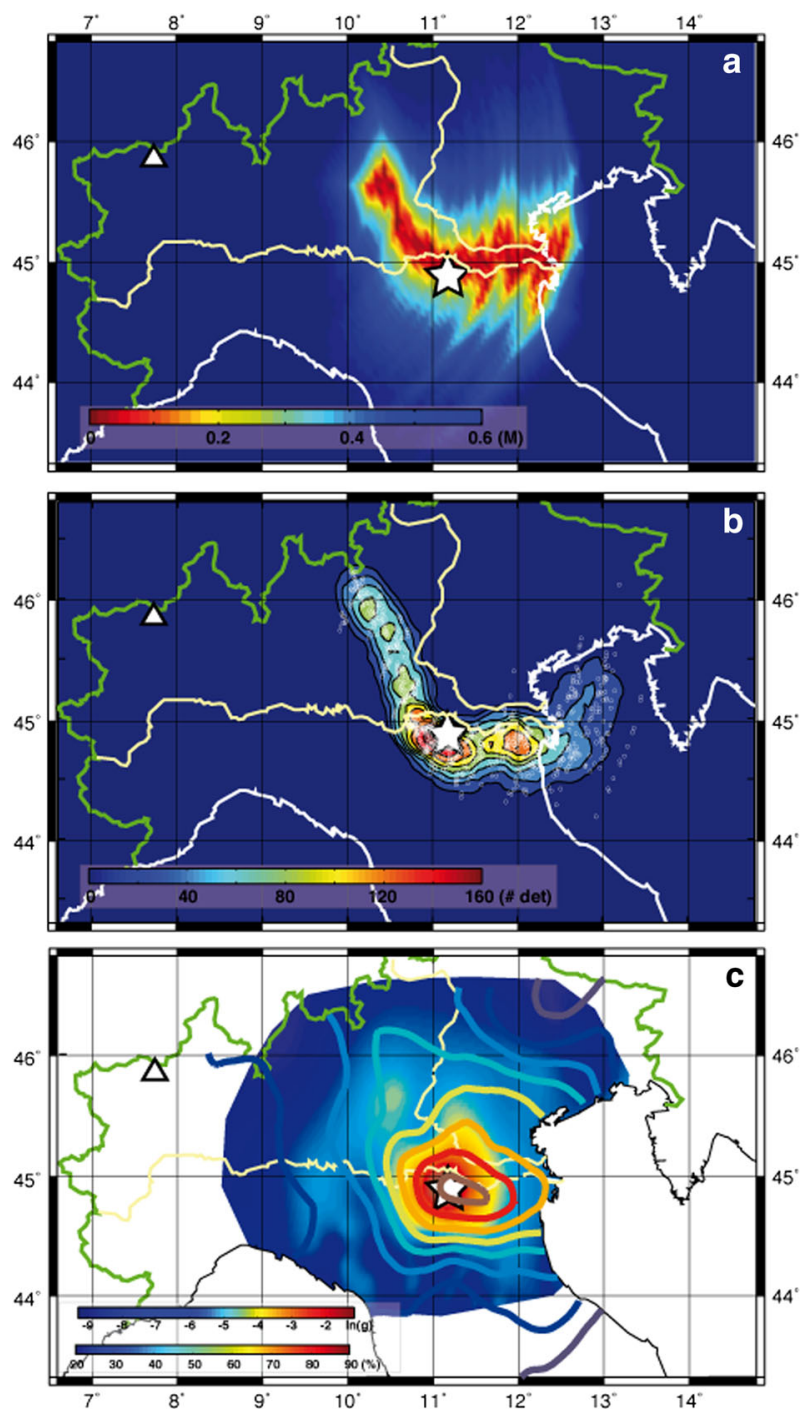

Fig. 11 ARISE infrasound observations for the May 20, 2012, Ferrara earthquake (epicenter $\left.44.8886792^{\circ} \mathrm{N}, 11.066887^{\circ} \mathrm{E}\right)$. Modeled infrasound radiation area a for the main May 20,2012 , event obtained by combining differences in expected and observed back azimuth and travel times for all the infrasound detections of the earthquake. b Location (white circles) and density map of infrasonic sources based on ray tracing. $\mathbf{c}$ Distribution of earthquake booms felt in northern Italy (contour lines) and shake map (colored map). Contour lines represent the percentage of felt boom within the total number of reports. In all subplots, position of the earthquake epicenter (white star) and of the CHA array (white triangles) is shown as well as national border (green line) coastline (white line) and the main rivers (yellow lines). (Redrawn from Marchetti et al. 2016a)

\subsubsection{Earthquake Infrasound in the Ionosphere}

During an earthquake, the vertical displacement of the ground, either near the epicenter or due to Rayleigh waves, induces upward propagating waves in the atmosphere which can be 

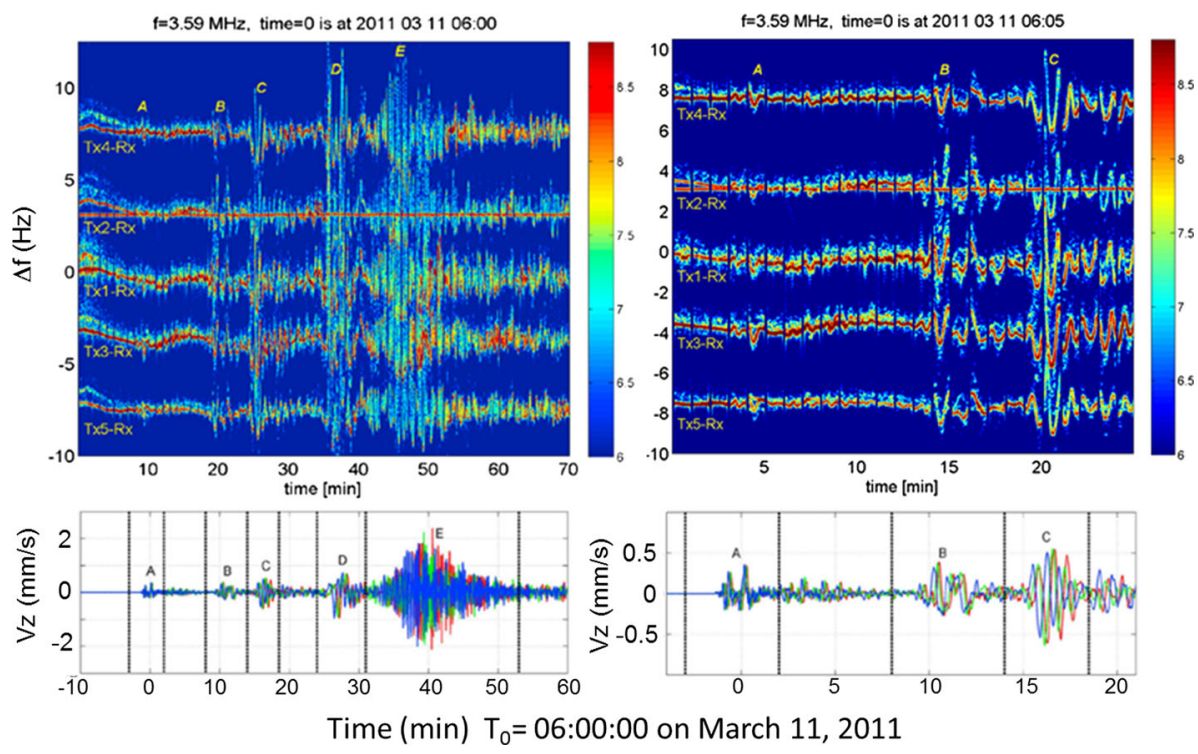

Fig. 12 (Top) Doppler shift spectrogram recorded in Prague, Czech Republic, at $\sim 9000 \mathrm{~km}$ from the epicenter of the Tohoku earthquake on March 11, 2011, from 06:00 UT to 07:10 and to 06:05 to 06:30 UT (zoom). The five different sounding paths are shifted by $4 \mathrm{~Hz}$ to be differentiated. The color indicates the common logarithm of power spectral intensity of the received sounding radio waves in arbitrary units. (Bottom) Corresponding seismic signal. (Adapted from Chum et al. 2012a)

observed up to the ionosphere. The amplitude of earth displacement of Rayleigh waves on the ground is about few mm. This oscillation is strongly amplified toward the ionosphere because of the exponential decrease in the density with height, reaching several tens to $100 \mathrm{~m}$. Signals can be detected in the ionosphere by HF sounding or VHF radars (Artru et al. 2001, 2004; Occhipinti et al. 2010).

Such ionospheric train of large amplitude infrasound wave packets was observed by a multi-point continuous Doppler sounding system in the ionosphere over the Czech Republic and is represented in Fig. 12. This technology consists in measuring the Doppler effect $\Delta f$, which determines the vertical velocity of the reflection point of electromagnetic HF wave emitted from the ground and its counterpart reflected by the ionosphere. It was shown that the observed wave packets originated from vertical motion of ground surface that was caused by arrival of seismic waves generated by the strong Tohoku earthquake on March 11, 2011, with the epicenter $9000 \mathrm{~km}$ away from the Czech Republic. Letters A to $\mathrm{E}$ mark the ionospheric disturbances caused by seismic wave packets A to E. The first three infrasound wave packets that were generated by P, S and SS seismic waves are marked by A, B and C, respectively. The cross-correlation coefficients between ionospheric and ground measurements were higher than 0.9 (up to 0.98). The observed time delay of $\sim 9$ min between the record of seismic wave packets on the ground and ionospheric response at $\sim 210 \mathrm{~km}$ corresponded well with the calculated time for infrasound propagation. The individual wave packets were related to different types of seismic waves, starting from $\mathrm{P}$ waves. The majority of previous reports of similar measurements at comparable distances from epicenter reported an ionospheric response only to Rayleigh waves, exceptionally to $\mathrm{S}$ waves. 
It was also demonstrated by comparing the value of vertical velocity of the ground motion with the value of Doppler shift that the usually used simple assumption of mirrorlike reflection cannot be used to determine the oscillation velocities of air particles since it provides unrealistically large values, inconsistent with energy conservation even for lossless infrasound propagation of a plane wave. It was shown that it is necessary to consider air (plasma) compression owing to the sound wave and the electron density gradient. The integration of phase path along the sounding radio wave, used in some previous studies modeling the value of Doppler shift, was, however, avoided, and a useful approximation that includes air (plasma) compression and electron density gradient was derived to calculate the air oscillation velocities after the observed Doppler shift directly. The measured values of air particle oscillation velocities are in reasonable agreement with the anticipated values obtained by simple models for infrasound wave attenuation (Chum et al. 2012a).

The measurements of the extreme events in the ionosphere determine the contribution of the atmospheric disturbances to the ionospheric dynamics. These effects can be significant in case of repetitive or long-duration sources such as thunderstorms in the tropical regions, mountain waves or ocean swell. The evaluation of these effects is an objective of the ARISE project.

\subsection{Volcano Long-Range Monitoring}

\subsubsection{Volcano Monitoring Using Infrasound Observations}

Infrasound is an efficient monitoring system for explosive volcanoes. Short-range observations $(<10 \mathrm{~s} \mathrm{~km})$ can be used to reconstruct in detail the eruptive chronology and are currently used to provide near-real-time notification of ongoing activity to civil protection authorities (Ulivieri et al. 2013). At larger source-to-receiver distances (hundreds $\mathrm{km}$ ), infrasound observations showed to somehow match with the reported height of the eruptive column (e.g., Dabrowa et al. 2011) and in some specific cases infrasound could efficiently reconstruct the eruptive chronology for non-monitored volcanoes (e.g., Matoza et al. 2011a). This suggests that infrasound observations, especially when combined with network sensitivity analyses (Tailpied et al. 2013), represent a significant tool for a future global volcano monitoring.

Figure 13 presents an example of eruption chronology that can be inferred from remote infrasound observations $(640 \mathrm{~km})$ from the Sarychev Peak (Kuril Islands). A good

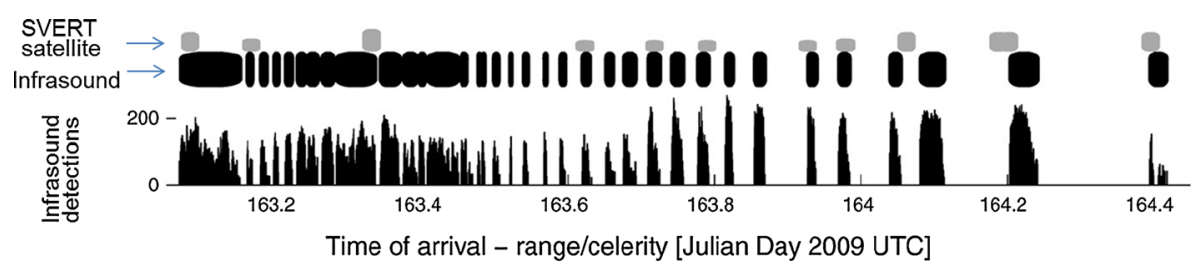

Fig. 13 Chronology of coherent infrasonic signals compared to the eruption chronology inferred from satellite data by SVERT. Times of arrivals are corrected back to an inferred origin time assuming a celerity of $0.33 \mathrm{~km} / \mathrm{s}$. Black horizontal bars above plot represent beginning and end times of coherent signal packets. Gray bars represent explosion onset times \pm 15 min inferred from satellite data by SVERT. Vertical extent of each gray bar is scaled relative to the maximum plume altitude inferred by SVERT clouds. (Matoza et al. 2011a) 
correlation between the explosion origin times inferred by infrasound data and those inferred by satellite data is found. Moreover, it appears that infrasound data can construct the eruption chronology with greater temporal resolution than is possible with satellite data alone.

Satellite imagery technique provides relevant information on ash plume dispersion triggered by strong eruptions. However, cloud cover can hide eruption plumes and therefore strongly limit the capability of this technique. The cloud coverage over one active volcanic zone in Southeast Asia often exceeds 0.8 during several months. Infrasound observations can efficiently complete satellite detection of hazardous volcanic activity (Prata 2009) leading to a more efficient mitigation of the risk volcanic ash encounters. The different episodes of eruptions are currently analyzed using infrasound recordings while they are not fully detected by satellites.

The efficiency of this technology for long-range monitoring was demonstrated in 2010 by the detection of the Eyjafjallajökull volcano eruption (Iceland) by 14 atmospheric infrasound sensor arrays at ranges between 1700 and $3700 \mathrm{~km}$ (Matoza et al. 2011b). More recently, long-lasting acoustic signal, concurrent with major stratospheric ash injection of the 2014 eruption of Kelud volcano (Indonesia), was recorded by infrasound arrays up to $11,000 \mathrm{~km}$ away. A volcanic episode, not detected by satellites, indicated a "bottom-up" eruption trigger that could have been induced by magma mixing (Caudron et al. 2015).

ARISE is a key infrastructure to provide novel valuable information to the Volcanic Ash Advisory Centres (VAAC) of the International Civil Aviation Organisation for its potentials on remote infrasound monitoring of eruptive volcanoes (IAVWOPSG 2013, 2014). ARISE aims to provide notifications of ongoing distant volcanic eruptions following prototype systems developed locally for Etna volcano (Ulivieri et al. 2013).

Particular interest is thus devoted to ash-rich eruptions, which can inject large ash amounts into the atmosphere, posing threats to aviation. Previous studies showed a general agreement between the acoustic power and plume height for high-energy Plinian or subPlinian events (Fee et al. 2010). However, a clear relationship is still missing especially for lower-energy eruptions (Marchetti et al. 2016b).

Volcanic eruptions are typically characterized by a varying eruptive style through time going from single explosions of short duration to longer-lasting sustained emission. Despite efficiently radiating infrasonic waves into the atmosphere, the effects in terms of atmospheric ash injection are extremely different and this should be considered when notification of volcanic activity with infrasound is delivered. Within ARISE, such a problem has been analyzed in detail based on eruptive activity at Etna volcano. Lava fountains, which are able to inject ash into the atmosphere, are typically preceded by discrete Strombolian explosions which, despite efficiently radiating infrasound, have a limited impact on atmospheric ash. Figure 14 shows the infrasound record of a lava fountain episode at Etna volcano which occurred on March 16, 2013, and was recorded at three infrasound arrays at distances from 5 to $1080 \mathrm{~km}$. The Lava Fountain started at 17:54 UTC, when the automatic notification based on local array observation was delivered (Ulivieri et al. 2013) and atmospheric ash injection did actually occur, but was preceded by several hours of sustained explosive activity very well detected also at large source-toreceiver distances as shown in the top of Fig. 14.

The infrasound notification at Etna volcano is based on an infrasound parameter (IP) (Ulivieri et al. 2013) which depends on the infrasound excess pressure and the rate of occurrence of infrasound detections. It increases for both larger pressure values and higher detection rates. The work initiated in ARISE clearly shows that such a transition can be efficiently identified with infrasound observations, even at distances of several hundreds of 

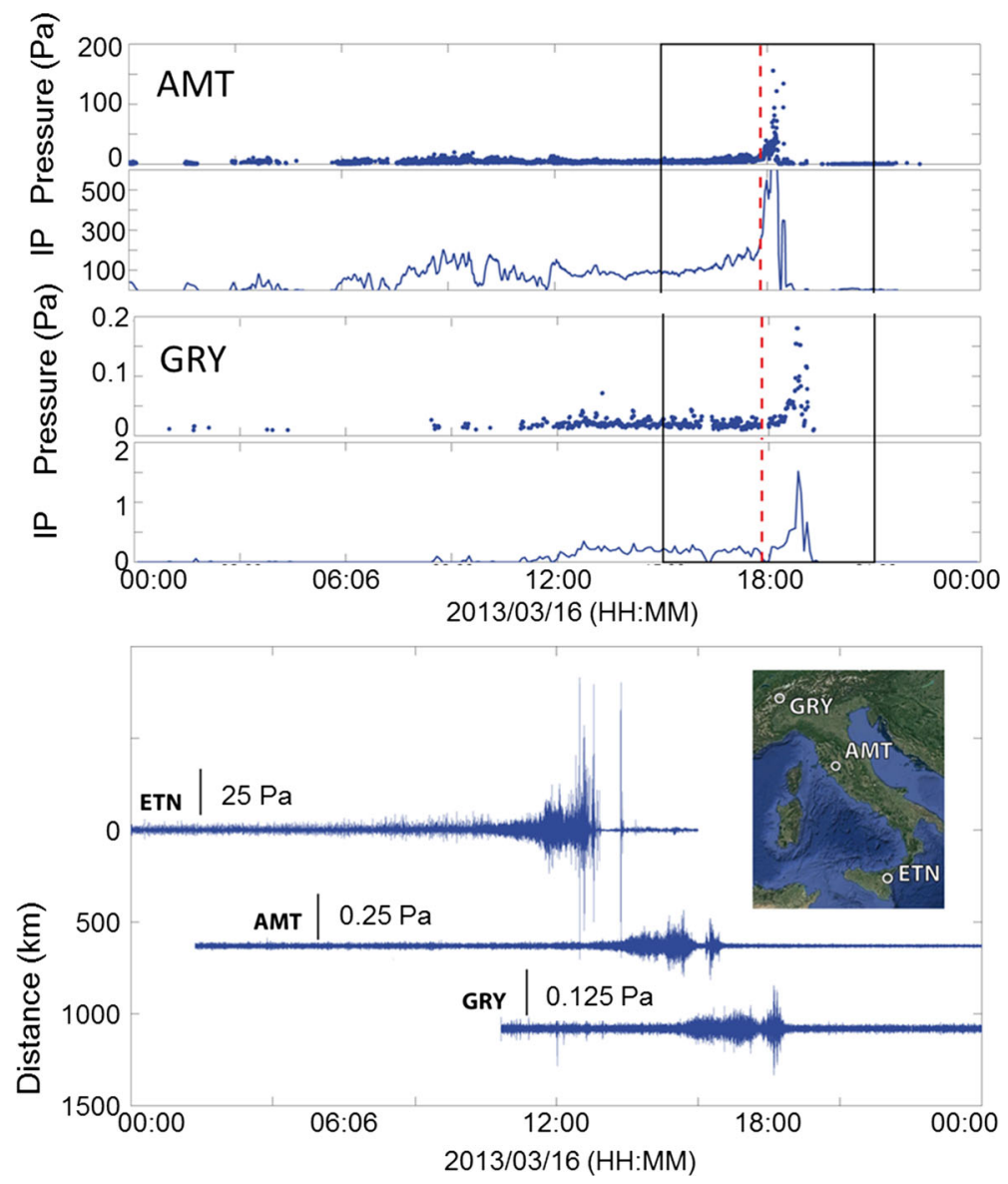

Fig. 14 (Bottom) Infrasonic record of the March 16, 2013, lava fountain from Etna at ETN array ( $\sim 5 \mathrm{~km}$ from the source) at AMT array ( $\sim 630 \mathrm{~km}$ from the source) and at GRY array $(\sim 1080 \mathrm{~km}$ from the source). (Top) Infrasound detections and infrasound parameter (IP) derived following the procedure described by Ulivieri et al. (2013) at Etna (a) and AMT (b). The red line represents the onset of the proper lava fountain (17:54 UTC)

$\mathrm{km}$, thus improving significantly the possibility to identify ash-rich eruptions. In the specific case of Etna volcano, where discrete Strombolian explosions precede the lava fountain and reflect a transition in the two-phase flow regime of gas within the liquid magma (Ulivieri et al. 2013), long-range infrasound appears able to identify the loweramplitude precursory phase. Despite considering a flight time of approximately $30 \mathrm{~min}$, notification can be delivered before the proper event occurrence. Out of 23 Lava Fountains episodes recorded in 2013 notification could be delivered successfully for $\sim 35 \%$ of the events (Marchetti et al. 2016b). Such a result could be improved considering multiple arrays at various back azimuth which could reduce the effect of seasonal ducting of infrasonic waves and/or increasing the array sensitivity.

The ARISE inter-technology approach will assess the detection probability of active volcanic zones of specific interest for the civil aviation security, depending on the eruptive styles, propagation and could cover conditions, throughout the year. Over the long term, 


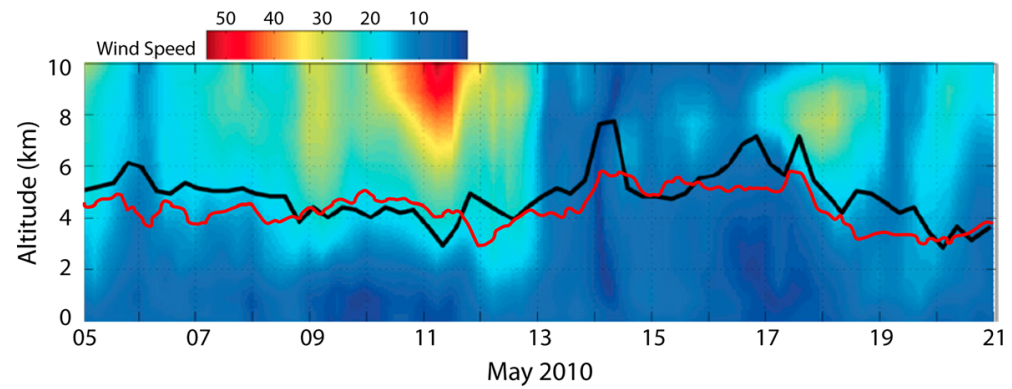

Fig. 15 Vertical wind speed profile at the volcano vent for the period May 5-21, 2010, retrieved from ECMWF ERA-Interim re-analysis. Plume height (black line) detected by the weather radar in Keflavik (at $155 \mathrm{~km}$ from the volcano) seems to reflect the wind profile reaching the maximum height when wind decreases below $10 \mathrm{~m} / \mathrm{s}$. Plume height (red line) modeling the mass eruption rate (MER) derived from infrasound observations by using the radially averaged buoyant plume theory (BPT) equations. (Redrawn after Ripepe et al. 2013)

ARISE proposes to cover the existing gap between the ground-based geophysical observations, extremely reliable but unfortunately available for a limited number of active volcanoes worldwide, and space-borne observations, which often are limited by a lack of temporal resolution and observation constraints.

\subsubsection{Eruption Characterization}

The waveforms from volcano eruptions provide indications about the source processes as they differ significantly for different volcano types producing, for example, Strombolian or vulcanian explosions. The energy of explosive eruptions is based on the amount of ejected material and plume height (Marchetti et al. 2013). The infrasound observations could then help to characterize the eruption source term which strongly controls the ash plume dispersion in the atmosphere and is needed for modeling (Bonadonna et al. 2012) especially for remote volcanic eruptions. The physical conditions at the eruptive vent are difficult to estimate, especially when volcanoes are not closely monitored by on-site instruments.

The 2010 eruption of volcano Eyjafjallajökull in Iceland clearly showed that in densely populated areas, such as European cities, high-quality volcanic ash information is needed, given the great societal and economic impacts (Bonadonna et al. 2012). However, in order to model reliably the amount of ash in the atmosphere, several source parameters (i.e., plume height, mass eruption rate, grain size of erupted material) should be known in real time. Infrasound signals provide near-field and far-field characteristics up to several thousands of kilometers from the eruption. Methodologies to retrieve the volcanic ash plume height from local infrasound observations are developed (Fig. 15; Ripepe et al. 2013). Plume height (black line) detected by weather Radar in Keflavik (at $155 \mathrm{~km}$ from the volcano) seems to reflect the wind profile, reaching the maximum heights of $8 \mathrm{~km}$ during May 13-17 only when the wind intensity decreases below $10 \mathrm{~m} / \mathrm{s}$ over the whole 10-km high-altitude profile.

\subsubsection{Volcanoes Quasi-permanent Sources Infrasound Calibrations}

ARISE results highlighted the potential of the infrasound technology to provide enhanced information on active volcanoes either near the volcanic eruptive sources or at large 
a Minimum detectable source amplitude - station IS48
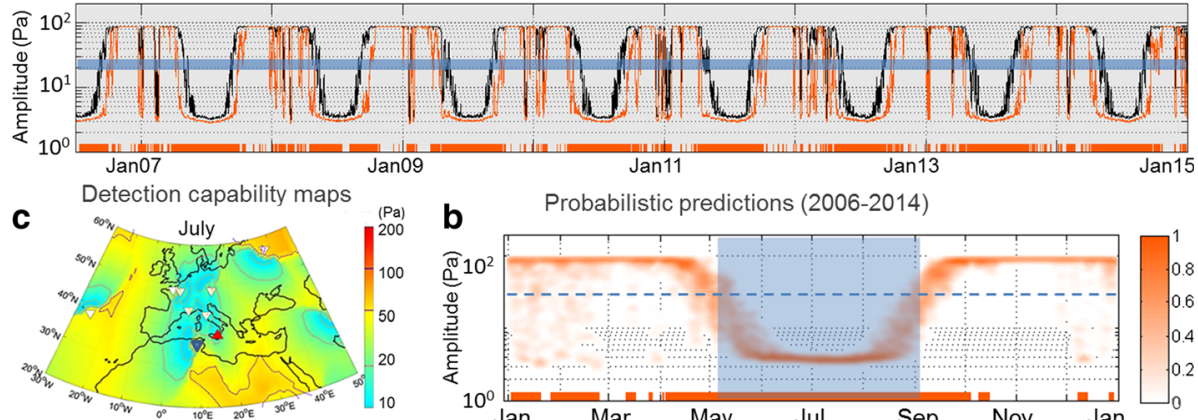

b Probabilistic predictions (2006-2014)
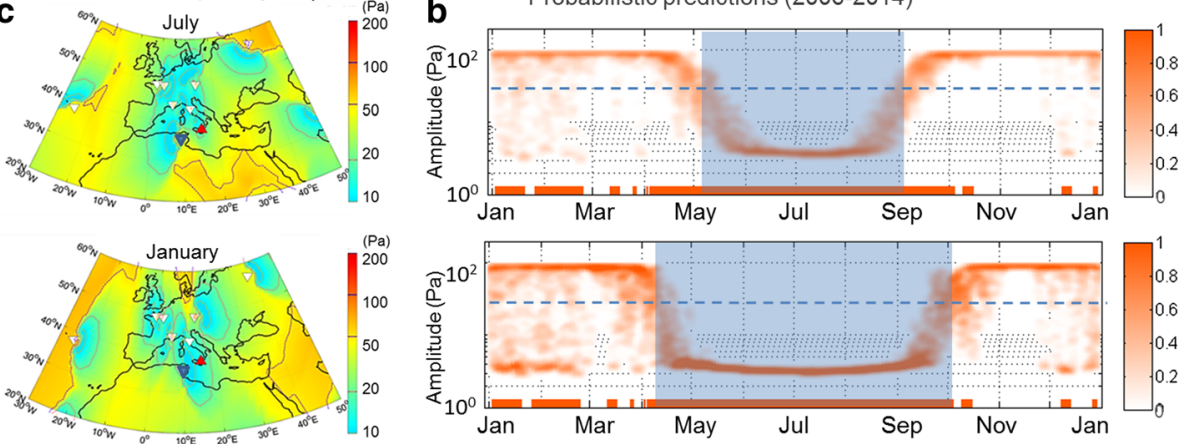

Fig. 16 Simulation of detection capability of the IMS station IS48 to monitor explosive signals from Mt. Etna: Temporal fluctuation of predicted detection threshold at $0.8 \mathrm{~Hz}$ from July 1, 2006, to January 1, 2015 (a), and from January 1, 2014, to January 1, 2015 (b), using the ECMWF High-Resolution Atmospheric Model (HRES) analyses at 91 mean pressure levels up to 0.01, without (black curve) and with (red curve) incorporating wind perturbations. Red horizontal bars indicate detection periods of Etna at IS48. The blue horizontal bar indicates the average source amplitude measured in the near-field by a permanent experiment array operated by the University of Firenze (UNIFI). c Detection capability maps of the infrasound network in July and January. The colors indicate the minimum amplitude detectable by the network

distances for remote monitoring. To reach these objectives, the atmospheric effects on the eruption detection and characterization need to be thoroughly determined. The simulations developed to assess the monitoring capabilities in different atmospheric conditions (see Sect. 4.1) are used to determine the confidence index when an eruption is detected. Methods are validated using near- and far-field observations of Mt. Etna eruptions performed during several years (Fig. 16).

Mt. Etna in Italy $\left(37.73^{\circ} \mathrm{N}, 15.00^{\circ} \mathrm{E}\right)$ is the highest and most active strato-volcano in Europe. Its current activity is typically effusive with explosive episodes and lava fountaining, with often large ash ejection into the atmosphere affecting nearby cities and local air traffic. As the activity of Etna is mostly effusive, sometimes accompanied by small-tomoderate explosions, it often yields a small Volcanic Explosivity Index (VEI 1-2). At a distance of about $550 \mathrm{~km}$, Mt. Etna is permanently monitored by the IS48 IMS station $\left(35.80^{\circ} \mathrm{N}, 9.32^{\circ} \mathrm{E}\right)$ located in Tunisia (e.g., Assink et al. 2014a). In case of major eruption, signals can be detected by other IMS stations like IS26 in Germany and IS43 in Russia, at a distance of 1240 and $2680 \mathrm{~km}$, respectively.

Because of its regular activity, Mt. Etna represents a natural source of repetitive of signals for evaluating the effects of the atmospheric disturbances on the infrasound propagation and quantifying the perturbation terms which are not represented by the numerical modeling predictions. Figure 16 presents a multi-year simulation of the detection capability of the IS48 to monitor eruptive signals from Mt. Etna. Signals are quasipermanently detected from May to September due to an efficient stratospheric ducting and occasionally in winter during stratospheric wind reversal periods when SSW events occur. Overall, there is a first-order agreement between the detection periods and periods when 
detection thresholds remain smaller than the averaged source amplitude. However, discrepancies are identified around some equinox periods (April-May and September-October) and during anomalous wintertime intervals when the atmosphere is unstable. Such deviations have already been explained by misrepresented small-scale structures in ECMWF analysis (e.g., Assink et al. 2014b).

Following the OHP campaign, the wind fluctuations measured with the OHP infrasound station were statistically extrapolated up to Tunisia and incorporated into ECMWF effective sound speed profiles calculated along the propagation paths at $50 \mathrm{~km}$ altitude to assess the detection capability of the IS48 Tunisian station. For each propagation simulation, random realizations of vertical wind profiles accounting for a Gaussian enhancement of $20 \mathrm{~km}$ width, centered at $50 \mathrm{~km}$ altitude, in a range of $30 \mathrm{~m} / \mathrm{s}$ were integrated. Incorporating these deviations into network performance simulation tools allows assessing the sensitivity of the infrasound detection capability to small changes in the stratospheric winds. Including these wind perturbations enlarges the detection periods, as observed in Fig. 16, by several weeks and resolves reasonably well the unpredicted observations. While the effects of such perturbations on infrasound propagation dominate when stratospheric winds reduce and reverse, the effects are limited when stratospheric winds are well developed. These fluctuations are mainly produced by GW activity. The maps of Fig. 16c represent the corresponding detection capability (as described in Sect. 4.1) computed in January and July.

It is expected that continuing such studies will enhance network performance predictions and help optimizing the design of future network in order to monitor regions of interest.

\section{Climatology of Gravity Waves at Middle Latitude}

Global satellite observations of GW momentum fluxes clearly reveal that GW activity is not homogeneously distributed over the globe as currently assumed by most GW parameterizations in climate models. It rather occurs in pronounced hot spots that can be attributed to distinct generation mechanisms like generation by topography, jet stream instabilities or convection (Ern et al. 2011; Hoffmann et al. 2014). The objective of this section is to present examples of ARISE multi-instrument observations of GWs performed at different latitudes and altitude ranges.

\subsection{Lidar Observations}

GWs are known to play a major role in the energy and momentum budget in the MA, and their influence on the atmospheric structure and circulation has been recognized. Rayleigh lidar provides vertical profiles of the total density of the atmosphere from about 30-90 km depending on the signal-to-noise ratio, and it is a powerful tool for the study of atmospheric perturbations. Lidars produce accurate observations with high temporal and spatial resolution, well adapted for studying atmospheric GWs. Lidar measurements have been taken continuously at OHP since late 1978 (in the beginning, the vertical resolution was $0.3 \mathrm{~km}$, and it has been improved to $0.075 \mathrm{~km}$ since 1994). GW activity, in terms of potential energy $\left(E_{\mathrm{p}}\right)$, is estimated by analyzing raw lidar signals with a variance method at OHP. 

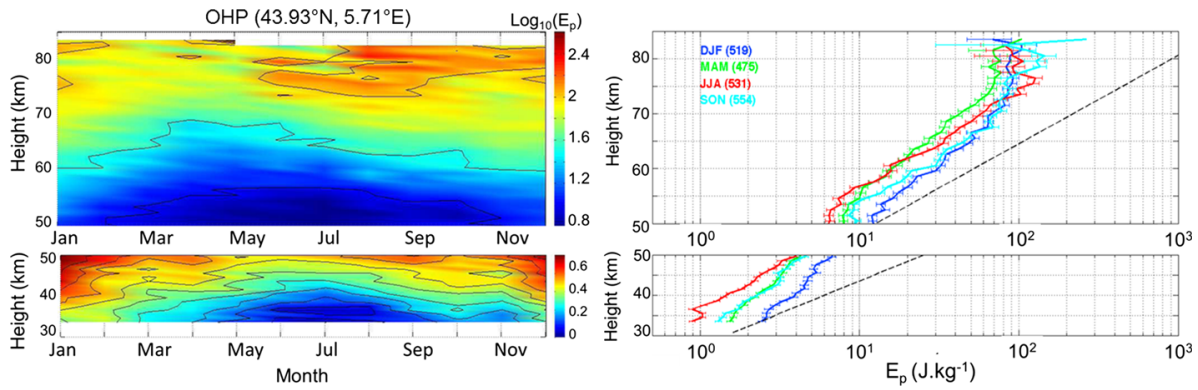

Fig. 17 (Left) Contour plots of the GW climatology (in $\mathrm{J} \mathrm{kg}^{-1}$ ) from lidar observations above OHP. (Right) Vertical profiles of potential energy per unit mass (in $\mathrm{J} \mathrm{kg}^{-1}$ ) averaged over winter (DecemberJanuary-February, blue line), spring (March-April-May, green line), summer (June-July-August, red line) and autumn (September-October-November, cyan line). The conservative growth curve is also superimposed (black dashed line) with a constant density scale height $H \sim 7 \mathrm{~km}$. (From Mze et al. 2014)

We used the potential energy per unit mass, $E_{\mathrm{p}}\left(\right.$ in $\mathrm{J} \mathrm{kg}^{-1}$ ) in order to characterize $\mathrm{GW}$ activity, and it is given by:

$$
E_{\mathrm{p}}=(g / N)^{2} V_{\mathrm{atm}} / 2
$$

where $g$ is the gravitational acceleration $\left(\sim 9.8 \mathrm{~m} \mathrm{~s}^{-2}\right), N$ the Brunt-Väisälä frequency and $V_{\text {atm }}$ the atmospheric variance.

Sixteen years of Rayleigh lidar data from 1996 to 2012 have been used to build a climatology of GW potential energy above OHP.

Figure 17 presents the annual variation of the potential energy at five levels from the middle stratosphere to the upper mesosphere. We found an annual cycle with a maximum of GW activity occurring in winter and a minimum in summer in the upper stratospherelower mesosphere. We also found a semiannual cycle with a maximum of GW activity occurring in winter and in summer and a minimum during the equinoxes in the upper mesosphere (Mze et al. 2014). Seasonal averages of GW potential energy based on the same 16-year lidar observations are illustrated in Fig. 17. The dashed line represents the slope of expected energy growth with altitude without dissipation. GW energy dissipation is observed at all altitudes but is strongly enhanced above $\sim 70 \mathrm{~km}$ during the four seasons.

\subsection{Comparison Between Lidar and Satellite Observations}

Rayleigh lidar data provide accurate and altitude-resolved GW energy profiles but are only available at about 10 locations in the world. A global view of the GW field can only be determined using satellite data. The GPS radio occultation (RO) temperature profiling technique, featuring high vertical resolution and global coverage, represents a powerful means for studying the sources and climatology of GWs. Operational since April 2006, the COSMIC GPS RO system provides 1500-2000 occultations per day with sampling density maximizing at mid-latitudes. The GPS RO temperature observations cover the altitude range between about 8 and $35 \mathrm{~km}$, with the highest accuracy $(<0.5 \mathrm{~K})$ in the lower stratosphere and a vertical resolution of $0.2-1.4 \mathrm{~km}$.

Figure 18 shows time series of GW potential energy retrieved from the fluctuations in vertical temperature profiles using the two different techniques, GPS RO from 10 to $35 \mathrm{~km}$ and Rayleigh lidar above $30 \mathrm{~km}$ (Khaykin et al. 2015). This allows the reconstruction of 

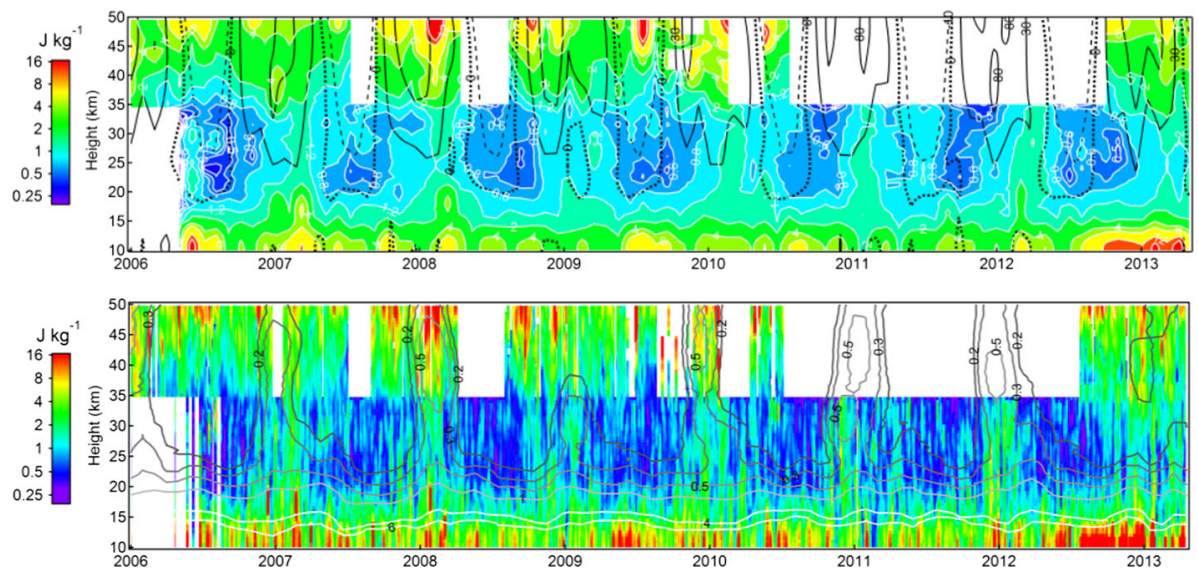

Fig. 18 Combined time series of GW $E_{\mathrm{p}}$ from Rayleigh lidar at OHP and COSMIC $\left(5^{\circ} \times 5^{\circ}\right.$ domain centered at OHP). White areas represent the missing data. a Monthly mean $E_{\mathrm{p}}$ (color map) and zonal wind (solid contours - westerly winds of 30 and $80 \mathrm{~m} / \mathrm{s}$, dotted contour-zero wind, dashed contour-easterly wind of $10 \mathrm{~m} / \mathrm{s}$ ). b Weekly means of $E_{\mathrm{p}}$ from COSMIC and lidar (color map) and monthly means of MERRA $E_{\mathrm{p}}$. (From Khaykin et al. 2015)

the GW time evolution from the troposphere near their sources to the stratosphere and the mesosphere in the regions of their dissipation.

In the common altitude range $33-35 \mathrm{~km}$, we observe a good agreement between the two techniques. The time of enhancement of GW energy estimated from MERRA meteorological re-analysis (white lines) is also in good agreement with the observations, but the energy is about five times lower in the re-analysis because the model can only capture one part of the GW spectrum.

\subsection{Gravity Waves in the Ionosphere}

Complementary IAP Prague ionospheric Doppler sounder network measurements extend ARISE shorter-period GW investigations to ionospheric altitudes. These measurements have been run in the Czech Republic, South Africa, Argentina and Taiwan. They allow one to monitor basic characteristics of shorter-period GWs and long-period infrasound at ionospheric heights, excited by various sources of meteorological, seismic or upper atmospheric origin. During the summer, propagation in the north to northwest direction clearly dominates, whereas in winter the dominant direction of propagation of GWs is quite clearly opposite, to the southeast at northern mid-latitudes. This is shown in Fig. 19. The comparison with the horizontal wind model HWM07 shows that the analyzed GWs propagated against the prevailing meridional wind direction in both seasons as theoretically predicted. GWs are relatively slow and when their phase speed becomes equal to wind speed, the critical layer wave absorption and dissipation appears.

These observations are in agreement with theoretical studies, showing that GWs from the lower atmosphere are absorbed into the mean flow and can propagate upwards only when the propagation direction of GW is opposite to the neutral wind direction (Fritts and Vadas 2008). The seasonal variation of GW propagation directions reported from optical observations in mesopause region is similar, indicating that the GWs propagate upward from the lower atmosphere (Chum et al. 2012b). These observations provide indication 

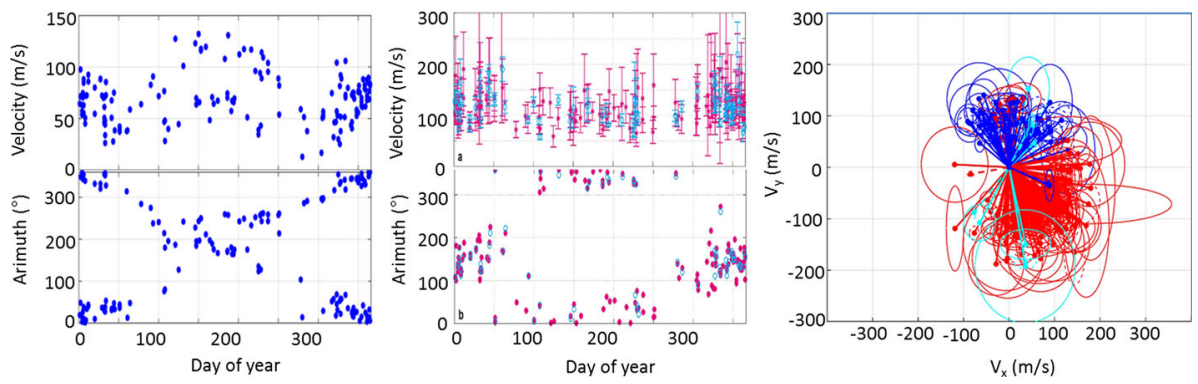

Fig. 19 From left to right: (i) Velocity and azimuth of neutral wind velocities model (HWM07) at the observation height, (ii) velocity and azimuth of GWs, (iii) horizontal propagation velocities (vx, vy) and directions of GWs over the Czech Republic; vx is positive to the East, vy to the north. Red-winter (October-February), blue-summer (April-August), light blue-equinoxes (March-September). The observed horizontal velocities represent intrinsic velocities + wind velocities. Data cover 1-year period from June 2010 to May 2011 (from Chum et al. 2012b)

about the contribution of GWs to the global atmospheric circulation in the upper atmosphere.

\section{Characterizing Gravity Waves from ARISE Observations and Simulations}

\subsection{Gravity Waves from Deep Convection}

\subsubsection{Gravity Waves Observed by the Infrasound Technology}

Convection is responsible for the strong near-equatorial GW activity in the Summer Hemisphere (Fritts and Alexander 2003). It is observed in various satellite data sets (Ern and Preuse 2012) but difficult to quantify at or near its source due its high spatial and temporal variability.

An ARISE challenge is to perform new observations in equatorial and tropical Africa for a better understanding of these phenomena and to determine their impact on the environment. The objective is to quantify the effects of convection on the general circulation system in the troposphere, stratosphere and mesosphere for weather and climate models.

The thunderstorm activity at the origin of convection is very strong over ARISE stations located in Africa as shown in the map of Fig. 20, performed using the LIS experiment data (Christian et al. 2003; Cecil et al. 2014 (http://thunder.msfc.nasa.gov) recorded in 2013.

The low-latitude dynamical activity is mainly controlled by the thunderstorm activity. This was demonstrated by previous ARISE work which showed that GWs observed using the Ivory Coast IS17 IMS infrasound station $\left(6.67^{\circ} \mathrm{N}, 4.85^{\circ} \mathrm{W}\right)$ are strongly related to convection associated with thunderstorms (Blanc et al. 2014). Figure 20 shows the GW activity recorded during 13 years. This activity is very important in comparison with activity recorded in mid- and high-latitude regions. The seasonal azimuth change in the GW direction represents the motion of the ITCZ (inter-tropical convergence zone) which drive the thunderstorm activity north and south of the station every year. 

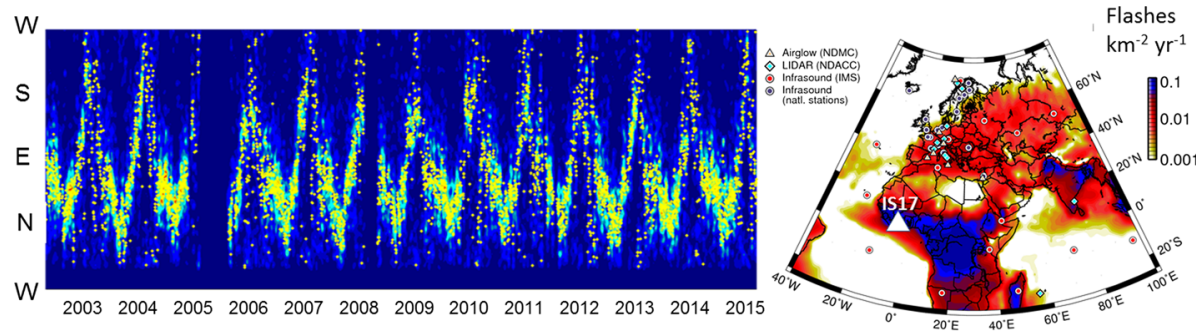

Fig. 20 Left: GW activity measured during 13 years in the IS17 infrasound station in Ivory Coast. The color scale indicates the logarithm of the number of detections. GWs originate from deep convection. The GW azimuth variations are produced by the thunderstorm seasonal north-south motion over the infrasound station. Right: Map of thunderstorm activity in Euro-African sector superimposed on the infrasound stations

The deep convection also produces a significant cooling in the upper troposphere and lower stratosphere at global scale as observed by COSMIC GPS radio occultation during summer in the afternoon over the low-latitude continents. This corresponds to the precipitation regions observed by the TRMM satellite above $14 \mathrm{~km}$ (Khaykin et al. 2013). This shows that convection can be a proxy of precipitations and the interest of the lowlatitude GW multi-instrument observations in relation with thunderstorm activity. The infrasound data set covering more than 10 years could provide relevant estimation of this activity as measurements are continuously recorded.

\subsubsection{Upward Propagation of Convection Waves}

GWs produced by thunderstorms propagate vertically into the stratosphere, mesosphere and lower thermosphere. They form concentric rings in the mesosphere imagers (Alexander et al. 2004; Yue et al. 2009) and in stratospheric satellite observations (Hoffmann et al. 2014). These waves can be filtered by the background winds as they propagate upwards through the stratosphere. To quantify the contribution of the large convection activity produced by thunderstorms in tropical and equatorial regions to the dynamical exchanges in the atmospheric layers, high-resolution simulations using the Weather Research and Forecasting (WRF) model were performed and compared to the observations during strong tropical thunderstorms.

Figure 21 (left) illustrates the continuous generation and propagation of GW packets during a thunderstorm in Africa to quantify the wave energy which penetrate in the upper atmosphere. There is a strong asymmetry in wave propagation which is driven by the eastward wind shear. The arrows show the horizontal component of background wind velocity. On the left side (upwind), the horizontal wind speed is small but positive and waves can propagate vertically in the stratosphere. Their amplitude, increasing with altitude, may reach the threshold value beyond which wave saturation can occur. On the right side (downwind), waves break under the wind filtering process and can no longer penetrate into the upper stratosphere (Costantino and Heinrich 2013). This study suggests that the cold-pool outflow from the thunderstorm may be the leading factor in generating initial high-frequency pressure changes observed by the infrasound station, though later peaks in pressure are not replicated.

Lidar observations were used for the validation of the model. Figure 21 (right) shows the vertical profiles of potential energy derived from the WRF model (red line) and lidar observations (blue line) on a semi-log scale ( $x$ axis) in October. The conservative growth 

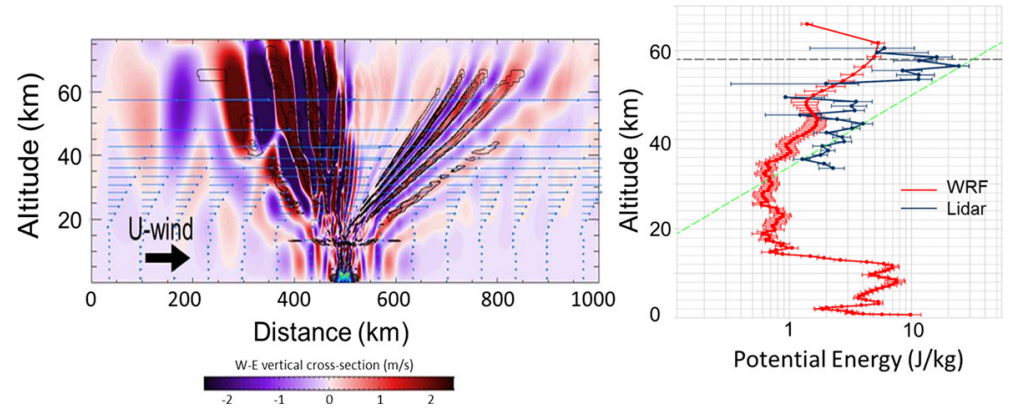

Fig. 21 (Left) GWs generated by a thunderstorm (in blue, at the bottom of the figure) for a vertically sheared horizontal velocity. Vertical velocity is computed from ground to an altitude of $77 \mathrm{~km}$. Black contours represent strong variations of the potential temperature. (Right) Comparison between the vertical profiles of potential energy derived from WRF model (red) and lidar observations (blue) shows a general good agreement. The conservative growth rate is superimposed in green dashed line (from Costantino et al. 2015)

rate curve is also superimposed (green dashed line) with a constant density scale height of $7 \mathrm{~km}$. Horizontal error bars indicate the uncertainty with respect to the temporal variability (Costantino et al. 2015).

This study quantifies the contribution of GWs from thunderstorms to the general circulation of the atmosphere which can be very strong in tropical configurations. It can be validated in the next project steps using complementary ARISE instruments.

The penetration of GW from thunderstorm convection into the ionosphere was observed with the ionosonde located in Francourville (center of France) operating at the rate of one ionogram per minute for an observation campaign. The same configuration was used when observing the total solar eclipse of August 11, 1999 (Farges et al. 2001). A major thunderstorm occurred near the ionosonde on the August 16, 2004, between 02:00 UT and 06: $00 \mathrm{UT}$ as shown in the lightning map (Meteorage) of Fig. 22. The ionization of the F region peak increased by $40 \%$ in comparison with the International Reference Ionosphere (IRI) model (Bilitza 2001). Ionospheric altitude oscillations at a few tens of minutes period
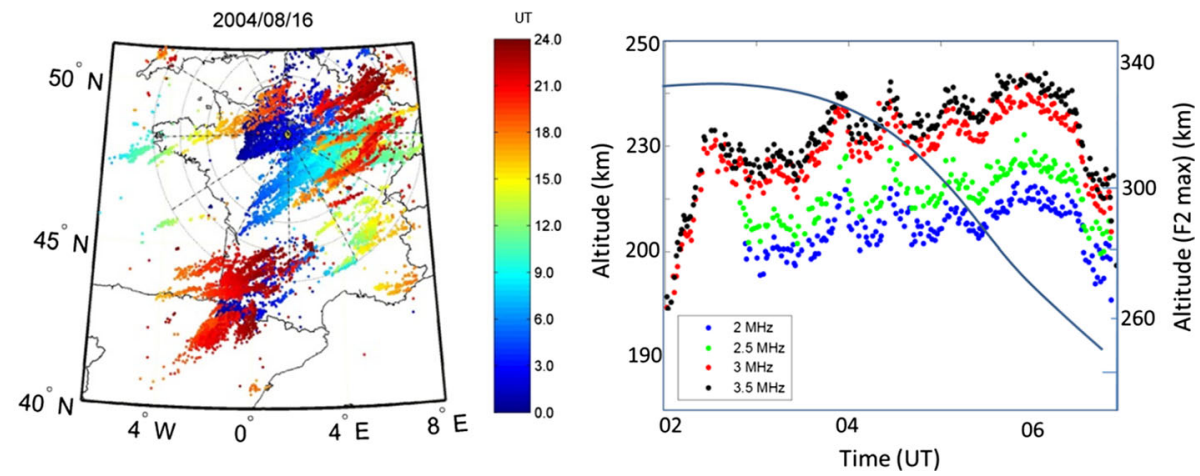

Fig. 22 Example of GW activity observed in the ionosphere during a thunderstorm. (Left) Map illustrating the lightning impacts over France on August 16, 2004 (color indicates the impact time in UT). The yellow diamond gives the location of the Francourville ionosonde. (Right) Altitude versus time for different plasma frequencies $(2,2.5,3$ and $3.5 \mathrm{MHz})$. The blue line indicates the height variation of the F2 layer (IRI model) 
were observed at different plasma frequencies (related to the electron density). The altitude variation of the F2 layer is generally decreasing during this time period as shown by the blue line (IRI model). Such waves are characteristic of thunderstorm convective activity as observed at ground with infrasound sensors (Blanc et al. 2014). This example shows that ionospheric observations can provide a relevant indication about the $\mathrm{GW}$ penetration into the upper atmosphere, as a complement to the other ARISE instrumentations.

\subsection{Observations of Mountain Waves with the Infrasound Technology}

Mountain waves are well identified as a component of the Earth wave activity (Fritts and Alexander 2003). They are generated by a stably stratified air flow over a topography barrier. Air parcels are lifted up by the mountain and generate turbulences and atmospheric waves as they move downstream from the mountain. Mountain GWs are expected to be stationary with respect to the ground. Horizontal wavelengths for vertically propagating waves are typically tens to hundreds of kilometers. They are observed by satellites in specific mountain regions (Wu et al. 2006) and by balloons (Plougonven et al. 2008), showing that topography may be an important source of drag on the atmospheric circulation (Alexander et al. 2009). However, because of the difficulty to observe their small horizontal scales and short periods, their climatology and variability is not fully understood. The determination of their global impact compared to GWs from other different sources is also challenging.

Infrasound waves originating from mountain areas were identified by the IMS network. Their period is few tens of seconds and their duration can vary from hours to days with a stable azimuth directed toward mountain areas. As these waves propagate over large distances in the infrasound wave guide, they can be detected by several stations of the IMS infrasound network and their origin can be determined. This work performed at global scale provided the map of Fig. 23 showing the infrasound sources in the mountain areas and their seasonal variability.
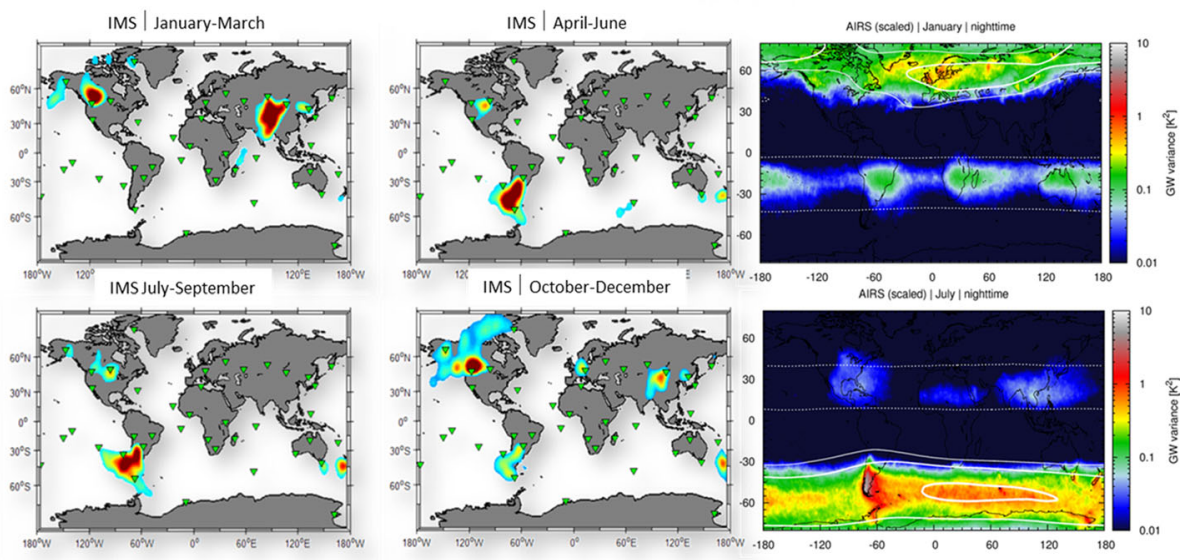

Fig. 23 Left: Map of mountain waves from remote observations in the infrasound frequency range compared with GW maps observed by satellite (right) (from Hoffmann et al. 2014). The large mountain wave activity over South America is observed by both technologies indicating that the infrasound mountain waves are indicators of the GWs observed by satellites over mountains. The infrasound technology isolates mountain waves from waves generated by other sources (convection) 
The infrasound mountain waves could be originating from turbulences which are also involved at larger scales in the origin of mountain GWs. Because of this possible related origin, the infrasound mountain waves are expected to be a tracer of the mountain GWs. The mountain waves observed by the infrasound technology differ from the other infrasound waves by specific criteria depending on frequency range and signal duration. The separation of waves from deep convection from other types of GWs could be difficult in satellite observations (Hoffmann et al. 2014). The interest of the proposed observations is the possibility of continuous remote monitoring at high temporal resolution and at global scale. The stationarity of the GWs makes difficult remote observations at global scales by ground-based observations.

\subsection{Parametrization of Gravity Waves}

\subsubsection{Example of Parametrization of Gravity Waves from Fronts and Jets}

The spatial scales of GWs being too small to be represented in Earth system models at present, the effects of GWs on the resolved scales need to be parameterized either in GCMs or in atmosphere-dependent studies (e.g., long-range infrasound propagation).

Different methods were developed and realistic GW energy spectra were produced out of a stochastic multi-wave scheme by averaging over a large ensemble of realizations (de la Camara et al. 2014). Based on the theoretical and experimental facts that GWs can be spontaneously emitted during the evolution of a near-balanced flow, a new parameterization of GWs linked to fronts and jets was proposed by de la Camara and Lott (2015). The parameterization used the stochastic series of few monochromatic waves, whose wave properties are chosen randomly, to analyze GWs from off-line runs using daily data from the ECMWF re-analysis ERA-Interim (ERAI).

Figure 24 shows the launched momentum flux evaluated off-line using background fields of wind, vorticity and temperature from ERAI. The absolute momentum flux is calculated using the explicit formula (3) and (4) in de la Camara and Lott (2015), after testing that GWs transporting that stress are not saturated at the $950 \mathrm{hPa}$ GW launching

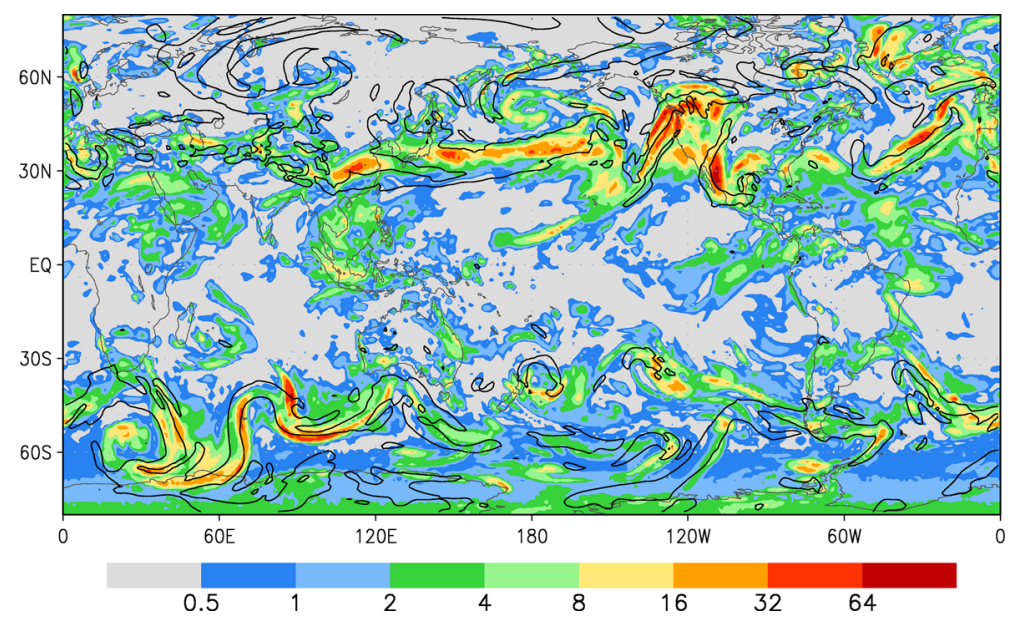

Fig. 24 Frontal launched GW stress in $\mathrm{mPa}$ (shaded) and the $0.012 \mathrm{~K} \mathrm{~km}^{-1}$ isoline of horizontal gradient at $600 \mathrm{hPa}$, for the January 15, 2010 (de la Camara and Lott 2015) 
level. The results show that at a given altitude, the probability density functions present longer tails in the extratropical winter. Their shape evolves toward shorter tails as we go up in the atmosphere. These results qualitatively agree with those derived from the HIRDLS instrument on NASA's Aura satellite shown by Wright et al. (2013) especially in the extratropical regions. The cause of such distribution is related to dynamical filtering by the winds that modifies the shape of the launched probability density function toward a lognormal distribution (de la Camara and Lott 2015) as suggested by previous studies (e.g., Hertzog et al. 2012).

Figure 24 is obtained during one single day on January 15, 2010. The GW stress is stronger at mid-latitudes, particularly in the Northern Hemisphere, and presents pronounced regional variations with peak values larger than $60 \mathrm{mPa}$. However, the parameters in the parameterizations themselves are not fully constrained by GW observations.

\subsubsection{Gravity Waves Parametrization in Infrasound Simulations}

Realistic GW models are needed for the representation of the infrasound propagation as GWs strongly produce additional partial reflections in the stratosphere and mesosphere. Recently, a linear solution has been developed to model the interaction between an incoming acoustic wave and a randomly perturbed atmosphere, by using the forwardscattering approximation. The wave mode structure is determined by the effective sound speed profile which is strongly affected by GW breaking. The values of the tunable parameters were chosen in order to produce GW momentum flux intermittency that compares well with the balloon measurements over oceanic areas (Hertzog et al. 2012). While some of the characteristics of the stable front can be directly related to that of a few individual GWs, the amount of the launched GWs included in climate models can be estimated. By considering a set of plausible GW profiles and examining how the GWs manifest within the infrasound model, we can learn about the probability distribution underlying the numerically obtained parameters.

In long-range infrasound propagation studies, it is currently assumed that the vertical sound speed profiles are fixed and obtained from operational numerical weather predictions (e.g., ECMWF) or atmospheric climate re-analysis. This assumption, although providing a good approximation of the tropospheric infrasound waves, cannot be used to compute the stratospheric arrivals without adding uncertainties. In most cases, the ECMWF profiles are matched to statistical data for altitudes higher than $70-80 \mathrm{~km}$, using simplified functions. The resulting atmospheric fields include uncertainties that depend on the altitude. The point is that there is no consensus on how such atmospheric specifications can be obtained from atmospheric data and it is now generally recognized that small-scale GW is filtered out in the resulting fields (Drob et al. 2013). To first order, the amplitude of the upward propagating waves grows in altitude as $1 / \sqrt{ } r$, where $r$ is the density of the atmosphere. Above $60 \mathrm{~km}$, the amplitude of the unresolved waves can reach more than $10 \%$ of the sound speed. Even though in the lower atmosphere the amplitude of these waves represents a small fraction of the overall variations of the average background state, recent studies (e.g., Bertin et al. 2014) have shown that GW may dramatically alter the stratospheric phases. This appears to be due to both the extreme sensitivity of the signal amplitude to wind gradients and to the inherent need to deal with small-scale fluctuations when trying to determine the waveform (Millet et al. 2007). 


\section{ARISE Observations of Sudden Stratospheric Warming Events}

Sudden stratospheric warmings (SSWs) are regularly occurring features in winter in the northern hemisphere (Charlton and Polvani 2007) characterized by dramatic changes in the stratospheric wind and temperature. SSWs are the clearest and strongest manifestation of the stratosphere-troposphere interactions (Charlton and Polvani 2007; Shaw and Shepherd 2008a; Gerber et al. 2009) and are thought to lead to prolonged periods of colder weather in Northern Europe during winter and spring. The importance of stratospheric variability and especially major SSWs increased notably since the evidence indicating that processes in the stratosphere present a challenge for weather forecasting (Baldwin and Dunkerton 2001; Charlton-Perez et al. 2004; Shaw and Shepherd 2008a). Progress has been made toward a more comprehensive representation of the atmosphere in order to better capture this stratospheric-tropospheric coupling (Randel et al. 2004; Charlton-Perez et al. 2013). For that reason, an important part of trying to understand and model these events more effectively is building a detailed understanding of their dynamics through multiple complementary observational platforms. As a demonstration, the major warming of January 2013 is briefly discussed to demonstrate the capabilities of the ARISE network.

\subsection{Multi-instrument Observations of Sudden Stratospheric Warming Events}

The ARISE measurements during the OHP 2012-2013 field campaign help to better describe the interaction between atmospheric layers from the ground to the mesosphere during these events and the influence of large-scale waves on the atmospheric dynamics. Figure 25 shows the development of the major SSW in January 2013 and compares the temperature from ECMWF forecasts with temperature profiles observed by lidar. This comparison reveals large temperature differences between the analyses and measurements reaching $30^{\circ} \mathrm{K}$ especially after the polar vortex split. A significant cooling around the upper stratosphere and mesopause preceded the SSW.

Before vortex displacement, temperature profiles over OHP from later forecasts are similar to lidar observations. After vortex displacement, temperature profiles from

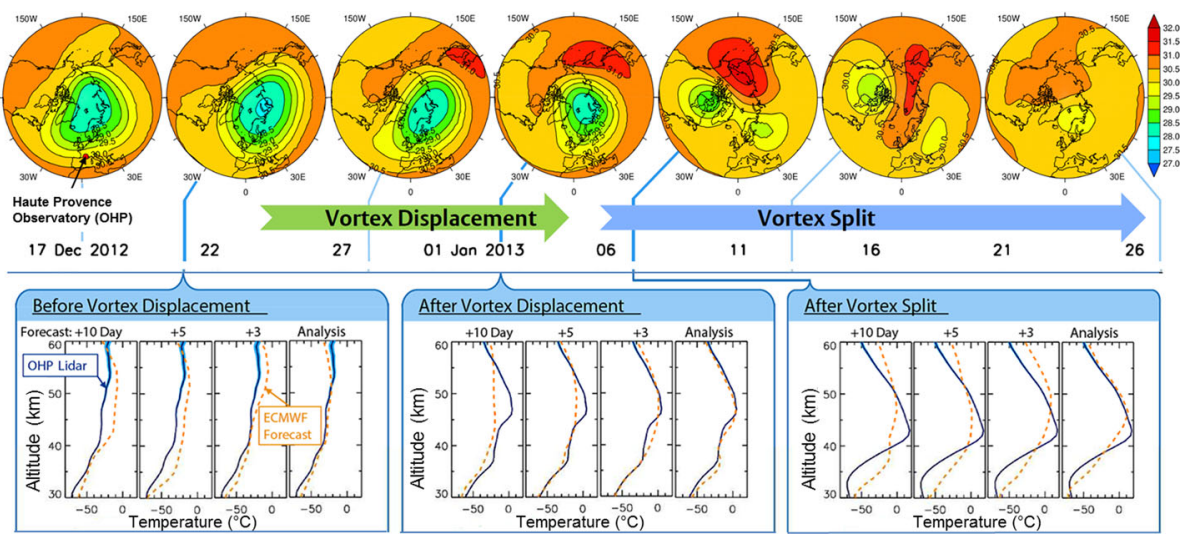

Fig. 25 Maps of the temperature ECMWF forecasts during the winter 2012/13 SSW (top). Comparison between the temperature lidar profiles and ECMWF models (bottom). After the polar vortex split, lidar observations show that the temperature is underestimated by the model in the stratosphere and overestimated in the mesosphere where a cooling is expected 

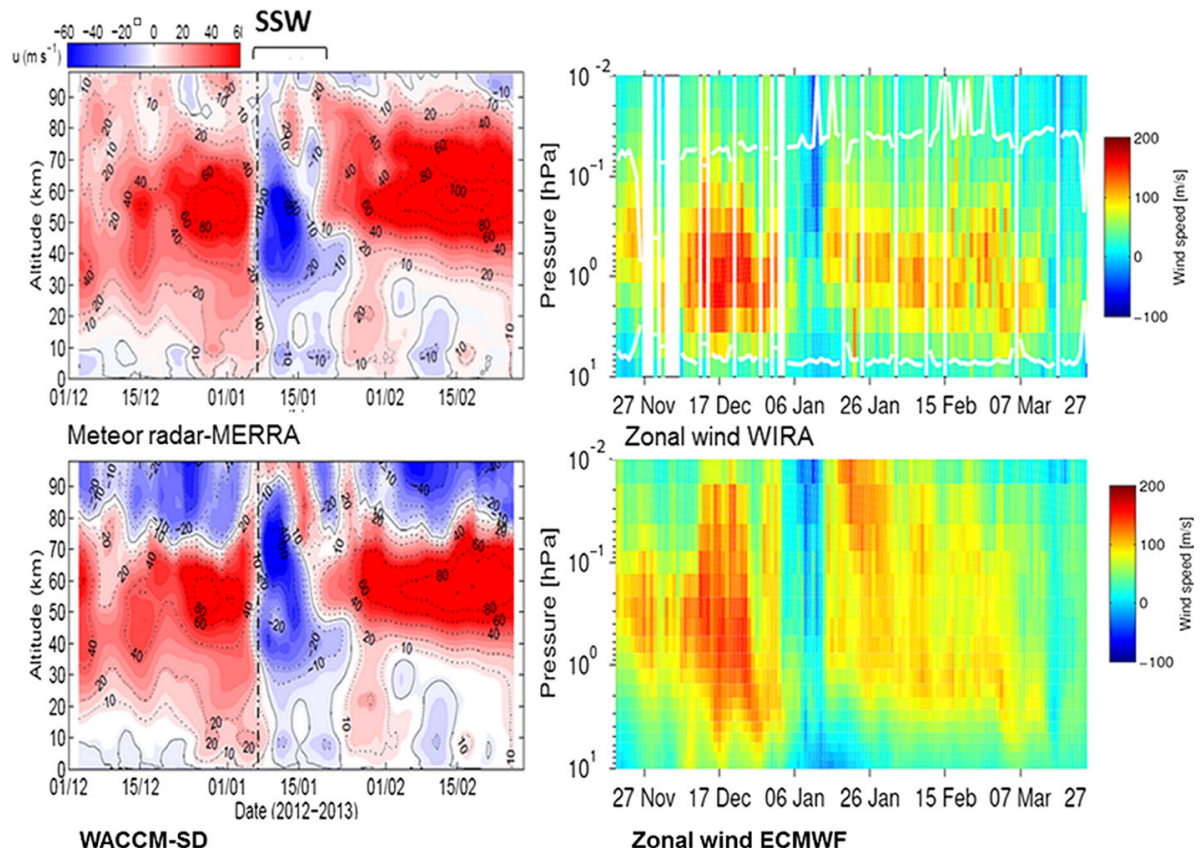

Fig. 26 (Left top) Four-day moving average zonal wind (in $\mathrm{m} / \mathrm{s}$, with tides removed) from meteor radar observations (70-100 km) complemented with MERRA re-analysis results (below $68 \mathrm{~km}$ ) (from de Wit et al. 2014). (Left bottom) Similar diagram using the Whole Atmosphere Community Climate Model with Specified Dynamics (WACCM-SD). (Right top) WIRA zonal wind between 30 and $80 \mathrm{~km}$. (Right bottom) ECMWF zonal wind. During the January, SSW stratospheric zonal winds are reversed

forecasts out to 7 days are consistent with OHP lidar observations, and the analysis replicates the temperature structure at all altitudes. After the vortex split, forecasts struggle to replicate the temperature profile at all altitudes, and the upper stratosphere is poorly represented in the analysis (attributed to poor forecasting of the split-vortex positions).

The right panels of Fig. 26 present comparison between WIRA zonal wind measurements performed at OHP (Rüfenacht et al. 2014) and ECMWF during the same 2013 SSW. The wind difference between the model and measurements reaches several tens of $\mathrm{m} / \mathrm{s}$ in the upper stratosphere. The spatial coverage of disturbances related to SSWs is very large, as shown in the ECMWF maps in Fig. 25, and results were also compared with meteor radar observations performed during the same time at higher latitude in Trondheim $\left(63.4^{\circ} \mathrm{N}, 10.5^{\circ} \mathrm{E}\right)$. This radar measures wind and temperature (above $70 \mathrm{~km}$ ) from meteor echoes (Hocking et al. 2001). The four-day moving average zonal wind profile (in $\mathrm{m} / \mathrm{s}$ ) is presented in Fig. 26 (left top panel).

The measured profile is merged with tropospheric and stratospheric winds from the MERRA model. Dotted lines highlight $\pm 10, \pm 20, \pm 40, \pm 60, \pm 80$ and $\pm 100 \mathrm{~m} / \mathrm{s}$. The zero wind contour and onset of the SSW are indicated by a black line and black dashdotted line, respectively. The mesospheric winds measured during the SSW are different from the Whole Atmosphere Community Climate Model (WACCM) (bottom left panel) showing the limitation of models in describing the wind in the mesosphere where no nudging is applied. 


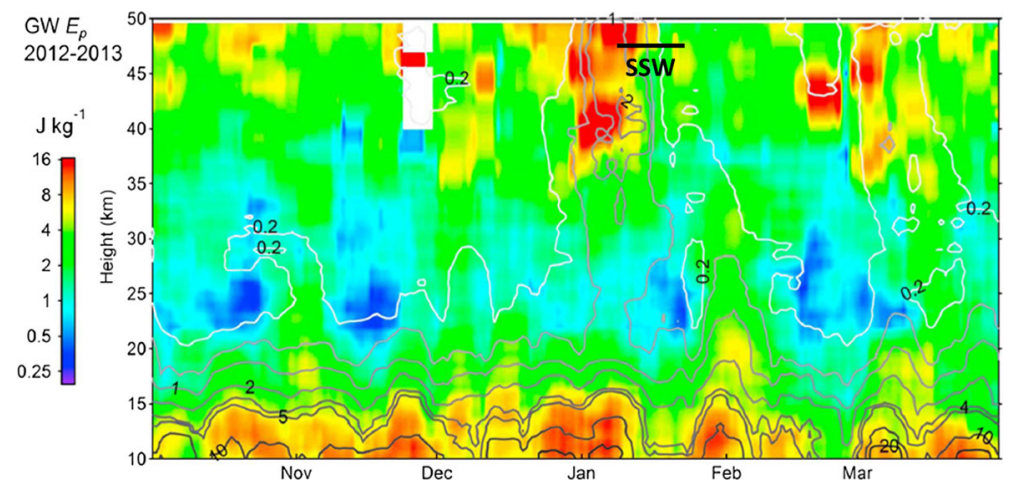

Fig. 27 Combined weekly means time series of GW potential energy (GW Ep) from Rayleigh lidar and COSMIC at OHP and monthly means of MERRA $E_{\mathrm{p}}$ (gray-scaled contours, denoting 0.2, 0.3, 0.5, 1, 2, 4 and 6 units of $\mathrm{J} \mathrm{kg}^{-1}$ ). (From Khaykin et al. 2015)

The meteor radar data show a divergence in the momentum flux at $90 \mathrm{~km}$ altitude 6 days prior to the SSW onset of January 7, 2013 (as determined from the timing of the stratospheric zonal wind reversal). During this time, a maximum eastward forcing of $\sim+145 \pm 60 \mathrm{~ms}^{-1} \mathrm{~d}^{-1}$ was measured. As the SSW evolves, GW forcing turns westward, reaching a minimum of $\sim-240 \pm 70 \mathrm{~m} \mathrm{~s}^{-1} \mathrm{~d}^{-1} \sim 18$ days after the SSW onset (de Wit et al. 2014, 2015).

GW precursor activity was also observed by lidar and satellite, up to one week in advance in the temperature and wind fields of the upper stratosphere, as shown in Fig. 27 for the same SSW. A strong GW increase is detected above $37 \mathrm{~km}$ by the lidar in late December to early January reflecting a MA strongly perturbed by PW activity, which led to the major sudden stratospheric warming (SSW) with an onset on 7 January.

The increase in GW energy begins above the stratopause (located at $\sim 45 \mathrm{~km}$ ) around mid-December and extends down to $37 \mathrm{~km}$ in late December (Khaykin et al. 2015). The combination of observations and numerical modeling will contribute to a better understanding and prediction of these atmospheric events.

\subsection{Evaluation of Forecasting Using Infrasound Remote Sensing During Sudden Stratospheric Warming Events}

The infrasound propagation strongly depends on the state of the atmosphere. During a SSW, changes in the stratospheric wind and temperature substantially influence the infrasound atmospheric waveguide, which is detectable in the infrasound observations at the ground (e.g., Donn and Rind 1971; Evers and Siegmund 2009; Hedlin and Drob 2014; Assink et al. 2014a). Variations range from minor, for example, small bearing variations, to dramatic, i.e., no longer detecting a signal in a specific direction. Figure 3 (bottom) shows that during the January 2013 major stratospheric warming, westerly microbaroms from the Atlantic Ocean changed for microbaroms coming from the northeast and corresponding to Pacific Ocean microbaroms under the effect of stratospheric wind inversion. Microbaroms observed by the IMS infrasound network around the globe (e.g., Evers and Siegmund 2009; Smets and Evers 2014) can then be used to provide a global SSW signature. A difficulty, however, of using ambient noise from ocean surface wave interaction is the source variability. 

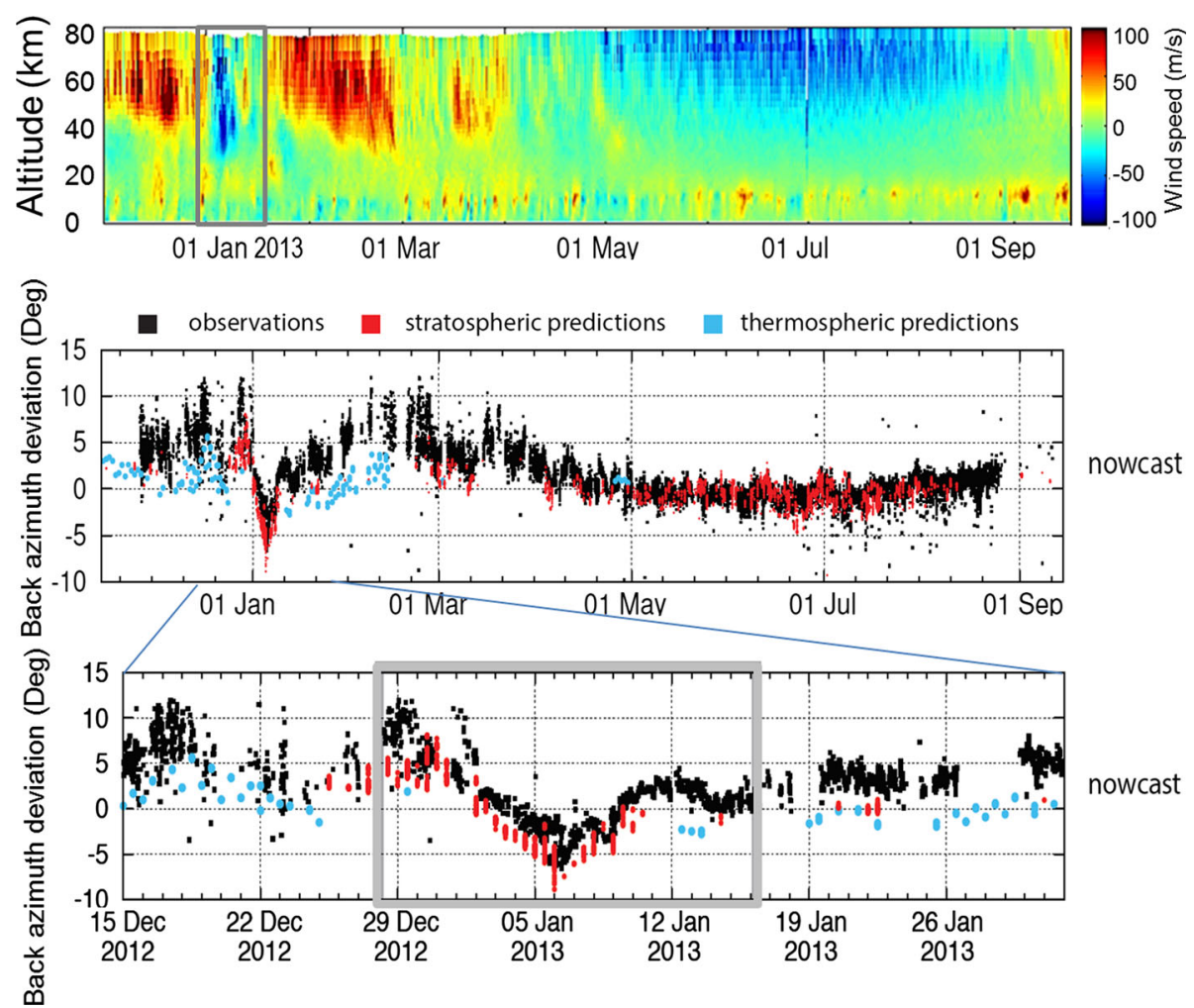

Fig. 28 (Top) ECMWF zonal wind profile showing the seasonal variation of the wind direction and the 2013 SSW (delimited in gray) generating an inversion of the winds in winter. (Middle) Back azimuth deviation of the quasi-continuous infrasound signals from the Mount Tolbachik volcano (Kamchatka, RU) during the 2013 SSW period. Comparison between observations (black dots) and 3-D tracing results (red dots) as a function of time using the ECMWF HRES forecast (nowcast). The blue dots correspond to the simulated arrivals that have propagated through the mesosphere and lower thermosphere, for which the MSIS and HWM climatology has been used (from Smets et al. 2016). (Bottom) Details of the comparisons during the SSW event. This comparison shows that the differences between back azimuth forecasting and observations are larger during the SSW and SSW recovery time

Therefore, the capability of infrasound to evaluate the stratospheric predictability is demonstrated for the same SSW of January 2013 using a volcano, as the source location is fixed and relatively well understood (Fee et al. 2010; Matoza et al. 2011a, b; Marchetti et al. 2013). A year of near-continuous infrasound detections from Mount Tolbachik is used, observed by IMS IS44 infrasound station on the Kamchatka peninsula in Russian Federation $\left(55.8^{\circ} \mathrm{N}, 160.3^{\circ} \mathrm{E}\right)$. IS44 is located at approximately $347 \mathrm{~km}$ southwest of Mount Tolbachik, with a true bearing of $28.11^{\circ}$ clockwise from north. For the first time, weather forecasts for different forecast steps are evaluated using infrasound. Top of Fig. 28 shows the stratospheric zonal wind inversion during the SSW, inducing summer wind conditions in winter. Figure 28 (middle) shows a comparison between the observed signals and the propagation simulations using three-dimensional ray tracing and ECMWF highresolution deterministic forecast. Significant inconsistencies or lack of simulated returns indicates a possible difference between the true state of the atmosphere and the consulted forecast in the vicinity of the return height. In summer, the deviations fall within the array 
uncertainty. During the SSW and equinox, significantly large bearing deviations are denoted with an increased mean deviation. Large misfits occur at the warming onset and offset. The middle atmospheric forecast skill drop is related to data assimilation issues (Diamantakis 2014), and the present example shows that infrasound observable could provide relevant data sets for improving future assimilations.

\section{Data Utilization for Weather Forecasting and Climate Models}

The ARISE project also investigated the way in which the ARISE network could fill current and future data gaps for both numerical weather prediction and climate simulations. One of the most exciting results of ARISE is the progress made toward developing methods to assimilate ARISE data in future weather forecasting models (ECMWF) to increase their accuracy from about 10 days today, to monthly and seasonal timescales. ARISE work set the objectives for ARISE in this respect.

ARISE observations could help constrain the uncertainty in these measurements and provide high-resolution information to improve our knowledge of the MA dynamics and to create advanced dynamics data products that will be used for the validation and improvement of weather forecast and climate numerical models. The inter-technology ARISE measurement campaigns at OHP provided high-resolution data of high quality which have been used to evaluate NWP and climate models by characterizing the mean state of the MA GWs and PWs.

Data provided the vertical structure of the wind and temperature from the ground to the mesosphere by using lidar and mesospheric observations, complemented by continuous infrasound measurements. Together with additional ground-based wind radar system, such complementary techniques help to better describe the interaction between atmospheric layers from the ground to the mesosphere and the influence of GWs and PWs on the atmospheric dynamics.

The analyses of the ARISE data allowed characterizing atmospheric perturbations in the MA and their effects on the mean circulation. GWs cannot be resolved directly by current global circulation models due to their sub-grid scales. The ARISE database provides novel observations on the spatial and temporal distribution of GW characteristics at different ranges of altitudes and time of year, thus building a detailed understanding of large-scale atmospheric disturbances through multiple independent and complementary observational platforms.

\subsection{Impact of the Stratosphere Dynamics on Numerical Weather Prediction}

As reviewed by Tripathi et al.(2014) as a part of the ARISE project, correctly predicting the evolution of extreme events in the stratosphere such as SSW can lead to improvements in tropospheric weather forecasts on weekly timescales. One of the main ARISE application is then the use of these data to improve the weather forecasting models.

As part of the ARISE project, test experiments a general circulation model (specifically the HADGEM2 Met Office Unified Model-UM) were conducted to diagnose the impact of representative upper stratospheric errors on forecasts of the troposphere and stratosphere.

An idealized approach was taken, in which forecasts of the state of a long control run of the model were made by initializing runs with small perturbations from this control state. 


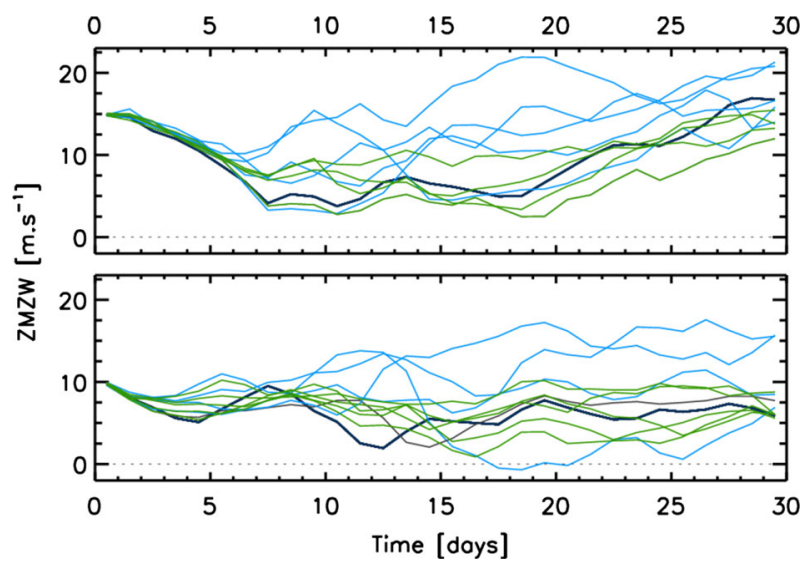

Fig. 29 Zonal mean zonal winds (ZMZW) of two SSW cases from the control run (thick dark line) and their 30-day ensemble forecasts (light blue) with upper-stratosphere nudged ensemble (green lines) for the lower troposphere $(1000 \mathrm{hPa})$. Stratospheric nudging reduces the ensemble spread for the nudged ensemble, indicating enhanced predictability at these altitudes

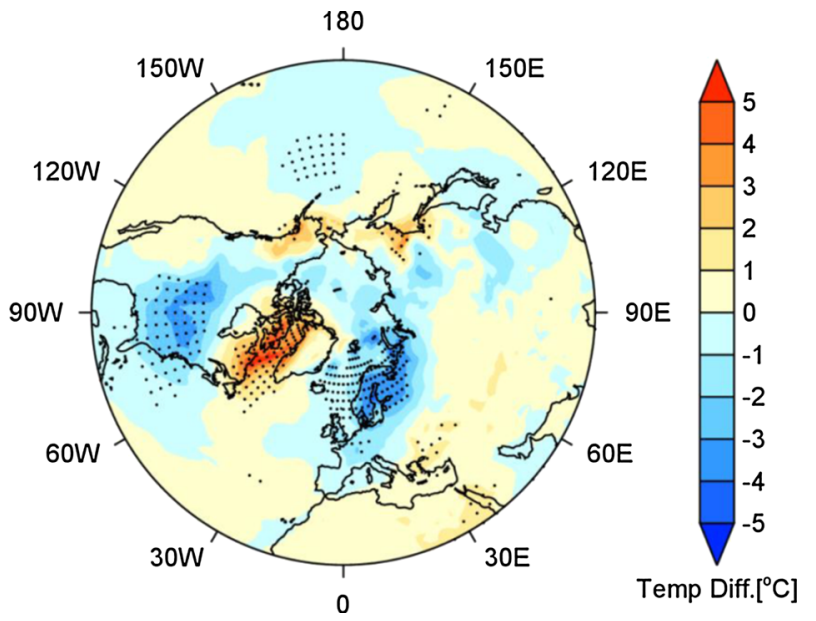

Fig. 30 Sudden stratospheric warming impact on weather. The surface temperature anomalies are averaged over forecast days 15-30 for $15 \mathrm{SSW}$ cases. The stippling indicates significance at the $95 \%$ confidence level

To simulate the impact of observations at different altitudes, the model was nudged back to the control run over the whole stratosphere and in the upper stratosphere only (above $40 \mathrm{~km}$ ) where there is a dearth of current observations.

Figure 29 shows the ensembles of zonal mean zonal wind in the upper troposphere, for un-nudged and nudged (upper stratosphere) forecasts. The ensemble spread of the latter is much smaller, because the dynamics at this level are influenced by the stratosphere. The ensemble spread shown here, and the differences between the forecasts, is a realistic representation of different operational forecasts at these levels.

These idealized experiments replicated the surface effects of SSW reported in previous studies. Figure 30 shows the pattern of surface temperature anomalies averaged over days 15-30 for 15 SSW cases. The negative northern annular mode (NAM) pattern is clear, with 
a warming over North America and a cooling over Northern Europe. This pattern has been shown in previous studies, illustrates the teleconnection between the stratosphere and lower troposphere and indicates that idealized experiments give a realistic representation of the associated atmospheric dynamics.

The weather forecasting studies found that relaxation of either the whole stratosphere or the upper stratosphere only (simulating the effect of data assimilation at these altitudes) improved the representation of average surface temperature patterns, especially over eastern North America and Northern Russia (Fig. 30). Similar results were shown in studies looking at longer forecasts (out to 60 days); however, our results are particularly useful because they demonstrate an impact on routine weather forecasting timescales (up to 30 days). Additionally, they also demonstrate the potential impact of upper stratospheric observations on forecast quality for the stratosphere and troposphere during SSW events.

\subsection{Toward Data Parametrization and Assimilation}

The OHP campaigns with collocated ARISE measurements help to better describe the interaction between atmospheric layers from the ground to the mesosphere and the influence of large-scale waves on the atmospheric dynamics. Comparing ARISE observations of the winter 2012/2013 SSWs with forecasts reveals that there was cooling around the mesopause that preceded both major SSWs and that there was difficultly in forecasting vortex positions after the vortex split. There were also significant changes in infrasound propagation associated with the changes in stratospheric winds.

Most GWs are too small to be explicitly resolved by NWP models; instead, parameterizations are used to simulate the drag on the mean flow caused by wave breaking. However, the paucity of measurements means that NWP parameterization schemes are often tuned to produce more realistic temperature structures near the tropopause, or to improve representation of winds, rather than to replicate the actual deposition of GW momentum. In addition, non-orographic GW parameterizations used in NWP models are usually spatially and temporally invariant and will not capture the seasonal behavior.

ARISE infrasound observations can be used to measure small-scale GWs that are not observed by other techniques. GW measurements, made during 13 years by the microbarometer array IS17 in Ivory Coast, have been analyzed. The results clearly demonstrate a seasonal trend in GW propagation directions, average momentum flux, intrinsic frequency and vertical and horizontal wave numbers. The seasonal trend in propagation direction was identified by Blanc et al. (2014) and is attributed to seasonal changes in the tropical convergence zone of the winds, driving thunderstorm activity. The waves measured here are thought to be triggered by deep convection.

The analysis of the dominant GWs shows that the distribution of momentum flux peaks at around $10 \mathrm{mPa}$. This flux is larger than satellite climatologies, which are temporal averages, measuring larger scales than those detected by the microbarometer array, and at very different altitudes. Particularly encouraging is the distribution of horizontal and vertical wave numbers and the intrinsic frequencies. The frequencies and GW numbers measured by the array show that the instrument resolves smaller-scale waves than other techniques. Measurements at these scales are particularly valuable because they are at the scales parameterized in NWP models, where measurements have previously been lacking. Additionally, the ability to capture the intermittency of GWs means that GW measurements made by these instruments have the potential to provide valuable information to the modeling community. 
Fig. 31 Comparison of GW scales observed by the Ivory Coast infrasound array (blue) and other technologies: satellites microwave sub-limb, infrared nadir viewing, super pressure balloons, radiosondes (green)

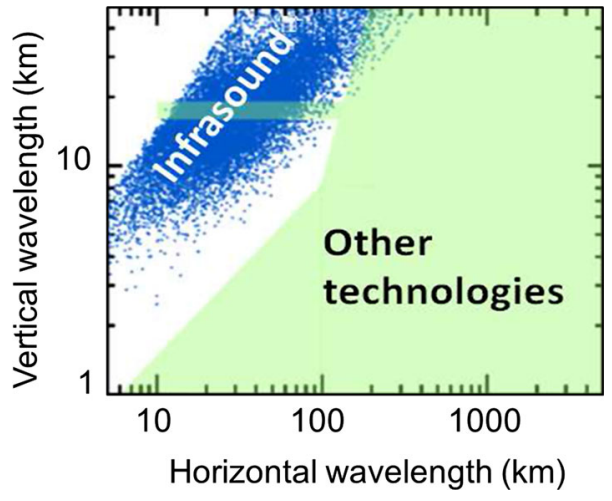

Figure 31 shows the typical vertical and horizontal wave number measured by existing techniques (shown by the green shading) and those observed at IS17 (blue dots). Results at IS17 show that horizontal and vertical wave number distributions both peak close to $20 \mathrm{~km}$ $\left(4-5 \times 10^{-4} \mathrm{~m}^{-1}\right)$; the distributions extend from approximately $3 \mathrm{~km}$ up to 400 and $50 \mathrm{~km}$ for horizontal and vertical wave numbers, respectively. The dominant intrinsic frequencies have periods of around 10-20 min (around $10^{-2} \mathrm{~s}^{-1}$ ). This covers most of the region that cannot be seen by any of the other observation conventional techniques. This improved resolution provides a long-term data set of GWs at parameterization scales.

The practicalities of the data use were discussed in the ARISE roadmap for the use of ARISE measurements for weather and climate monitoring. In the ARISE project, the basis toward NWP is formed, assessing the model variability and model bias estimation and preliminary achievements in GW parameter estimation. Although ARISE shows great potential toward NWP, the first impact is still rather limited because of the complexity of atmospheric processes, inducing difficulties in the GW parametrization, and the still limited improved observations which will be developed in the next stage of the project. Actual use the data for weather and climate monitoring is challenging. Direct assimilation of new observations is extremely costly, and risky for operational weather centers, requiring clear proof of the benefits. Therefore, different steps and aspects that meet the needs of weather and climate monitoring are identified, aimed at being part of the community of weather and climate monitoring. In particular, the next step will be to develop a spatially and temporally varying climatology of the GW spectrum at the ground (from infrasound measurements) and in the stratosphere (from lidar measurements) and mesosphere (from meteor radar measurements). This climatology will be compared to outputs from the GW parameterization of the HADGEM and IPSL-LMDz models and to outputs of meteorological mesoscale models.

\section{Conclusion and Perspectives}

ARISE demonstrates the advantage of an infrastructure that integrates various independent middle atmospheric measurement techniques to provide quantitative understanding of the troposphere stratosphere-mesosphere-thermosphere dynamical coupling relevant to a broad community and for a wide variety of applications: 


\subsection{Characterization of Tropospheric and Stratospheric Gravity Wave Variability}

An important driver of the stratospheric variability is severe weather. When GWs produced by convection from thunderstorms propagate vertically into the stratosphere, their cumulative effects may disturb the general atmospheric circulation. Valuable information for climate studies has been derived from the analysis of archived GW data recorded in tropical infrasound stations where activity is very intense. Lidar network provides GWinduced fluctuations in the wind profiles which are needed to fully retrieve the structure of these disturbances in the stratosphere and mesosphere. Mountain waves can also be characterized. Global satellite observations of the MA GW momentum fluxes clearly reveal that the activity induced by convection systems is not homogeneously distributed throughout the atmosphere as currently assumed by most GW parameterizations in climate models. ARISE data provide then an efficient way to more precisely determine the impact of wave activity on the environment at different latitudes. They also provide useful information that improves knowledge about the source mechanism involved in the generation and coupling processes between the troposphere and the stratosphere.

\subsection{Better Representation of Stratospheric Variability for Further Improving Weather Forecasts on Timescales up to Weeks Ahead}

Comparisons between the OHP observations by lidar, airglow, infrasound and the ECMWF model already quantified model uncertainties at short timescales. The standard deviation of the mean difference exceeds $5 \mathrm{~K}$ for the temperature and $20 \mathrm{~m} / \mathrm{s}$ for the zonal wind between 40 and $60 \mathrm{~km}$ altitude. These data sets have begun to be used as a benchmark for model validation.

The GW and PW climatology and the better SSW description, possible with the systematic integration of ARISE data, will allow a better description of their effects in the general circulation system. In ARISE next step, data will be assimilated for further improving the accuracy in short- and medium-range weather forecasts on timescales up to several weeks. This application concerns important topics such as agriculture, prediction of energy consumption, tourism, insurance, civil protection, renewable energy production and other environmental issues.

\subsection{Near-Real-Time and Continuous Monitoring of Natural Hazard}

ARISE investigated the potentials and benefits of the ARISE technologies for monitoring extreme events including volcanoes, earthquakes, severe weather, meteors, industrial or accidental explosions. For each type of extreme event, advanced data products are identified for potential use by ARISE infrastructure end users, such as civil security and decision-making agencies and the scientific community. The ARISE network appears to be quite well developed to monitor most of the expected extreme events in Europe.

With the future completion of the IMS infrasound network and the addition of local and regional networks, the infrasound technology is becoming a reliable observation system to monitor volcanoes at large distances. This technology is extremely efficient both in providing real-time reliable source-term parameters from local (tens of $\mathrm{km}$ ) observations, necessary for improved modeling ash dispersal in the atmosphere, and also in monitoring activity from long-range (thousands of $\mathrm{km}$ ) observations of unmonitored volcanoes. In 
particular, the eruption chronology can be inferred from remote infrasound observations (hundreds of $\mathrm{km}$ from the source) with greater temporal resolution and larger observation periods than is possible with satellite data alone.

ARISE provides the eruption notifications including confidence index representative on propagation conditions and additional analysis results. In a further stage, infrasound signal parameters characterizing the intensity of the eruptions (Volcanic Explosivity Index) and the amount of ash injected into the atmosphere, as well as ash height, will be explored. Such studies interest several VAACs (including VAAC Toulouse) and the IAVWOPSG.

In parallel, volcanoes are repetitive infrasound sources which can be used for remote sensing of the atmosphere when the source parameters are well determined. Methods using volcanic infrasound sources are developed to reconstruct wind profiles in the stratosphere and mesosphere. Other permanent sources of interest, globally detected, like the ocean swell or man-made sources such as repetitive quarry explosions, could also provide new constraints to better characterize the atmospheric mean flow and its variability.

\subsection{Evolution of the Atmospheric Disturbances in Relation to Climate Change}

The ARISE platform is dedicated to an implementation period of several decades. The perspective of an optimized infrastructure with improved coverage, especially at high and low latitudes, and additional complementary observations in the stratosphere and mesosphere could change our vision of the dynamics of the atmosphere and its disturbances as well as encourage long-term studies in Europe.

Future changes in stratospheric climate could play a significant role in determining changes in surface climate over the coming century. ARISE data are already used to quantify trends in the temperature in the different atmospheric layers which are valuable indicators for climate change studies. Archived lidar data contribute to monitoring longterm stratospheric cooling at different latitudes. The infrasound data recorded during over more than ten years at some stations also present a potential to monitor long-term mean trends of weather events. The long-term evolution of convection in Africa presents a large environmental interest as it is related to precipitation as rain. ARISE integrates operational infrastructures dedicated to long-term atmospheric monitoring (IMS infrasound network for CTBT verification, NDACC lidar network), complemented by observatories (OHP, OPAR, ASC, Esrange), national infrastructures (i.e., forming the European infrasound network), and such observations are ongoing. The provided long-duration database will be used for weather, climate and extreme event studies.

Acknowledgements This work was mainly performed during the course of the ARISE design study (http:// arise-project.eu) funded by the European Union's 7th Framework Programme for Research and Technological Development under Grant Agreement No. 284387. ARISE is now funded by the European Union's Horizon 2020 Research and Innovation Programme under Grant Agreement No. 653980. We thank the ARISE advisory board (Guy Brasseur, Adrian Simmons, Geir Braathen, Philippe Husson) for relevant recommendations and the CTBTO for its support in the infrasound topic. We also thank the ARISE2 partners for their support to ARISE and strong motivation.

Open Access This article is distributed under the terms of the Creative Commons Attribution 4.0 International License (http://creativecommons.org/licenses/by/4.0/), which permits unrestricted use, distribution, and reproduction in any medium, provided you give appropriate credit to the original author(s) and the source, provide a link to the Creative Commons license, and indicate if changes were made. 


\section{References}

Alexander MJ, May PT, Beres JH (2004) Gravity waves generated by convection in the Darwin area during the Darwin Area Wave Experiment. J Geophys Res 109:D2S04. https://doi.org/10.1029/ 2004JD004729

Alexander MJ, Eckermann SD, Broutman D, Ma J (2009) Momentum flux estimates for South Georgia Island mountain waves in the stratosphere observed via satellite. Geophys Res Lett 36:L12816. https:// doi.org/10.1029/2009GL038587

Alexander MJ, Geller M, McLandress C, Polavarapu S, Preusse P, Sassi F, Sato K, Eckermann S, Ern M, Hertzog A, Kawatani YA, Pulido M, Shaw T, Sigmond M, Vincent R, Watanabe S (2010) Recent developments in gravity-wave effects in climate models and the global distribution of gravity-wave momentum flux from observations and models. Q J R Meteorol Soc 136:1103-1124. https://doi.org/10. 1002/qj.637

Angot G, Keckhut P, Hauchecorne A, Claud C (2012) Contribution of stratospheric warmings to temperature trends in the middle atmosphere from the lidar series obtained at Haute-Provence Observatory (44 N). J Geophys Res 117:D21102. https://doi.org/10.1029/2012JD017631

Ardhuin F, Herbers THC (2013) Noise generation in the solid Earth, oceans and atmosphere, from nonlinear interacting surface gravity waves in finite depth. J Fluid Mech 716:316-348

Ardhuin F, Collard F, Chapron P, Girard-Ardhuin F, Guitton G, Mouche A, Stopa JE (2015) Estimates of ocean wave heights and attenuation in sea ice using the SAR wave mode on Sentinel-1A. Geophys Res Lett 42:2317-2325. https://doi.org/10.1002/2014GL062940

Arechiga R, Stock M, Thomas R, Erives H, Rison W, Edens H, Lapierre J (2014) Location and analysis of acoustic infrasound pulses in lightning. Geophys Res Lett 41:4735-4744. https://doi.org/10.1002/ 2014GL060375

Artru J, Lognonné P, Blanc E (2001) Normal modes modeling of post-seismic ionospheric oscillations. Geophys Res Lett 28:697-700

Artru J, Farges T, Lognonne P (2004) Acoustic waves generated from seismic surface waves: Propagation properties determined from Doppler sounding observations and normal-mode modeling. Geophys J Int 158:1067-1077

Assink JD, Le Pichon A, Blanc E, Kallel M, Khemiri L (2014a) Evaluation of wind and temperature profiles from ECMWF analysis on two hemispheres using volcanic infrasound. J Geophys Res 119:8659-8683. https://doi.org/10.1002/2014JD021632

Assink JD, Waxler R, Smets P, Evers LG (2014b) Bidirectional infrasonic ducts associated with sudden stratospheric warming events. J Geophys Res 119:1140-1153. https://doi.org/10.1002/2013JD021062

Baldwin MP, Dunkerton TJ (2001) Stratospheric harbingers of anomalous weather regimes. Science. https:// doi.org/10.1126/science.1063315

Baldwin MP, Stephenson DB, Thompson DWJ, Dunkerton TJ, Charlton AJ, O'Neill A (2003) Stratospheric memory and extended-range weather forecasts. Science 301:636-640

Baray JL, Courcoux Y, Keckhut P, Portafaix T, Tulet P, Cammas JP, Hauchecorne A, Godin Beekmann S, De Mazière M, Hermans C, Desmet F, Sellegri K, Colomb A, Ramonet M, Sciare J, Vuillemin C, Hoareau C, Dionisi D, Duflot V, Vérèmes H, Porteneuve J, Gabarrot F, Gaudo T, Metzger JM, Payen G, Leclair de Bellevue J, Barthe C, Posny F, Ricaud P, Abchiche A, Delmas R (2013) Maïdo observatory: a new high-altitude station facility at Reunion Island $\left(21^{\circ} \mathrm{S}, 55^{\circ} \mathrm{E}\right)$ for long-term atmospheric remote sensing and in situ measurements. Atmos Meas Tech 6:2865-2877. https://doi.org/10. 5194/amt-6-2865-2013

Bertin M, Millet C, Bouche D (2014) A low-order reduced model for the long range propagation of infrasounds in the atmosphere. J Acoust Soc Am 136:37. https://doi.org/10.1121/1.4883388

Bilitza B (2001) International reference ionosphere 2000. Radio Sci 36(2):261-275

Blanc E (1985) Observations in the upper atmosphere of infrasonic waves from natural or artificial sources: a summary. Ann Geophys 3:673-687

Blanc E (2010) Space observations of Transient Luminous Events and associated emissions in the upper atmosphere above thunderstorm areas. C R Geosci 342:312-322

Blanc E, Lefeuvre F, Roussel-Dupré RA, Sauvaud JA (2007) TARANIS: A microsatellite project dedicated to the study of impulsive transfers of energy between the Earth atmosphere, the ionosphere and the magnetosphere. Adv Space Res. https://doi.org/10.1016/j.asr.2007.06.037

Blanc E, Le Pichon A, Ceranna L, Farges T, Marty J, Herry P (2010) Global scale monitoring of acoustic and gravity waves for the study of the atmospheric dynamics. In: Le Pichon A, Blanc E, Hauchecorne A (eds) Infrasound monitoring for atmospheric studies, chap. 21. Springer, Berlin, pp 647-664 
Blanc E, Farges T, Le Pichon A, Heinrich P (2014) Ten year observations of gravity waves from thunderstorms in western Africa. J Geophys Res 119(11):6409-6418. https://doi.org/10.1002/ 2013JD020499

Blanc E, Charlton-Perez A, Keckhut P, Evers L, Heinrich P, Le Pichon A, Hauchecorne A (2015) The ARISE project: dynamics of the atmosphere and climate. Our common future under climate change. International scientific conference. July 2015, Paris, France. pp 1108-01. https://hal-insu.archivesouvertes.fr/insu-01183228/

Bonadonna C, Folch A, Loughlin S, Puempel H (2012) Future developments in modeling and monitoring of volcanic ash clouds: outcomes from the first IAVCEI-WMO workshop on Ash Dispersal Forecast and Civil Aviation. Bull Volcanol 74(1):1-10. https://doi.org/10.1007/s00445-011-0508-6

Brachet N, Brown D, Bras RL, Cansi Y, Mialle P, Coyne J (2010) Monitoring the Earth's atmosphere with the global IMS infrasound network. In: Le Pichon A, Blanc E, Hauchecorne A (eds) Infrasound monitoring for atmospheric studies, chap. 3. Springer, Berlin, pp 77-118

Butchart N (2014) The Brewer-Dobson circulation. Rev Geophys 52:157-184. https://doi.org/10.1002/ 2013RG000448

Campus P, Christie DR (2010) Worldwide observations of infrasonic waves. In: Le Pichon A, Blanc E, Hauchecorne A (eds) Infrasound monitoring for atmospheric studies. Springer, Dordrecht, pp 185-234, ISBN: 978-1-4020-9507-8

Caudron C, Taisne B, Garcés M, Le Pichon A, Mialle P (2015) On the use of remote infrasound and seismic stations to constrain the eruptive sequence and intensity for the 2014 Kelud eruption. Geophys Res Lett 42:6614-6621. https://doi.org/10.1002/2015GL064885

Cecil DJ, Buechler DE, Blakeslee RJ (2014) Gridded lightning climatology from TRMM-LIS and OTD: dataset description. Atmos Res. https://doi.org/10.1016/j.atmosres.2012.06.028

Chanin ML, Garnier A, Hauchecorne A, Porteneuve J (1989) A Doppler Lidar for measuring winds in the middle atmosphere. Geophys Res Lett 16:1273-1276

Charlton A, Polvani L (2007) A new look at stratospheric sudden warming. Part I: climatology and modeling benchmarks. J Clim 20:449-469. https://doi.org/10.1175/JCLI3996.1

Charlton-Perez AJ, O’Neill A, Lahoz WA, Massacand AC (2004) Sensitivity of tropospheric forecasts to stratospheric initial conditions. Q J R Meteorol Soc 130:1771-1792. https://doi.org/10.1256/qj.03.167

Charlton-Perez AJ, Baldwin MP, Birner T, Black RX, Butler AH, Calvo N, Davis NA, Gerber EP, Gillett N, Hardiman S, Kim J, Krüger K, Lee Y, Manzini E, McDaniel BA, Polvani L, Reichler T, Shaw TA, Sigmond M, Son S, Toohey M, Wilcox L, Yoden S, Christiansen B, Lott F, Shindell D, Yukimoto S, Watanabe S (2013) On the lack of stratospheric dynamical variability in low-top versions of the CMIP5 models. J Geophys Res 118(6):2494-2505. https://doi.org/10.1002/jgrd.50125

Christian HJ, Blakeslee RJ, Boccippio DJ, Boeck WL, Buechler DE, Driscoll KT, Goodman SJ, Hall JM, Koshak WJ, Mach DM, Stewart MF (2003) Global frequency and distribution of lightning as observed from space by the Optical Transient Detector. J Geophys Res 108(D1):4005. https://doi.org/10.1029/ 2002JD002347

Christie D, Campus P (2010) The IMS infrasound network: design and establishment of infrasound stations. In: Le Pichon A, Blanc E, Hauchecorne A (eds) Infrasound monitoring for atmospheric studies, chap. 2. Springer, pp 29-75

Chum J, Hruska F, Zednik J, Lastovicka J (2012a) Ionospheric disturbances (infrasound waves) over the Czech Republic excited by the 2011 Tohoku earthquake. J Geophys Res 117:A08319. https://doi.org/ 10.1029/2012JA017767

Chum J, Athieno R, Base J, Buresova D, Hruska F, Lastovicka J, McKinnell LA, Sindelarova T (2012b) statistical investigation of horizontal propagation of gravity waves in the ionosphere over Europe and South Africa. J Geophys Res 117:A03312. https://doi.org/10.1029/2011JA017161

Chunchuzov IP, Kulichkov SN, Popov OE, Waxler R, Assink JD (2011) Infrasound scattering from atmospheric anisotropic inhomogeneities. Izv Atmos Ocean Phys 47:540-557

Chunchuzov IP, Kulichkov SN, Perepelkin V, Popov O, Firstov P, Assink JD, Marchetti E (2015) Study of the wind velocity-layered structure in the stratosphere, mesosphere, and lower thermosphere by using infrasound probing of the atmosphere. J Geophys Res Atmos 120:8828-8840. https://doi.org/10.1002/ 2015JD023276

Claud C, Heinemann G, Raustein E, McMurdie L (2004) Polar low le cygne: satellite observations and numerical simulations. Q J R Meteorol Soc 130:1075-1102

Costantino L, Heinrich P (2013) Tropical deep convection and density current signature in surface pressure: comparison between WRF model simulations and infrasound measurements. Atmos Chem Phys Discuss. https://doi.org/10.5194/acpd-13-15993-2013 
Costantino L, Heinrich P, Mze N, Hauchecorne A (2015) Convective gravity wave propagation and breaking in the stratosphere, comparison between WRF model simulations and LIDAR data. Ann Geophys 33:1155-1171

Da Silva CL, Pasko VP (2014) Infrasonic acoustic waves generated by fast air heating in sprite cores. Geophys Res Lett 41:1789-1795. https://doi.org/10.1002/2013GL059164

Dabrowa AL, Green DN, Rust AC, Phillips JC (2011) A global study of volcanic infrasound characteristics and the potential for long-range monitoring. Earth Planet Sci Lett 310:369-379

de la Camara A, Lott F (2015) A parameterization of gravity waves emitted by fronts and jets. Geophys Res Lett 42:2071-2078. https://doi.org/10.1002/2015GL063298

de la Camara A, Lott F, Hertzog A (2014) Intermittency in a stochastic parameterization of nonoro-graphic gravity waves. J Geophys Res Atmos 119:11905-11919. https://doi.org/10.1002/2014JD022002

de Larquier S, Pasko VP (2010) Mechanism of inverted-chirp infrasonic radiation from sprites. Geophys Res Lett 37:L24803. https://doi.org/10.1029/2010GL045304

de Wit RJ, Hibbins RE, Espy PJ, Orsolini YJ, Limpasuvan V, Kinnison DE (2014) Observations of gravity wave forcing of the mesopause region during the January 2013 major sudden stratospheric warming. Geophys Res Lett 41:4745-4752. https://doi.org/10.1002/2014GL060501

de Wit RJ, Hibbins RE, Espy PJ, Hennum EA (2015) Coupling in the middle atmosphere related to the 2013 major sudden stratospheric warming. Ann Geophys 33:309-319. https://doi.org/10.5194/angeo-33$309-2015$

Diamantakis M (2014) Improving ECMWF forecasts of sudden stratospheric warmings. ECMWF Newsl 141:30-36

Donn WL, Rind D (1971) Natural infrasound as an atmospheric probe. Geophys J R Astron Soc 26:111-133

Drob DP, Picone JM, Garces M (2003) Global morphology of infrasound propagation. J Geophys Res 108(D21):4680. https://doi.org/10.1029/2002JD003307

Drob D, Emmert JT, Crowley G, Picone JM, Shepherd GG, Skinner W, Hays Niciejewski RJ, Larsen M, She CY, Meriwether JW, Hernandez G, Jarvis M, Sipler Tepley CA, O’Brien MS, Bowman JR, Wu Q, Murayama Y, Kawamura S, Reid IM, Vincent RA (2008) An empirical model of the earth's horizontal wind fields: HWM07. J Geophys Res Space Phys. https://doi.org/10.1029/2008JA013668

Drob DP, Meier RR, Picone JM, Garcés M (2010) Inversion of infrasound signals for passive atmospheric remote sensing. In: Infrasound monitoring for atmospheric studies, chap. 24. Springer, pp 701-732

Drob DP, Broutman D, Hedlin MA, Winslow NW, Gibson RG (2013) A method for specifying atmospheric gravity-wave fields for long-range infrasound propagation calculations. J Geophys Res 118:3933-3943. https://doi.org/10.1029/2012JD018077

Dunkerton T (1978) On the mean meridional mass motions of the stratosphere and mesosphere. J Atmos Sci 35:2325-2333. https://doi.org/10.1175/1520-0469(1978)035<2325:OTMMMM $>2.0 . C O ; 2$

Ern M, Preuse P (2012) Gravity wave momentum flux spectra observed from satellite in the summertime subtropics: implications for global modeling. Geophys Res Lett 39:L15810. https://doi.org/10.1029/ 2012GL052659

Ern M, Preusse P, Gille JC, Hepplewhite CL, Mlynczak MG, Russell JM III, Riese M (2011) Implications for atmospheric dynamics derived from global observations of gravity wave momentum flux in stratosphere and mesosphere. J Geophys Res 116:D19107. https://doi.org/10.1029/2011JD015821

Evers LG, Siegmund P (2009) Infrasonic signature of the 2009 major sudden stratospheric warming. Geophys Res Lett. https://doi.org/10.1029/2009GL041323

Evers LG, Brown D, Heaney KD, Assink JD, Smets PSM, Snellen M (2014) Evanescent wave coupling in a geophysical system: airborne acoustic signals from the Mw 8.1 Macquarie Ridge earthquake. Geophys Res Lett 41:1644-1650. https://doi.org/10.1002/2013GL058801

Farges T (2009) Infrasound from lightning and sprites. In: Dieter Betz H, Schumann U, Laroche P (eds) Lightning: principles, instruments and applications, pp 417-432. ISBN: 978-1-4020-9078-3

Farges T, Blanc E (2010) Characteristics of infrasound from lightning and sprites near thunderstorm areas. J Geophys Res 115:31. https://doi.org/10.1029/2009JA014700

Farges T, Jodogne JC, Bamford R, Le Roux Y, Gauthier F, Vila PM, Altadill D, Sole JG, Miro G (2001) Disturbances of the western European ionosphere during the total solar eclipse of 11 August 1999 measured by a wide ionosonde and radar network. J Atmos Sol-Terr Phys 63(9):915-924

Farges T, Blanc E, Le Pichon A, Neubert T, Allin T (2005) Identification of infrasound produced by sprites during the Sprite 2003 campaign. Geophys Res Lett 32:L01813. https://doi.org/10.1029/ 2004GL021212

Fee D, Garcés M, Steffke A (2010) Infrasound from Tungurahua Volcano 2006-2008: Strombolian to Plinian eruptive activity. J Volcanol Geoth Res 193:67-81. https://doi.org/10.1016/j.jvolgeores.2010. 03.006 
Fishman GJ, Bhat PN, Mallozzi R, Horack JM, Koshut T, Kouveliotou C, Pendleton GN, Meegan CA, Wilson RB, Paciesas WS, Goodman SJ, Christian HJ (1994) Discovery of intense gamma ray flashes of atmospheric origin. Science 264:1313-1316

Francis SH (1975) Global propagation of atmospheric gravity waves: a review. J Atmos Sol-Terr Phys 37:1011-1054

Fritts DC, Alexander MJ (2003) Gravity wave dynamics and effects in the middle atmosphere. Rev Geophys 41(1):1003. https://doi.org/10.1029/2001RG000106

Fritts DC, Vadas SL (2008) Gravity wave penetration into the thermosphere: sensitivity to solar cycle variations and mean winds. Ann Geophys 26:3841-3861

Füllekrug M, Diver D, Pincon JL, Phelps ADR, Bourdon A, Helling C, Blanc E, Honary F, Harrison RG, Sauvaud JA, Renard JB, Lester M, Rycroft M, Kosch M, Horne RB, Soula S, Gaffet S (2013) Energetic charged particles above thunderclouds. Surv Geophys 34:1. https://doi.org/10.1007/s10712-012-9205-Z

Gainville O, Blanc-Benon P, Blanc E, Roche R, Millet C, Le Piver F, Despres B, Piserchia PF (2010) Misty picture: a unique experiment for the interpretation of the infrasound propagation from large explosive sources. In: Le Pichon A, Blanc E, Hauchecorne A (eds) Infrasound monitoring for atmospheric studies, chap. 18. Springer, Berlin, pp 575-598

Gallin LJ (2014) Caractérisation acoustique des éclairs d'orage. Ph.D. HAL Id: tel-01127524, 2015

Gallin LJ, Farges T, Marchiano R, Coulouvrat F, Defer E, Rison W, Schulz W, Nuret M (2016) Statistical analysis of storm electrical discharges reconstituted from a lightning mapping system, a lightning location system, and an acoustic array. J Geophys Res 121:3929-3953. https://doi.org/10.1002/ 2015JD023745

Garcés M, Willis M, Hetzer C, Le Pichon A, Drob D (2004) On using ocean swells for continuous infrasonic measurements of winds and temperature in the lower, middle, and upper atmosphere. Geophys Res Lett 31:L19304. https://doi.org/10.1029/2004GL020696

Garcés M, Caron P, Hetzer C, Le Pichon A, Bass H, Rob DD, Hattacharyya JB (2005) Deep infrasound radiated by the Sumatra Earthquake and Tsunami. EOS 86(35):317-320

Gerber EP, Orbe C, Polvani LM (2009) Stratospheric influence on the tropospheric circulation revealed by idealized ensemble forecasts. Geophys Res Lett 36:L24801. https://doi.org/10.1029/2009GL040913

Gibbons SJ, Asming V, Eliasson L, Fedorov A, Fyen J, Kero J, Koslovskaya E, Kvaerna T, Liszka L, Näsholm SP, Raita T, Roth M, Tiira T, Vinogradov Y (2015) The European arctic: a laboratory for seismoacoustic studies. Seismol Res Lett. https://doi.org/10.1785/0220140230

Goncharenko L, Chau JL, Condor P, Coster A, Benkevitch L (2013) Ionospheric effects of sudden stratospheric warming during moderate-to-high solar activity: case study of January 2013. Geophys Res Lett 40:4982-4986. https://doi.org/10.1002/grl.50980

Green DN, Bowers D (2010) Estimating the detection capability of the international monitoring system infrasound network. J Geophys Res 115:D18116. https://doi.org/10.1029/2010JD014017

Hauchecorne A, Chanin ML (1980) Density and temperature profiles obtained by lidar between 35 and $70 \mathrm{~km}$. Geophys Res Lett 7:565-568

Hauchecorne A, Bertaux JL, Dalaudier F, Russell JM, Mlynczak MG, Kyrölä E, Fussen D (2007) Large increase of $\mathrm{NO}_{2}$ in the north polar mesosphere in January-February 2004: evidence of a dynamical origin from GOMOS/ENVISAT and SABER/TIMED data. Geophys Res Lett 34:L03810. https://doi. org/10.1029/2006GL027628

Hedlin MAH, Drob DP (2014) Statistical characterization of atmospheric gravity waves by seismoacoustic observations. J Geophys Res. https://doi.org/10.1002/2013JD021304

Heinemann G, Claud C (1997) Report of a workshop on "Theoretical and observational studies of polar lows" of the European Geophysical Society Polar Lows Working Group. Bull Am Meteorol Soc $78: 2643-2658$

Hertzog A, Souprayen C, Hauchecorne A (2001) Measurements of gravity wave spectra in the lower stratosphere by Doppler lidar. J Geophys Res 106:7879-7890

Hertzog A, Alexander MJ, Plougonven R (2012) On the intermittency of gravity wave momentum flux in the stratosphere. J Atmos Sci 69:3433-3448

Hickey MP, Schubert G, Walterscheid RL (2001) Acoustic wave heating of the thermosphere. J Geophys Res 106(A10):21543-21548. https://doi.org/10.1029/2001JA000036

Hocking WK, Fuller B, Vandepeer B (2001) Real-time determination of meteor-related parameters utilizing modem digital technology. J Atmos Sol-Terr Phys 63(2-3):155-169. https://doi.org/10.1016/S13646826(00)00138-3

Hoffmann L, Alexander MJ, Clerbaux C, Grimsdell AW, Meyer CI, Rößler T, Tournier B (2014) Intercomparison of stratospheric gravity wave observations with AIRS and IASI. Atmos Meas Tech 7(4517-4537):2014. https://doi.org/10.5194/amt-7-4517-2014 
Holton JR (1983) The influence of gravity wave breaking on the general circulation of the middle atmosphere. J Atmos Sci 40:2497-2507

Holton JR, Haynes PH, McIntyre ME, Douglass AR, Rood RB, Pfister L (1995) Stratosphere-troposphere exchange. Rev Geophys 33(4):403-439

Hoppel KW, Eckermann SD, Coy L, Nedoluha GE, Allen DR, Swadley SD, Baker NL (2013) Evaluation of SSMIS upper atmosphere sounding channels for high-altitude data assimilation. Mon Weather Rev 141:3314-3330. https://doi.org/10.1175/mwr-d-13-00003.1

IAVWOPSG, International Airways Volcano Watch Operations Group, Volcano Infrasound Project between Toulouse VAAC, ARISE and CTBTO, 6th meeting, Dakar, Senegal, 19-23 Sept. 2011 and 8th meeting, Melbourne Australia, 17-20 Feb. 2014, IAVWOPSG/8-WP/31

Keckhut P, Randel WJ, Claud C, Leblanc T, Steinbrecht W, Funatsua BM, Bencherif H, McDermid IS, Hauchecorne A, Long C, Lin R, Baumgarten G (2011) An evaluation of uncertainties in monitoring middle atmosphere temperatures with the ground-based lidar network in support of space observations. J Atmos Sol-Terr Phys 73(5-6):627-642

Keckhut P, Funatsu BM, Claud C, Hauchecorne A (2015) Tidal effects on stratospheric temperature series derived from successive advanced microwave sounding units. Q J R Meteorol Soc. https://doi.org/10. 1002 /qj. 2368

Khaykin S, Pommereau JP, Hauchecorne A (2013) Impact of land convection on temperature diurnal variation in the tropical lower stratosphere inferred from COSMIC GPS radio occultations. Atmos Chem Phys 13:6391-6402. https://doi.org/10.5194/acpd-13-1-2013

Khaykin SM, Hauchecorne A, Mze N, Keckhut P (2015) Seasonal variation of gravity wave activity at midlatitudes from 7 years of COSMIC GPS and Rayleigh lidar temperature observations. Geophys Res Lett 42(4):1251-1258. https://doi.org/10.1002/2014GL062891

Kulichkov S (2010) On the prospects for acoustic sounding of the fine structure of the middle atmosphere. In: Le Pichon A, Blanc E, Hauchecorne A (eds) Infrasound monitoring for atmospheric studies, chap. 16. Springer, New York, pp 511-540

Kulichkov SN, Chunchuzov IP, Popov OI (2010) Simulating the influence of an atmospheric fine inhomogeneous structure on long-range propagation of pulsed acoustic signals. Izv Atmos Ocean Phys 46:69-77

Lalande JM, Sèbe O, Landès M, Blanc-Benon P, Matoza R, Le Pichon A, Blanc E (2012) Infrasound data inversion for atmospheric sounding. Geophys J Int 190:687-701. https://doi.org/10.1111/j.1365-246X. 2012.05518.x

Landes M, Le Pichon A, Shapiro NM, Hillers G, Campillo M (2014) Explaining global patterns of microbarom observations with wave action models. Geophys J Int 199:1328-1337. https://doi.org/10. 1093/gji/ggu324

Lastovicka J (2006) Forcing of the ionosphere by waves from below. J Atmos Sol-Terr Phys 68:479-497

Le Pichon A, Guilbert J, Vallee M, Dessa JX, Ulziibat M (2003) Infrasonic imaging of the Kunlun Mountains for the great 2001 China earthquake. Geophys Res Lett 30(15):1814. https://doi.org/10. 1029/2003GL017581

Le Pichon A, Blanc E, Drob D, Lambotte S, Dessa JX, Lardy M, Bani P, Vergniolle S (2005a) Infrasound monitoring of volcanoes to probe high-altitude winds. J Geophys Res 110:D1310. https://doi.org/10. 1029/2004JD005587

Le Pichon A, Blanc E, Drob D (2005b) Probing high-altitude winds using infrasound. J Geophys Res 110:D20104. https://doi.org/10.1029/2005JD006020

Le Pichon A, Ceranna L, Garcés M, Drob D, Millet C (2006) On using infrasound from interacting ocean swells for global continuous measurements of winds and temperature in the stratosphere. J Geophys Res 111:D11106. https://doi.org/10.1029/2005JD006690

Le Pichon A, Vergoz J, Herry P, Ceranna L (2008) Analyzing the detection capability of infrasound arrays in Central Europe. J Geophys Res 113:D12115. https://doi.org/10.1029/2007JD009509

Le Pichon A, Blanc E, Hauchecorne A (2010) Infrasound monitoring for atmospheric studies. Springer, Dordrecht, ISBN: 978-1-4020-9507-8

Le Pichon A, Ceranna L, Vergoz J (2012) Incorporating numerical modeling into estimates of the detection capability of the IMS infrasound network. J Geophys Res 117:D05121. https://doi.org/10.1029/ 2011JD016670

Le Pichon A, Ceranna L, Pilger C, Mialle P, Brown D, Herry P, Brachet N (2013) The 2013 Russian fireball largest ever detected by CTBTO infrasound sensors. Geophys Res Lett 40:3732-3737. https://doi.org/ $10.1002 /$ grl.50619

Le Pichon A, Assink JD, Heinrich P, Blanc E, Charlton-Perez A, Lee CF, Keckhut P, Hauchecorne A, Rüfenacht R, Kämpfer N, Drob DP, Smets PSM, Evers LG, Ceranna L, Pilger C, Ross O, Claud C (2015) Comparison of co-located independent ground-based middle atmospheric wind and temperature 
measurements with numerical weather prediction models. J Geophys Res. https://doi.org/10.1002/. 2015JD023273

Lefeuvre F, Blanc E, Pinçon JL, Roussel-Dupré RA, Lawrence D, Sauvaud JA, Rauch JL, de Feraudy H, Lagoutte D (2008) TARANIS - a satellite project dedicated to the physics of TLEs and TGFs. Space Sci Rev 137:301-315. https://doi.org/10.1007/s11214-008-9414-4

Lindzen RS (1981) Turbulence and stress owing to gravity wave and tidal breakdown. J Geophys Res 86:9707-9714

Liszka LJ (2004) The possible infrasound generation by sprites. J Low Freq Noise Vibr Active Control 23:85-93

Lott F, Guez L (2013) A stochastic parameterization of the gravity waves due to convection and its impact on the equatorial stratosphere. J Geophys Res 118(16):8897-8909. https://doi.org/10.1002/jgrd.50705

Manzini E, Yu Karpechko A, Anstey J, Baldwin MP, Black RX, Cagnazzo C, Calvo N, Charlton-Perez A, Christiansen B, Davini P, Gerber E, Giorgetta M, Gray L, Hardiman SC, Lee YY, Marsh DR, McDaniel BA, Purich A, Scaife AA, Shindell D, Son SW, Watanabe S, Zappa G (2014) Northern winter climate change: assessment of uncertainty in CMIP5 projections related to stratosphere-troposphere coupling. J Geophys Res 119:7979-7998. https://doi.org/10.1002/2013JD021403

Marchetti E, Ripepe M, Delle Donne D, Genco R, Finizola A, Garaebiti E (2013) Blast waves from violent explosive activity at Yasur Volcano, Vanuatu. Geophys Res Lett 40:5838-5843. https://doi.org/10. 1002/2013GL057900

Marchetti E, Lacanna G, le Pichon A, Piccinini D, Ripepe M (2016a) Evidence of large infrasonic radiation induced by earthquake interaction with alluvial sediments. Seismol Res Lett 87:678-684. https://doi. org/10.1785/0220150223

Marchetti E, Innocenti L, Ulivieri G, Lacanna G, Ripepe M (2016b) Long-range infrasound monitoring of eruptive volcanoes. EGU General Assembly, Vienna

Marty J, Ponceau D, Dalaudier F (2010) Using the international monitoring system infrasound network to study gravity waves. Geophys Res Lett 37:L19802. https://doi.org/10.1029/2010GL044181

Marty J, Dalaudier F, Ponceau D, Blanc E, Munkhuu U (2013) Surface pressure fluctuations produced by the total solar eclipse of 1 August 2008. J Atmos Sci 70:809-823. https://doi.org/10.1175/JAS-D-12-091.1

Matoza RS, Le Pichon A, Vergoz J, Herry P, Lalande JM, Lee H, Che IY, Rybin A (2011a) Infrasonic observations of the June 2009 Sarychev Peak eruption, Kuril Islands: implications for infrasonic monitoring of remote explosive volcanism. J Volcanol Geotherm Res. https://doi.org/10.1016/j. jvolgeores.2010.11.022

Matoza RS, Vergoz J, Le Pichon A, Ceranna L, Green DN, Evers LG, Ripepe M, Campus P, Liszka L, Kvaerna T, Kjartansson E, Höskuldsson A (2011b) Long-range acoustic observations of the Eyjafjallajökull eruption, Iceland, April-May 2010. Geophys Res Lett 38:L06308. https://doi.org/10.1029/ 2011 GL047019

Millet C, Robinet JC, Roblin C (2007) On using computational aeroacoustics for long-range propagation of infrasounds in realistic atmospheres. Geophys Res Lett 34:L14814. https://doi.org/10.1029/ 2007GL029449

Mze N, Hauchecorne A, Keckhut P, Thétis M (2014) Vertical distribution of gravity wave potential energy from long-term Rayleigh lidar data at a northern middle-latitude site. J Geophys Res 119:12069-12083. https://doi.org/10.1002/2014JD022035

Neubert T, The ASIM instrument team (2009) ASIM-an instrument suite for the international space station. AIP Conf Proc 1118:8. https://doi.org/10.1063/1.3137718

Neubert T, Rycroft M, Farges T, Blanc E, Chanrion O, Arnone E, Odzimek A, Arnold N, Enell C, Turunen E, Bösinger T, Mika A, Haldoupis C, Steiner R, Van der Velde O, Soula S, Berg P, Boberg F, Thejll P, Christiansen B, Ignaccolo M, Füllekrug M, Verronen P, Montanya J, Crosby N (2008) Recent results from studies of electric discharges in the mesosphere. Surv Geophys 29:71-137. https://doi.org/10. 1007/s10712-008-9043-1

Noer G, Sætra O, Lien T, Gusdal Y (2011) A climatological study of polar lows in the Nordic Seas. Q J R Meteorol Soc 137:1762-1772

Occhipinti G, Dorey P, Farges T, Lognonné P (2010) Nostradamus: the radar that wanted to be a seismometer. Geophys Res Lett 37:L18104. https://doi.org/10.1029/2010GL044009

Orbaek JB, Naustvik M (1995) Infrasonic signatures of a Polar Low in the Norwegian and Barents Sea on 23-27 March 1992. Tellus A 47:921-940. https://doi.org/10.1034/j.1600-0870.1995.00201.x

Pilger C, Schmidt C, Streicher F, Wust S, Bittner M (2013) Airglow observations of orographic, volcanic and meteorological infrasound signatures. J Atmos Sol-Terr Phys 104:55-66. https://doi.org/10.1016/j. jastp.2013.08.008 
Pilger C, Ceranna L, Ross JO, Le Pichon A, Mialle P, Garcés MA (2015) CTBT infrasound network performance to detect the 2013 Russian fireball event. Geophys Res Lett 42:2523-2531. https://doi. org/10.1002/2015GL063482

Plougonven R, Hertzog A, Teitelbaum H (2008) Observations and simulations of a large amplitude mountain wave breaking over the Antarctic Peninsula. J Geophys Res 113:D1611. https://doi.org/10. 1029/2007JD009739

Prata AJ (2009) Satellite detection of hazardous volcanic clouds and the risk to global air traffic. Nat Hazards 51:303-324. https://doi.org/10.1007/s11069-008-9273-Z

Ramaswamy V, Chanin ML, Angell J, Barnett J, Gaffen D, Gelman M, Keckhut P, Kolshelkov Y, Labitzke K, Lin JJR, O’Neill A, Nash J, Randel W, Rood R, Shine K, Shiotani M, Swinbank R (2001) Stratospheric temperature changes: observations and model simulations. Rev Geophys 39:71-122

Randel W, Udelhofen P, Fleming E, Geller M, Gelman M, Hamilton K, Karoly D, Ortland D, Pawson S, Swinbank R, Wu F, Baldwin M, Chanin ML, Keckhut P, Labitzke K, Remsberg E, Simmons A, Wu D (2004) The SPARC intercomparison of middle atmosphere climatologies. J Clim 17:987-1003

Ray RD, Ponte RM (2003) Barometric tides from ECMWF operational analyses. Ann Geophys 2003(21):1897-1910

Rind D (1977) Heating of the lower thermosphere by the dissipation of acoustic waves. J Atmos Terr Phys 39:445-456. https://doi.org/10.1016/0021-9169(77)90152-0

Rind D, Donn WL (1975) Further use of natural infrasound as a continuous monitor of the upper atmosphere. J Atmos Sci 32:1694-1704

Rind D, Donn WL, Dede E (1973) Upper air wind speeds calculated from observations of natural infrasound. J Atmos Sci 30:1726-1729

Ripepe M, Bonadonna C, Folch A, Delle Donne D, Lacanna G, Marchetti E, Hoskuldsson A (2013) Ashplume dynamics and eruption source parameters by infrasound and thermal imagery: the 2010 Eyjafjallajokull eruption. Earth Planet Sci Lett 366:112-121. https://doi.org/10.1016/j.epsl.2013.02. 005

Rojo M, Claud C, Mallet PE, Noer G, Carleton AM, Vicomte M (2015) Polar low tracks over the Nordic Seas: a 14 winter climatological analysis. Tellus 67(24):660. https://doi.org/10.3402/tellusa.v67.24660

Rüfenacht R, Murk A, Kämpfer N, Eriksson P, Buehler SA (2014) Middle-atmospheric zonal and meridional wind profiles from polar, tropical and mid-latitudes with the ground-based microwave Doppler wind radiometer WIRA. Atmos Meas Tech 7:4491-4505. https://doi.org/10.5194/amt-7-4491-2014

Screen JA, Simmonds I (2014) Nature climate change, amplified mid-latitude planetary waves favour particular regional weather extremes. Nat Clim Change 4:704-709. https://doi.org/10.1038/ nclimate 2271

Sentman DD, Wescott EM (1993) Observations of upper atmospheric optical flashes recorded from an aircraft. Geophys Res Lett 20:2857-2860

Shaw TA, Shepherd TG (2008a) Raising the roof. Nature Geosci 1(12-13):1053. https://doi.org/10.1038/ ngeo.2007.53

Shaw TA, Shepherd TG (2008b) Wave-activity conservation laws for the three-dimensional anelastic and Boussinesq equations with a horizontally homogeneous background flow. J Fluid Mech 594:493-506

Sigmond M, Scinocca JF, Kharin VV, Shepherd TG (2013) Enhanced seasonal forecast skill following stratospheric sudden warmings. Nat Geosci 6:98-102. https://doi.org/10.1038/ngeo1698

Sindelarova T, Chum J, Skripnikova K, Base J (2015) Atmospheric infrasound observed during intense convective storms on 9-10 July 2011. J Atmos Sol-Terr Phys 122:66-74. https://doi.org/10.1016/j. jastp.20142.10.014

Smets PSM, Evers LG (2014) The life cycle of a sudden stratospheric warming from infrasonic ambient noise observations. J Geophys Res 119:12084-12099. https://doi.org/10.1002/2014JD021905

Smets PSM, Evers LG, Näsholm SP, Gibbons SJ (2015) Probabilistic infrasound propagation using realistic atmospheric perturbations. Geophys Res Lett. https://doi.org/10.1002/2015GL064992

Smets PSM, Assink JD, Le Pichon A, Evers LG (2016) ECMWF SSW forecast evaluation usinginfrasound. J Geophys Res 121:4637-4650. https://doi.org/10.1002/2015JD024251

Smith AK (2012) Global dynamics of the MLT. Surv Geophys 33:1177-1230. https://doi.org/10.1007/ s10712-012-9196-9

Stenbaek-Nielsen HC, McHarg MG, Kanmae T, Sentman DD (2007) Observed emission rates in sprite streamer heads. Geophys Res Lett 34:L11105. https://doi.org/10.1029/2007GL029881

Stopa JE, Cheung KF, Garcés MA, Badger N (2012) Atmospheric infrasound from nonlinear wave interactions during Hurricanes Felicia and Neki of 2009. J Geophys Res 117:C12017. https://doi.org/10. 1029/2012JC008257 
Tailpied D, Le Pichon A, Marchetti E, Ripepe M, Kallel M, Ceranna L, Brachet N (2013) Remote infrasound monitoring of Mount Etna: observed and predicted network detection capability. InfraMatics. https://doi.org/10.4236/inframatics.2013.21001

Thompson DWJ, Seidel DJ, Randel WJ, Zou CZ, Butler AH, Mears C, Osso A, Long C, Lin R (2012) Nature. The mystery of recent stratospheric temperature trends. https://doi.org/10.1038/nature11579

Tripathi OP, Baldwin M, Charlton-Perez AJ, Charron M, Eckermann SD, Gerber E, Harrison RG, Jackson DR, Kim BM, Kuroda Y, Lang A, Mahmood S, Mizuta R, Roff G, Sigmond M, Son SW (2014) Review: the predictability of the extra-tropical stratosphere on monthly timescales and its impact on the skill of tropospheric forecasts. Q J R Meteorol Soc. ISSN 1477-870X. https://doi.org/10.1002/qj. 2432

Ulivieri G, Ripepe M, Marchetti E (2013) Infrasound reveals transition to oscillatory gas flow regime during lava fountaining: implication for early-warning. Geophys Res Lett 40:3008-3013. https://doi.org/10. $1002 /$ grl.50592

Vincent RA (2009) Gravity wave coupling from below: a review. In: Tsuda T, Fujii R, Shibata K, Geller MA (eds) Climate and weather of the Sun-Earth System (CAWSES): Selected papers from the 2007 Kyoto symposium, pp 279-293. _c TERRAPUB, Tokyo

Vincent RA (2015) The dynamics of the mesosphere and lower thermosphere: a brief review. Progr Earth Planet Sci 2:4. https://doi.org/10.1186/s40645-015-0035-8

Wright CJ, Osprey SM, Gille JC (2013) Global observations of gravity wave intermittency and its impact on the observed momentum flux morphology. J Geophys Res 118:10980-10993. https://doi.org/10.1002/ jgrd.50869

Wu DL, Preusse P, Eckermann SD, Jiang JH, de la Torre Juarez M, Coy L, Wang DY (2006) Remote sounding of atmospheric gravity waves with satellite limb and nadir techniques. Adv Space Res 37:2269-2277

Yue J, Vadas SL, She CY, Nakamura T, Reising SC, Liu HL, Stamus P, Krueger DA, Lyons W, Li T (2009) Concentric gravity waves in the mesosphere generated by deep convective plumes in the lower atmosphere near Fort Collins, Colorado. J Geophys Res 114:6104. https://doi.org/10.1029/ 2008JD011244 